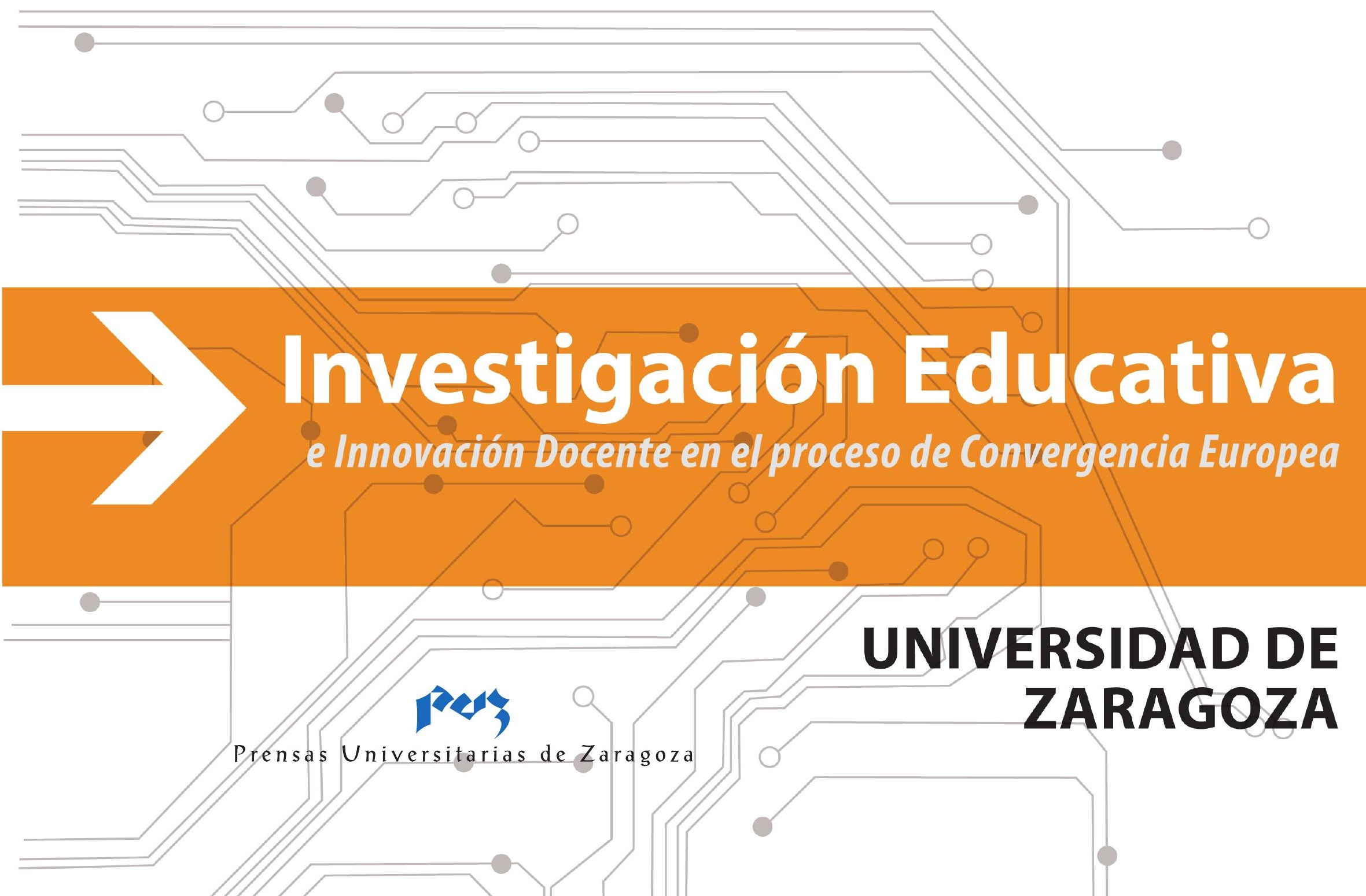





\section{Investigación Educativa e Innovación Docente en el proceso de Convergencia Europea}

Ma Victoria Sanagustín Fons, Javier Paricio Royo, Ma del Carmen Agustín Lacruz y Fernando Cruz Bello (eds. lits.)

Universidad de Zaragoza

Consejo Social de la Universidad de Zaragoza

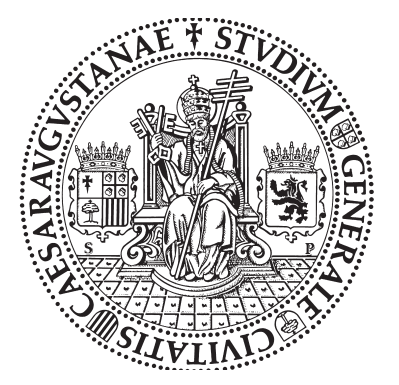

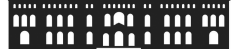
CONSEJO SOCIAL UNIVERSIDAD DE ZARAGOZA 


\section{FICHA CATALOGRÁFICA:}

Investigación educativa e innovación docente en el proceso de convergencia europea/ M. ${ }^{a}$ Victoria Sanagustín Fons, Javier Paricio Royo, M. ${ }^{a}$ del Carmen Agustín Lacruz y Fernando Cruz Bello (eds. lits.).- Zaragoza: Universidad de Zaragoza: Consejo Social de la Universidad de Zaragoza, 2008.- 140 p.; 25,4 x 19,05 cm.; 1 CD-ROM.

ISBN 978-84-92774-13-5

I. Sanagustín Fons, M. ${ }^{a}$ Victoria. II. Paricio Royo, Javier. III. Agustín Lacruz, M. ${ }^{a}$ del Carmen. IV. Cruz Bello, Fernando. 1. Universidad de Zaragoza-Actividad científica. 2. Innovaciones educativas 3. Tecnología educativa.

378.4(460.224 Z.):001.891

\section{COLABORADORES:}

Antonio Herrera Marteache

Julián Muela Ezquerra

Francisco Serón Arbeloa

$M^{a}$ Victoria Sanagustín Fons

Javier Paricio Royo

Manuel Aguado Benedí

Javier García Marco

José Luis Bernal Agudo

Ramón Garcés Campos

Carmen Agustín Lacruz

Esperanza Velasco de la Peña

Juan Luis Cano Fernández

José Antonio Rojo Martínez

Rubén Rebollar Rubio

José Antonio Moseñe Fierro

Fernando Cruz Bello

Laura Encuentra Pardillos

$M^{a}$ Carmen Galán López

María Teresa Pérez Yago

Begoña Vigo Arrazola

Ana Arraiz Pérez

Tomás Escudero Escorza

Fernando Sabirón Sierra

Concha Bueno García

José María Rodanés Vicente

\section{PATROCINADORES:}

Ministerio de Educación y Ciencia

Gobierno de Aragón. Departamento de Ciencia, Tecnología y Universidad

Universidad de Zaragoza

Consejo Social de la Universidad de Zaragoza

(c) Los autores

( De la presente edición, Prensas Universitarias de Zaragoza

Prensas Unversitarias de Zaragoza. Edificio de Ciencias Geológicas. C/Pedro Cerbuna, 1250009 Zaragoza, España Tel 976761330.

Fax 976761063

Prensas Universitarias de Zaragoza es la editorial de la Universidad de Zaragoza, que edita e imprime libros de su fundación en 1542

Impreso en España

Imprime: INO Reproducciones

ISBN: 978-84-92774-13-5

DL: Z-2569-2009 


\section{TABLA DE CONTENIDO}

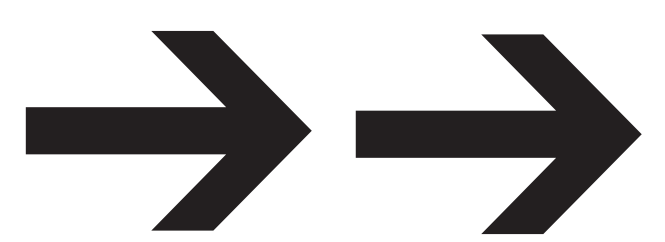

$5 \quad$ Tabla de contenido

$7 \quad$ Prólogo

11 Introducción

23 Diseño curricular

$41 \quad$ Evaluación, innovación y factores de calidad

55 Tecnologías aplicadas al mundo de la enseñanza superior

73 Experiencias de trabajo cooperativo y trabajo en grupo

$87 \quad$ Metodologías activas

105 Herramientas de resolución de casos y Proyecto Tutor

117 Conclusiones

123 Material Docente

127 Índice de Autores 


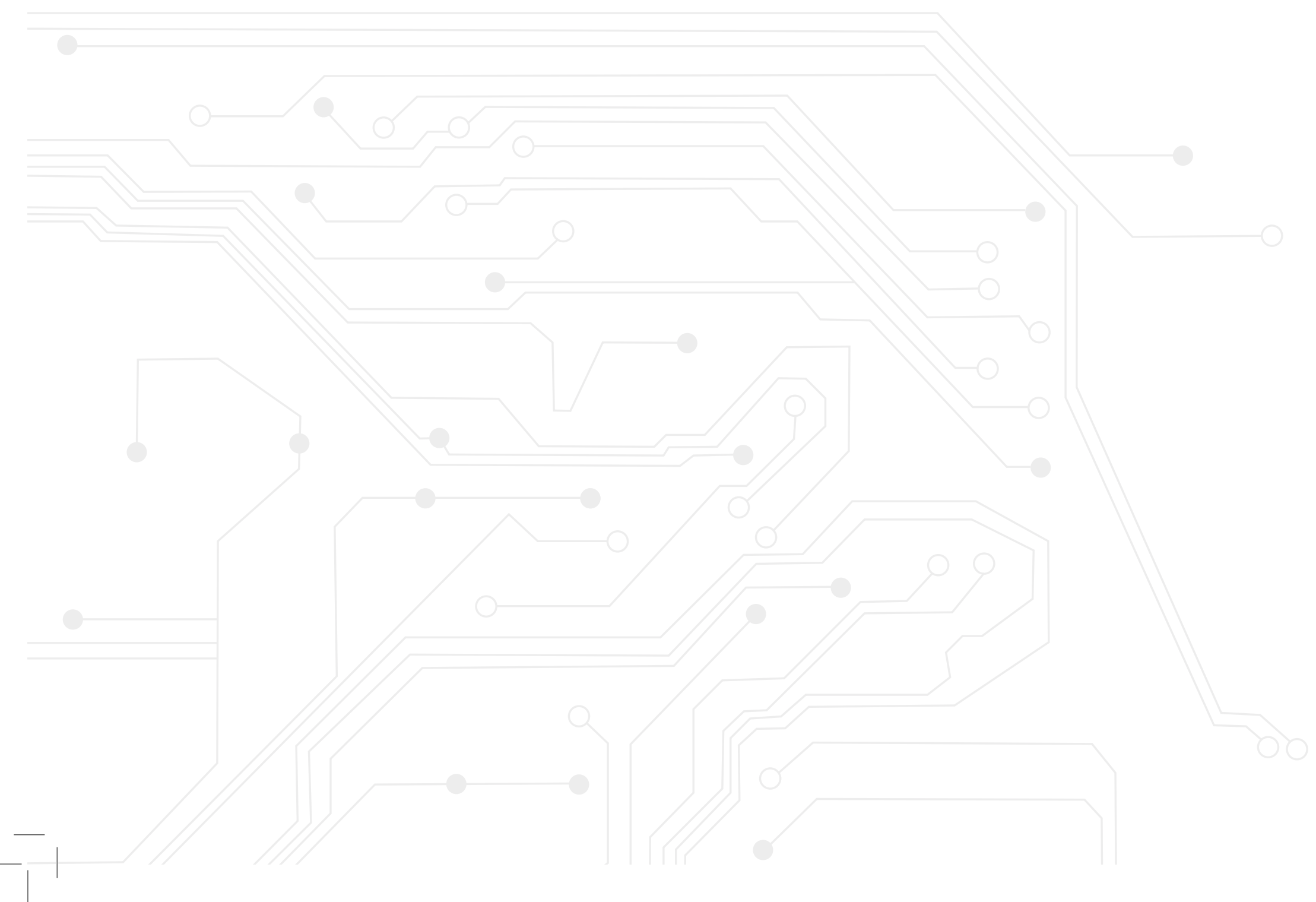




\section{Prólogo}

La Universidad de Zaragoza está implicada en la Innovación Docente desde hace años y tiene como uno de sus principales objetivos y misión la mejora permanente de la calidad de los procesos de enseñanza-aprendizaje. El libro que se presenta incluye VI bloques temáticos que son el reflejo de la innovación y la mejora docente que durante los últimos años está realizando la Universidad de Zaragoza. Así, se recopila el esfuerzo innovador y de entrega docente/discente que cientos de profesores y profesoras, estudiantes y profesionales de la administración de nuestra universidad, han llevando a cabo a lo largo del último curso académico. tes:

Esta publicación se enmarca en el ámbito de la investigación educativa universitaria y tiene como objetivos los siguien-

- Difundir las experiencias sobre el diseño de nuevas titulaciones en el entorno del Espacio Europeo de Educación Superior en la Universidad de Zaragoza, bajo el enfoque de perfiles profesionales y el desarrollo de competencias profesionales.

- Divulgar las prácticas de utilización de metodologías activas y colaborativas en la docencia para la adaptación de las titulaciones actuales al entorno de la Convergencia Europea.

- Dar a conocer los proyectos de innovación docente, algunos de los cuáles incluyen la utilización de las Tecnologías de la Información y la Comunicación en la docencia, que se están llevando a cabo en nuestra Universidad.

- Informar sobre las líneas básicas y aspectos fundamentales para la elaboración de Códigos de buenas prácticas docentes y de los procesos de reflexión y análisis, abiertos en la Universidad de Zaragoza, sobre las competencias profesionales de los docentes excelentes, que están ayudando a identificar las buenas prácticas existentes y aquellas otras que se desean alcanzar.

La introducción a este trabajo la realiza el profesor Flemming K. Fink explicando el concepto pedagógico de Aprendizaje Basado en Problemas Organizados (POPBL o PBL) que se viene desarrollando desde 1974 en la Universidad de Aalborg, de la cuál procede. Se presenta el modelo básico de puesta en práctica de PBL en la citada universidad. Para el impulso de experiencias basadas en este concepto, describe cómo han desarrollado metodologías específicas con el fin de integrar la ingeniería productiva y la ingeniería educativa. Recientemente, han desarrollado una metodología para la educación continua integrada en las tareas diarias, Ilamada "Aprendizaje Basado en Trabajo Facilitado" (FWBL).

A continuación se exponen organizados en 6 bloques temáticos los diversos capítulos de este trabajo organizados en torno a los siguientes ejes: Diseño curricular; evaluación, innovación y factores de calidad; tecnologías aplicadas al mundo de la enseñanza superior; experiencias de trabajo cooperativo y trabajo en grupo; metodologías activas y herramientas de resolución de casos y Proyecto Tutor. Cada uno de estos bloques temáticos han sido coordinados por profesores de nuestra 
Universidad: José Luis Bernal Agudo, Begoña Vigo Arrazola, Tomás Escudero Escorza, Fernando Sabirón Sierra, Ana Arraiz Pérez, Francisco Serón Arbeloa, Javier Paricio Royo, Javier García Marco, Concepción Bueno García, José Antonio Rojo Martínez, José María Rodanés Vicente, Juan Luis Cano Fernández y Rubén Rebollar Rubio.

Conviene destacar la labor desarrollada por los numerosos profesores que a lo largo de estas páginas han pretendido exponer las más variadas experiencias sobre muy diversos temas, que plantean cuestiones ya resueltas y experiencias definidas, así como otras en las que se abordan dudas, debates y reflexiones de elevada trascendencia para la docencia universitaria.

En el bloque temático dedicado al Diseño curricular, los 34 capítulos que lo conforman se ocupan, entre otros asuntos, de: La implantación de las metodologías asociadas al ECTS (Crédito Europeo) en asignaturas y titulaciones actuales; las experiencias de los nuevos másteres oficiales adaptados a la estructura de titulaciones convergentes con Europa, su diseño e implantación; presentación y elaboración de las nuevas guías docentes y el análisis de las experiencias piloto de adaptación al EEES llevadas a cabo en asignaturas, cursos y titulaciones de nuestra universidad.

En el bloque temático dedicado a la Evaluación, innovación y factores de calidad, los 24 capítulos desarrollados giran en torno a las siguientes temáticas: Evaluación de proyectos de innovación docente llevados a cabo en la Universidad de Zaragoza; análisis de las perspectivas estudiantiles en torno a la implantación de nuevas metodologías docentes, nueva estructura y diseño curricular y nuevas formas de evaluación del proceso de enseñanza-aprendizaje; diversos métodos de evaluación de las diversas asignaturas actuales; la evaluación continua en el entorno universitario y el desarrollo de redes de evaluación formativa.

El siguiente bloque temático se ocupa de las tecnologías aplicadas al mundo de la enseñanza superior, incluye 33 capítulos que reflejan cómo nuestra universidad ha apostado por la incorporación decidida de las Tecnologías de la Información y la Comunicación a la docencia; buena prueba de ello es el Anillo Digital Docente, que inició su andadura en el curso académico 2001/2002 y ofrece en la actualidad las versiones semipresenciales de las titulaciones de Diplomado en Gestión y Administración Pública en Huesca, Licenciado en Ciencias de Trabajo en Teruel y Diplomado en Ciencias Empresariales en Zaragoza. Además, se encuentran recogidas en él cerca de mil asignaturas de $1^{\mathrm{er}}, 2^{\circ}$ y $3^{\mathrm{er}}$ ciclo a las que hay que añadir las setenta que pertenecen al Grupo de Universidades del G9. Un total de 950 profesores y unos 34.000 alumnos se han relacionado a través de esta nueva tecnología. Por otro lado las TIC también dan soporte a revistas electrónicas, páginas web de elevada calidad, etc...

El bloque temático que recoge experiencias sobre trabajo cooperativo y trabajo en grupo incluye 22 capítulos que versan sobre: La participación estudiantil en los procesos de enseñanza-aprendizaje en diversas asignaturas; la adquisición de la competencia profesional del trabajo en equipo así como análisis DAFO del mismo con estudiantes en las 


\section{Investigación Educativa e Innovación Docente en el proceso de Convergencia Europea}

titulaciones actuales, sus asignaturas y contenidos diversos; tutorías entre iguales desde los ECTS; trabajo colaborativo entre profesores de diversas asignaturas y la coordinación curricular y redes interuniversitarias europeas para la implantación de diversas enseñanzas en nuestra universidad.

El bloque temático centrado en las Metodologías activas incluye 31 capítulos, que recorren de forma exhaustiva y precisa la rica variedad de metodologías docentes así como sus adaptaciones a los distintos ámbitos del conocimiento, tratándose desde diversas perspectivas más o menos críticas. Se divulgan experiencias adquiridas por la pericia de profesores y profesoras que desde hace más de una década participan en el Programa de Formación del Profesorado gestionado por el Instituto de Ciencias de la Educación de la Universidad de Zaragoza.

El bloque temático dedicado a herramientas de resolución de casos y Proyecto Tutor, recopila 21 capítulos dedicados a la utilización del estudio de caso como herramienta imprescindible para la docencia universitaria en la actualidad. Además, se incluyen las experiencias de diversos centros de nuestra universidad en la implantación del Proyecto Tutor como herramienta de trabajo imprescindible para la adaptación de nuestras titulaciones y universidad al Espacio Europeo de Educación Superior, dado que rompe barreras comunicacionales entre los profesores y los estudiantes, ayudando a mejorar significativamente el proceso de enseñanza-aprendizaje pues se establece un vínculo de orientación académica y profesional integral que ayuda a todos, profesores y estudiantes, a mejorar la actividad universitaria en general.

Finalmente la monografía incluye un apartado de conclusiones en el que se analizan los principales logros y propuestas alcanzados en cada uno de los ejes temáticos desarrolados. Así mismo se recoge un último epígrafe dedicado a los materiales docentes utilizados como apoyo a la labor docente en la Universida de Zaragoza.

Es necesario destacar que el formato en el que se presenta esta publicación combina el soporte tradicional en papel y el soporte digital. En la publicación impresa se incluye un índice pormenorizado de todos los capítulos y un resumen impreso de los mismos, mientras que el contenido completo de cada trabajo se presenta en el anexo digital indexado con hipervínculos al documento en "pdf" completo. El tamaño y la extensión de todos los trabajos hacen imposible la publicación integra en formato tradicional. No obstante pensamos que la acceso a la versión integra se facilita notablemente con el formato adoptado en esta publicación.

La Universidad de Zaragoza contribuye con esta obra a la difusión de la innovación docente en el ámbito del Espacio Europeo de Educación Superior, con el objetivo de aprovechar experiencias positivas y aprender de las visiones críticas para mejorar siempre la actividad docente, núcleo de nuestra existencia como universidad. 


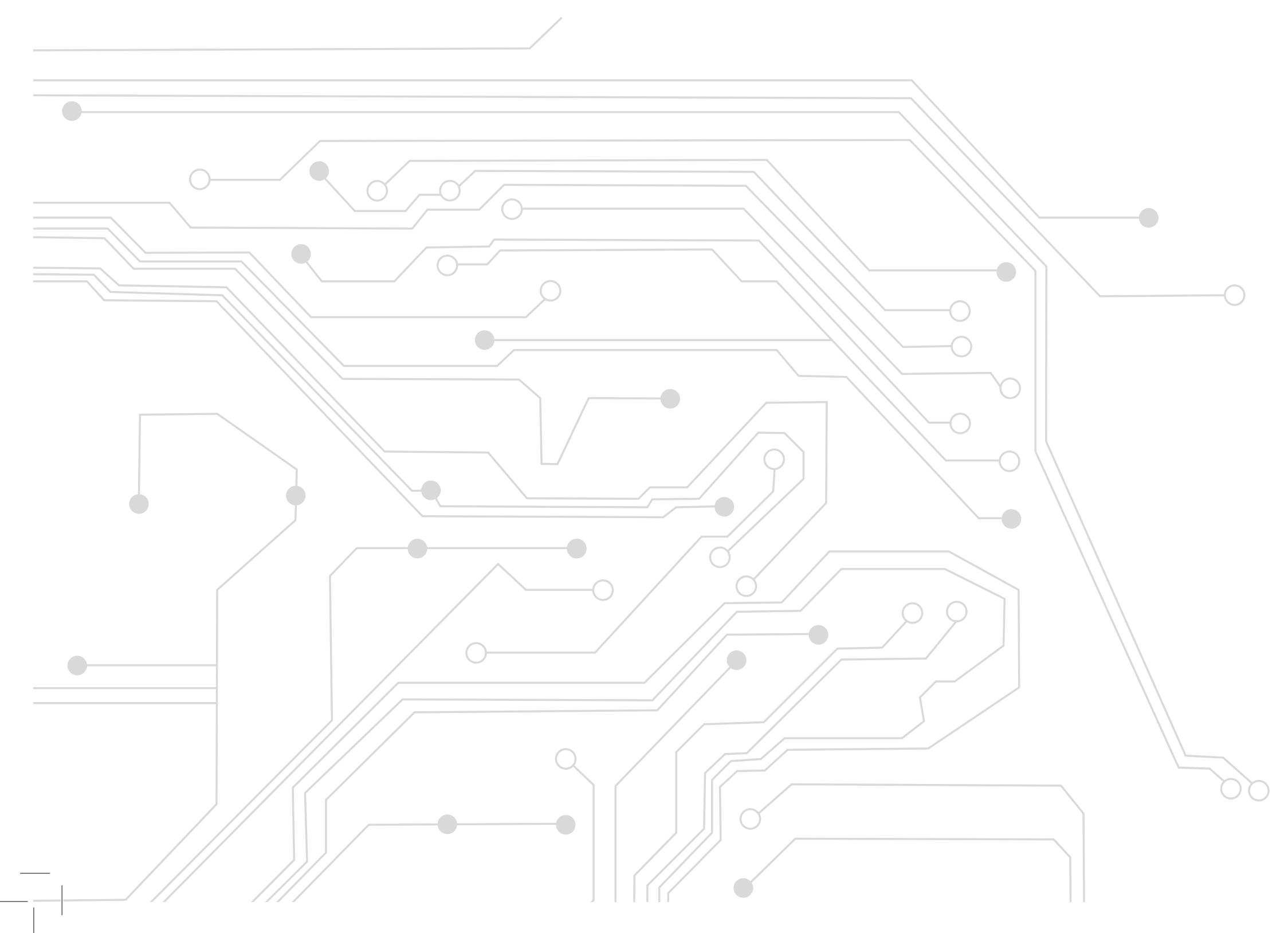




\section{INTRODUCCIÓN}

\section{El desarrollo de las competencias profesionales: El modelo universitario de Aalborg}

Flemming K. Fink , Aalborg University, Denmark

El concepto pedagógico del Aprendizaje Basado en Resolución de Problemas (POPBL o PBL) se ha llevado a cabo desde 1974 en la Universidad de Aalborg. El modelo para la aplicación de PBL en la Universidad de Aalborg se presenta en este trabajo. A partir de las experiencias obtenidas se han desarrollado metodologías específicas para integrar el desempeño profesional de la Ingeniería y las enseñanzas de la Ingeniería. Recientemente se ha desarrollado una metodología para la educación continuada integrada en las tareas diarias, Ilamada Trabajo Facilitado Basado en el Aprendizaje (FWBL), basada en la misma filosofía. Tanto POPBL y FWBL como la interrelación entre estas metodologías, se analizan en este capítulo.

\section{Fundamentos de Aprendizaje Basado en Resolución de Problemas en cada proyecto}

La Universidad de Aalborg se fundó en 1974 y al mismo tiempo el Aprendizaje Basado en Resolución de Problemas se implantó en la enseñanza de la Ingeniería Danesa. Desde el principio, el elemento clave ha sido el Aprendizaje Basado en la Resolución de Problemas reforzado con el trabajo en equipo. Cada semestre los alumnos deben llevar a cabo un proyecto extenso (aprox. 500 horas de trabajo por cada estudiante). Los equipos de 4-6 estudiantes desarrollan 2000-3000 horas de trabajo en cada proyecto. Esto requiere un grado alto de cooperación con la industria para encontrar problemas reales de Ingeniería que resolver. Cada proyecto Basado en el Problema comprende el análisis y definición del problema -según la terminología propia de la lngeniería- la resolución del problema y el aporte de documentación en formato de informe científico y póster.

Desde el principio, en 1974, el objetivo ha sido incorporar el programa en la Diplomatura de 3,5 años (B.Sc.) y en la Licenciatura de 5 años (M.Sc.) con una primera parte común en el Plan de Estudios. Inicialmente se esperaba que aproximadamente el $50 \%$ del los estudiantes terminasen la Diplomatura, perola realidad es que el $90 \%$ del los estudiantes cursan a la Licenciatura. Por consiguiente se considerará aquí sólo el programa de Licenciatura. En la figura 1 se reflejan los objetivos principales del Aprendizaje Basado en Resolución de Problemas. 


\section{Investigación Educativa e Innovación Docente en el proceso de Convergencia Europea}

\section{Literatura}

ANÁLISIS DEL PROBLEMA

Tutoriales
Disertaciones

RESOLUCIÓN DEL PROBLEMA

Estudios de campo

\author{
Grupo de trabajo \\ INFORME DOCUMENTACIÓN \\ Experimentos
}

Fig1. Los principios del Aprendizaje Basado en Resolución de Problemas [1].

El Plan de Estudios está organizado en semestres (10 semestres para una Licenciatura) con una estructura bien determinada y con un resultado muy bien definido. Un semestre es un programa de 20 semanas en el campus. Cada semestre es temático, por ejemplo Programar a gran escala ( $3^{\text {er }}$ semestre de Ingeniería SW), Tecnología Lingüística (4º semestre de Ingeniería SW ), Desarrollo de la Aplicación ( $5^{\circ}$ semestre de Ingeniería SW) , Cuerpo y Mente ( $3^{\text {er }}$ semestre de Medicina ) etc. El proyecto, aproximadamente 500 horas de trabajo por cada estudiante, debe estar incluido dentro del marco de la descripción del tema.

Se ofrecen algunos cursos relacionados con el proyecto a los estudiantes para que puedan aplicarse. Además, los estudiantes deben hacer algunos cursos obligatorios como Matemáticas, Programación de paradigmas y complejidad y Computabilidad. El trabajo de estos cursos ocupará otras 400 horas cada semestre. Esta organización del Plan de Estudios implica que los estudiantes aprenden a aplicar los contenidos teóricos desde el principio, a la vez que los temas fundamentales se extienden durante varios semestres.

Los problemas reales no aparecen definidos en términos de Ingeniería. Por consiguiente, el análisis del problema, la definición y formulación en la terminología adecuada son muy importantes antes de empezar con la resolución del problema. La parte que lleva a la resolución de problema es, con mucho, la que más exige de todo el proyecto, pero también es muy importante que los estudiantes aprendan a documentar y a comunicar el proceso y los resultados a otros ingenieros.

Al final de cada semestre los estudiantes deben pasar una evaluación oral basada en un informe de hasta 150 páginas, más "los productos", documentando su proyecto de trabajo en equipo. Esta evaluación normalmente cuesta hasta seis horas de trabajo en equipo. Los estudiantes obtienen calificaciones individuales.

Además de esto, los estudiantes deben pasar las evaluaciones individuales en los cursos obligatorios. 


\section{Investigación Educativa e Innovación Docente en el proceso de Convergencia Europea}

El Aprendizaje Basado en la Resolución del Problema permite a los estudiantes desarrollar habilidades analíticas excelentes y desarrollar una buena experiencia a la hora de confrontar y resolver problemas complejos de Ingeniería.

Además de una visión teórica completa, los estudiantes adquieren experiencia para aplicar los elementos teóricos en la Ingeniería práctica. Son necesarios una gran variedad de proyectos de problemas complejos de la Ingeniería a todos los niveles y la cooperación entre la universidad (los estudiantes, investigadores) y la industria ha aumentado significativamente con el consiguiente beneficio para todas las partes.

\section{Plan de Estudios dinámico}

La estructura del Plan de Estudios es fundamentalmente progresiva y además cada paso en esta progresión implica un alto grado de flexibilidad. Dentro de un programa específico, los temas pueden -y de hecho- cambian de año a año. Un tema como "el Proceso de la señal Estocástica" involucrará una gran variedad de problemas de ingeniería. Como los proyectos seleccionados son una combinación de; las propuestas de la industria, los intereses entre los estudiantes y el interés entre los supervisores (investigadores) etc., siempre existirán nuevos problemas que resolver.

Por consiguiente, aunque el objetivo y el contenido del tema están bien definidos en base al uso de la enseñanza de la taxonomía de Bloom, el plan de estudios es muy flexible y puede seguir el desarrollo de la tecnología e integrar la aplicación de nuevos resultados de la investigación.

El programa organizado del semestre ha demostrado ser una estructura muy dinámica por llevar a cabo las nuevas aplicaciones de la Ingeniería en el proyecto. Esto significa que es una herramienta buena para el co-funcionamiento con la industria y para poner al día el contenido profesional del Plan de Estudios.

Por otra parte, dado que:

- Los estudiantes prefieren los problemas reales frente a los problemas hipotéticos de naturaleza académica planteados por los profesores.

- Un equipzde seis estudiantes representa unas 3000 horas de trabajo por proyecto y semestre.

- Las empresas normalmente tienen claras las ideas que les gustaría que se desarrollasen.

- Los equipos de investigación pueden definir proyectos adecuados a los temas propuestos.

- Las empresas quieren comenzar a trabajar con los estudiantes antes de que se gradúen.

- Normalmente los estudiantes no son pagados por los proyectos que desarrollan. 


\section{Investigación Educativa e Innovación Docente en el proceso de Convergencia Europea}

Una gran variedad de proyectos a todos los niveles profesionales están disponibles para su resolución y la cooperación entre la universidad (estudiantes, investigadores) y la industria aumenta para beneficio de todos.

\section{Resultados del trabajo en equipo en Ingeniería y enseñanza de Ciencias}

El modelo pedagógico centrado en el trabajo en equipo Basado en la Resolución del Problema se considera como un valor añadido en el sistema educativo. En Dinamarca, recientes valoraciones internacionales acerca de la Ciencia Informática constataron que el mayor énfasis en la incorporación a la vida laboral, se orienta hacia el conocimiento de las competencias profesionales y la cooperación con la industria, combinado con un línea de Aprendizaje Basado en Resolución de Problemas, lo que asegura que la Universidad de Aalborg ha hecho una contribución importante a la educación en Dinamarca.

El proyecto basado en el trabajo en equipo es un elemento muy importante en el proceso de aprendizaje, puesto que aumentan las habilidades de los alumnos en su argumentación profesional, en la presentación de propuestas propias para la busqueda de soluciones y la evaluación crítica de las propuestas realizadas por otros estudiantes.

La preparación de documentación como informes, papeles científicos y posters, junto con la presentación oral, está entrenando a los estudiantes para la producción futura de material escrito y para la preparación y ejecución de presentaciones orales.

Debido al tamaño de los proyectos, los estudiantes consiguen una visión de conjunto de los problemas y se acostumbran a buscar y ordenar la nueva información, obteniendo conclusiones por si mismos. Aprenden a filtrar la información y a discernir aquella que necesitan ahora de la que necesitarán en el futuro.

\section{Situación del Aprendizaje Basado en Resolución de Problemas}

Los estudiantes de la Universidad de Aalborg se organizan en equipos de hasta seis miembros. A cada equipo se le asigna un despacho de $18 \mathrm{~m}^{2}$, que se convierte en su segunda casa. Este espacio es su base, aquí se desarrollan las discusiones sobre el proyecto, se llevan a cabo los planes, simulaciones, comunicaciones, etc...

Otra función importante del equipo del proyecto es el proceso de aprendizaje llevado a cabo después de cada disertación.

Las disertaciones duran aproximadamente dos horas y después los estudiantes vuelven a su despacho para resolver algunos problemas, llevar a cabo simulaciones o discusiones etc. basadas en lo impartido en la clase. Esto ocupa otras dos horas durante las cuales el disertante va de equipo en equipo para facilitar el proceso. 
Formando parte de un equipo los estudiantes aprenden a cooperar para la resolución de problemas mayores. Aprenden a desenvolverse en las discusiones profesionales en aspectos tales como la definición del problema y la argumentación para su opción de solución. Los estudiantes aprenden a defender y explicar con términos científicos lo que ellos creen que es la solución correcta, puesto que no es suficiente esgrimir que algo es correcto sino que debe además ser capaces de convencer a los otros miembros del grupo.

La argumentación profesional es una buena manera de aprender.

Aprenden a organizar el trabajo en equipo y que un equipo no funciona si todos no hacen su parte del trabajo. De esta manera, los estudiantes adquieren una actitud para trabajar diferente a la que adquieren aquellos que siguen el procedimiento tradicional de trabajo individual.

A cambio, los estudiantes consiguen una sensación de mayor seguridad, pues "el uso extensivo del Aprendizaje Basado en la Resolución de Problemas en los grupos conlleva un efecto muy positivo en la integración social. (...) El alumno se siente responsable de los otros miembros del grupo a la hora de permanecer y concluir el trabajo y por lo tanto el número de estudiantes que abandona es mucho menor".

El trabajo en equipo también produce el efecto de que los estudiantes se animan entre ellos. El objetivo de los estudiantes es resolver el problema, por ello se organizan tareas para cada miembro del grupo. Para tener éxito con la tarea asignada, hay que leer los textos, buscar información extra, leer documentación cinetífica, investigar en Internet y realizar las programaciones o actividades necesarias. Como ningún estudiante quiere acabar con una solución errónea, trabajan muy duro en su proyecto. El proyecto es el elemento clave en el Plan de Estudios pues se aplican los conocimientos teóricos para resolver los problemas prácticos.

“El trabajo de grupo en la Universidad de Aalborg comporta un efecto positivo en la consecución de la graduación. El estudiante como individuo se siente responsable del grupo y se motiva para pasar los exámenes y mantenerse al mismo nivel que el resto de los estudiantes" [2]. A cada equipo se le asigna un supervisor o facilitador. El facilitador se reúne con el grupo, aproximadamente una vez por semana, para comentar el progreso del proyecto, guiar al equipo si fuera necesario y leer y discutir los borradores. Es muy importante que el facilitador sea consciente de no ser un solucionador del problema, sino un facilitador.

Al final del semestre él es responsable de la última valoración del proyecto junto con examinadores externos nombrados por el Ministerio de Investigación y Educación danés. 
El tiempo medio de consecución de la licenciatura es de 5.0 años, comparados con los 6.7-8.8 años de otros cursos similares en Dinamarca [2].

\section{Desarrollo Profesional Continuado en Programas Cooperativos}

El Desarrollo Profesional Continuado (CPD) es un concepto que ha alcanzado gran relevancia, incluye el desarrollo de habilidades teóricas profesionales además del trabajo práctico funcional; es decir, supone una combinación de la educación continua junto con el trabajo productivo.

La mayoría de las compañías innovadoras son conscientes de la importancia que tiene mejorar la competencia profesional. Sin embargo, aunque el desarrollo profesional [3] se considera vital para el futuro de la compañía, los trabajadores afirman que no encuentran tiempo para los cursos de CPD. El dinero para financiarla formación no es ningún problema, pero el tiempo que requiere sí lo es. Otro parámetro que debe ser considerado es el reconocimiento del curso como parte del curriculum personal, lo que implica que sería deseable alguna forma de acreditación. Esto significa que los programas CPD deben desarrollarse para cumplir las expectativas tanto del patrón como del empleado y que los programas deben integrar el nuevo conocimiento académico en el proceso diario productivo.

\subsection{Programas Master a tiempo parcial}

En la Universidad de Aalborg se han llevado a cabo Programas Master con la metodología PBL adaptados a las necesidades de los trabajadores en proceso contínuo de reciclaje. Estos Master duran 1-1.5 años, pero desarrollados a tiempo parcial su consecución se extiende hasta 2-3 años.

El programa consiste en cursos y proyectos. Como en los estudios normales el proyecto debe cubrir por lo menos el $50 \%$ del tiempo y algunos de los cursos deben aplicarse en el proyecto. El programa está organizado en temas y para los ingenieros asistentes debería ser posible integrar sus tareas de trabajo en el estudio o proyecto. De esta manera se optimiza el tiempo. Esto no siempre es fácil, por consiguiente, se han desarrollado maneras de cooperación más directa entre la universidad y la empresa a nivel de dirección para definir el armazón del proceso educativo.

En estos Master la educación a distancia basada en las Tecnologías de la Información es muy importante [4 y 5].Estas herramientas se usan tanto en los cursos como en las comunicaciones entre alumnos, entre alumnos y profesores y en el desarrollo del proyecto. 
Esto significa, por ejemplo, que aunque un ingeniero se vaya a trabajar a otro país por un periodo de tiempo, todavía puede ser un estudiante activo. Los seminarios presenciales mantienen su importancia siempre y cuando sean posibles.

La Universidad de Aalborg tiende a establecer entre 4 y 7 seminarios presenciales de dos días al año. Aquí los estudiantes y profesores pueden encontrarse para llevar a cabo ejercicios prácticos de laboratorio, etc. Este concepto para los programas CPD se ha ensayado durante varios años.

\section{Aprendizaje Facilitado Basado en el Trabajo}

En PBL la resolución de problemas es una herramienta para aprender. Aprender es la meta. En Ingeniería Industrial el objetivo es resolver el problema planteado y las habilidades profesionales son las herramientas. Es necesario combinar estas dos maneras de pensar. El desafío es usar el concepto de PBL modificado para combinar Ingeniería Productiva y aprendizaje académico, así como para combinar las actividades industriales de los ingenieros con sus tareas en CPD. Los objetivos de aprendizaje deben ser definidos en base a las necesidades de las nuevas competencias de la empresa y la transferencia de conocimiento y aprendizaje de la universidad debe ser facilitado por un investigador universitario. Esto se denomina Aprendizaje Facilitado Basado en el Trabajo (FWBL) [6].

El Aprendizaje Facilitado Basado en el Trabajo puede definirse como un método de aprendizaje que dura toda la vida profesional, basado en una relación entre la universidad y la empresa con el propósito de establecer una investigación basada en la transferencia de conocimientos, como parte integral del trabajo diario. La empresa, la universidad y los empleados definen de forma conjunta las necesidades y los objetivos, basándose en las estrategias y necesidades de la empresa, ajustando la formación a las necesidades de los empleados tanto individual como colectivamente.

El proceso de aprendizaje se supervisa por el personal científico de la universidad y el aprendizaje se basa en las tareas de ingeniería de los equipos.

Por consiguiente, el objetivo de la metodología de FWBL es:

- Facilitarla tranferencia de conocimientos al empleado que trabaja en la industria sin tener que buscar tiempo para que participe en los cursos tradicionales.

- Integrar el nuevo conocimiento para el uso práctico inmediato del empleado.

- Planificar un proceso de aprendizaje que se ajuste a la estrategia de desarrollo de la empresa. 
- Adecuar el proceso de aprendizaje a cada empleado.

- Programar el proceso de aprendizaje para que se ajuste al proyecto específico de cada empresa.

- Usar las experiencias del Aprendizaje Basado en Resolución de Problemas.

- Optimizar los métodos y herramientas relacionadas de la empresa individual; su organización, sus competencias y su cultura de empresa, etc.

\section{La Definición de Aprendizaje Facilitado Basado en el Trabajo}

En la sección anterior se trató el concepto de Aprendizaje Facilitado Basado en el Trabajo. En ésta el Aprendizaje Facilitado Basado en el Trabajo se compara con el Aprendizaje Basado en el Problema y con el Aprendizaje Basado en el Trabajo, para entender las similitudes y diferencias entre estas metodologías.

El Aprendizaje Basado en el Problema (PBL) forma parte de los estudios universitarios presenciales. Los objetivos de aprendizaje son académicamente definidos en el Plan de Estudios que se prepara por la Universidad y en algunos países son aprobados por el gobierno o por un órgano acreditativo. Una gran parte del Plan de Estudios se dedica a los proyectos en equipo y los resultados académicos son evaluados rigurosamente. Los equipos de estudiantes tienen asignado un profesor universitario que los dirige en su proyecto para resolver problemas reales de Ingeniería. El equipo de estudiantes será homogéneo para reunir estudiantes con los mismos requisitos de aprendizaje. El objetivo del alumno es obtener un título [7].

El Aprendizaje Basado en el Trabajo (WBL) puede ser un programa de aprendizaje individual o un programa temático para un grupo de ingenieros en el que las competencias y las aptitudes basadas en el conocimiento se evidenciaron a través de la propuesta de trabajo de la organización [8]. Los objetivos de aprendizaje son el resultado de la negociación entre la Universidad, la empresa y los aprendices. El Aprendizaje Basado en el Trabajo está también relacionado con el aprendizaje en el lugar de trabajo que involucra la consecución de objetivos dentro del Plan de Estudios de una titulación, a través del uso del lugar de trabajo y del programa individual de trabajo [8]. Esta metodología requiere un proceso de negociación y acuerdo entre la empresa y la universidad para que el programa de trabajo se adecúe a los objetivos marcados dentro del programa académico.

El Aprendizaje Facilitado Basado en el Trabajo (FWBL) es un programa de aprendizaje diseñado para individuos o equipos de ingenieros en una compañía. Es un programa de aprendizaje considerado como una continuación del desarrollo 
profesional. Los objetivos de aprendizaje no se definen para conseguir metas académicas sino para ajustarse a la estrategia para desarrollar las competencias de la empresa. El aprendizaje es definido combinando las necesidades del individuo y de la empresa. Principalmente el aprendizaje tiene lugar en la empresa, integrado en el trabajo diario. Se asigna un investigador universitario como facilitador para el individuo o el equipo. El equipo normalmente es heterogéneo, integrado por personal con diferente formación, responsabilidades y objetivos, aunque en su conjunto debe tener o adquirir conocimientos comunes.

El objetivo del aprendiz es estar mejor cualificado para su trabajo. FWBL se desarrolla en diferentes fases continuas . Sin embargo el contenido de cada fase no es común para todos los programas de FWBL, ya que lo característico de FWBL es, precisamente, sus particularidades. Los programas de FWBL no sólo se diseñan para satisfacer las necesidades de la empresa sino también para ajustarse a las preferencias de cada empleado/aprendiz. FWBL puede caracterizarse como una unión entre tres partes: la empresa, los aprendices y la universidad representada por los facilitadores. Esta asociación es muy importante para el éxito del programa FWBL. Todos los miembros son igualmente responsables en el programa, lo cual significa que el compromiso de todos es esencial.

El proceso de FWBL no sigue un esquema rígido. Este proceso de aprendizaje normalmente ocupa más de la mitad un año e includo más tiempo, dependiendo de la magnitud y profundidad de los objetivos de aprendizaje, la intensidad y la proyección en el tiempo del proyecto en el que el FWBL está incorporado. Los investigadores universitarios y educadores normalmente no tienen experiencia a la hora de dirigir a los empleados en su esfuerzo para aplicar las nuevas teorías o métodos. Por consiguiente, el conocimiento y experiencia en PBL como método pedagógico, o al menos, algo de experiencia para dirigir un equipo de trabajo es un requisito previo para poder ser facilitador en FWBL. Además es muy útil que las compañías involucradas en FWBL estén organizadas en equipos o grupos de proyecto. La metodología de FWBL es descrita con más detalle por Fink y Nørgaard en [6].

\section{Lonely Wolf (Lobo Solitario). La aplicación de FWBL en 75 pequeñas empresas}

La metodología de FWBL se ha ensayado en un proyecto financiado por el Fondo Social Europeo [9]. En dicho proyecto la Universidad de Aalborg probó la metodología de FWBL en cooperación con 75 ingenieros de pequeñas empresas, cada una con un único ingeniero en su plantilla. La experiencia mostró que dicha figura dificilmente encontraba un curso que encajase con sus necesidades concretas. 


\section{Conclusiones}

La Universidad de Aalborg ha desarrollado programas con una fuerte orientación profesional, muy orientadas hacia el mercado laboral, sobre todo a través del trabajo en equipo que emula el trabajo que se realiza en la industria [2].

El modelo pedagógico fundamentado en el trabajo en equipo según el PBL se ha valorado muy positivamente dentro del sistema educativo. Esta metodología permite a los estudiantes desarrollar habilidades analíticas excelentes, a las que se suma una buena experiencia para confrontar y resolver problemas complejos. El Aprendizaje Basado en el Problema involucra y motiva a los estudiantes y crea un sentido de responsabilidad hacia los otros miembros del grupo. Esto contribuye a la permanencia del estudiante y se refleja en el bajo nivel de abandono y en el menor tiempo en la consecución de la graduación[2].

Se han identificado grandes similitudes entre los proyectos llevados a cabo por los estudiantes en un Plan de Estudios de PBL ordinario y los proyectos desarrollados fuera por aprendices en un programa de educación continua. Como la demanda de programas de educación profesional continua, formal o informal, cortos o largos, está aumentando y el tiempo para cursar estos programas es muy limitado, es obvio que hay que desarrollar y llevar a cabo el concepto de PBL de los programas a tiempo completo. Dicha reestructuración del programa de PBL es una oportunidad para que la universidad moderna deje de ser un mundo académico cerrado y se convierta en una parte abierta e integrada dentro de la comunidad.

Tanto las empresas como las universidades deben mostrar voluntad para comenzar este proceso. El personal universitario todavía se está formulando la pregunta ¿Porqué debemos involucrarnos en esto? Nuestro deber es enseñar a los estudiantes y dedicarnos a la investigación. Las empresas, por otro lado, a menudo piden cursos cortos y a demanda y les gustaría disponer de varios cursos para elegir, ya que ésta es una manera muy habitual de llevar a cabo la transferencia de conocimientos. En este sentido, el listado de cursos ofertados se reconoce como un menú de la especialización que la universidad puede ofrecer.

Tradicionalmente, el ingeniero individual busca los cursos que considera pertinentes y su superior, como el gerente de la empresa, toma la última decisión. Esto significa que hay una fractura entre la búsqueda de formación para la consecución de la nueva competencia y la última decisión al respecto. La definición de objetivos de aprendizaje involucra al aprendiz y a su superior.

Éste es, sin embargo, un proceso muy difícil ya que no es posible para ellos describir con palabras lo que desconocen. A menudo se piden soluciones y herramientas antes que teorías y metodologías. En la fase de aplicación, los profesores universitarios y los investigadores deben salir de su contexto académico y entrar en un contexto industrial que para muchos es un mundo desconocido. La transferencia de conocimiento sólo tendrá éxito si existe un mutuo entendimiento entre el facilitador y el 
aprendiz y si el facilitador entiende el contexto industrial y las condiciones en las que se desenvuelve el aprendiz. El diálogo debe estar abierto y el proceso ajustado al contrato de aprendizaje, o en caso contrario el contrato deberá revisarse. Se recomienda que las universidades organicen cursos de preparación para enseñar a su personal a enfrentar este nuevo desafío.

El acuerdo incluido en el contrato de aprendizaje debe respetarse. Basado en el contrato, se detallará el acuerdo entre el aprendiz y el facilitador. Esto implicará una agenda con las clases, las reuniones, las discusiones académicas, las revisiones de planes, los programas de las asignaciones, etc. Sin embargo, si surge algún desajuste entre estos compromisos acordados y las nuevas tareas impuestas por la empresa, el trabajador-estudiante deberá cancelar las clases en favor del trabajo.

Esto situación debe minimizarse para que el proceso de aprendizaje se respete y sea un éxito. El compromiso con la actividad de aprendizaje convenida por parte de todos los agentes es esencial.

\section{Referencias}

[1] Kjersdam, F. and Enemark, S.: The Aalborg Experiment: Project Innovation in University Education. Aalborg University Press (1994).

[2] The Danish Evaluation Institute: Computer Science, International Benchmarking of Danish Computer Science. The Danish Evaluation Institute, Copenhagen (2006). Disponible en http://www.eva.dk/Udgivelser/Rapporter_og_notater/Videregående_ uddannelse.aspx

[3] Fink, F. K.: Modelling the Context of Continuing Professional Development. Proceedings Frontiers in Education (FIE'01), Reno (2001).

[4] Borch, O., Knudsen, M. and Helbo, J.: From Classroom Teaching to Remote Teaching. EURO Education Conference 2000, Aalborg, Denmark (2000).

[5] Knudsen, M. et al: Project Work in Networked Distance Education. International Conference on Networked Learning, Lancaster, UK. (2000).

[6] Fink, F., K. and Nørgaard, B.: The Methodology of Facilitated Work Based Learning. 10 ${ }^{\text {th }}$ IACEE World Conference on Continuing Engineering Education, Vienna (2006).

[7] Kolmos, A., Fink, F. K. and Krogh, L. (eds): The Aalborg PBL Model: Progress, Diversity and Challenges. Aalborg University Press (2004). 
[8] Chisholm, C., U.: Negotiated Learning Systems: A Way Forward for Engineering Education. Proceedings of $1^{\text {st }}$ North-East Asia International Conference on Engineering and Technology, Taiwan (2003).

[9] ESF (2005). The European Social Fund Danish section, Objective 3, Human resources, development, competence and more people at work, Priority 3, Competence development among employees, Project "Lonely Wolf", 2005. 


\section{Diseño CURRICULAR}



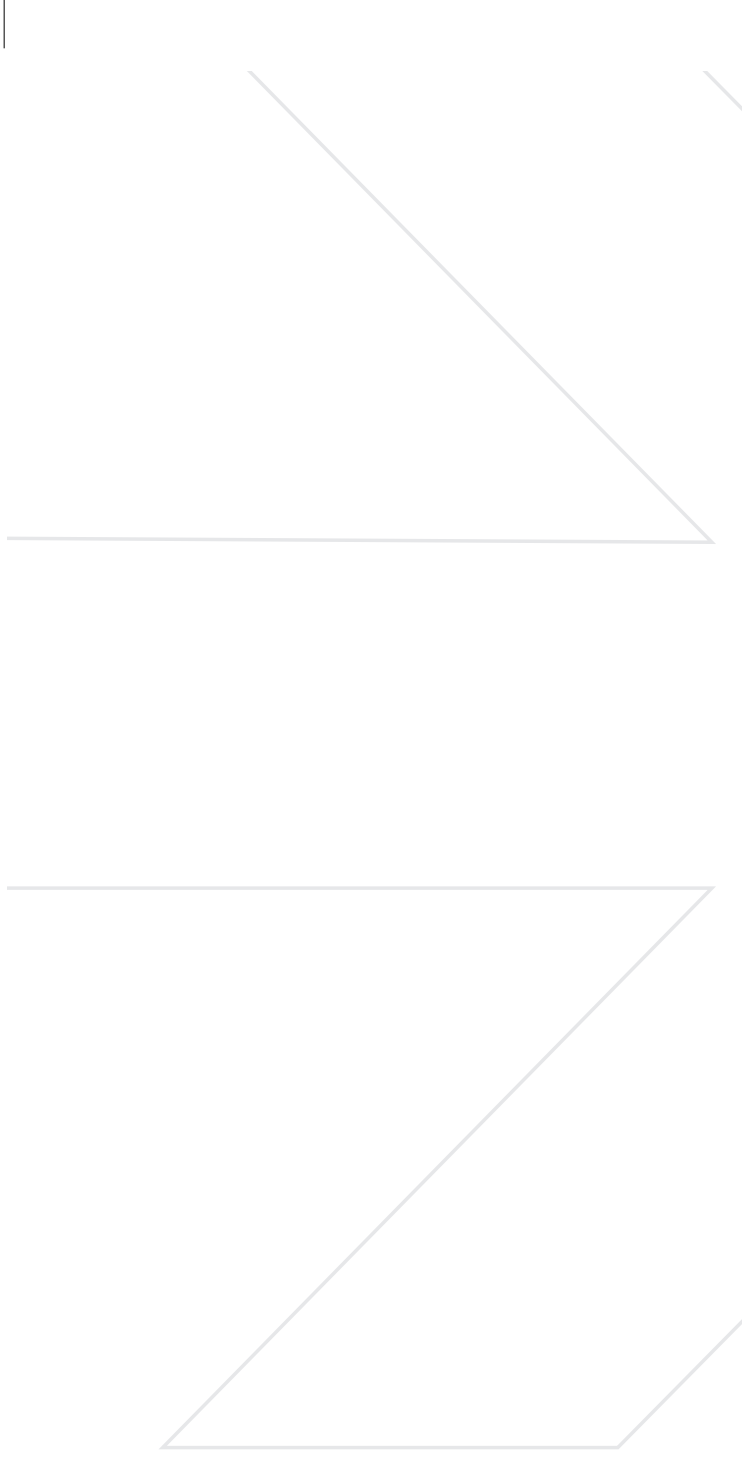
I. 1 Adaptación a la nueva filosofía docente de las asignaturas troncales correspondientes al primer ciclo de Microeconomía en LE, LADE, Derecho-ADE y Diplomatura en Ciencias Empresariales

Rosa Aísa, Joaquín Andaluz, Rosa Duarte, Mª Dolores Esteban, Mª Luisa Feijoo, Inmaculada García, Jose Mª Hernández, Carolina lbor, Luis Fernando Lanaspa, Gemma Larramona, Alfredo Mainar, Yolanda Martínez, José Alberto Molina, Juan Perote, Marcos Sanso, Fernando Sanz, Julieta Zubiaurre, Domingo Pérez, Agustín Gil

Las líneas trazadas por el EEES darán lugar a un cambio considerable en las estrategias docentes. Este proyecto ha tenido por objetivo avanzar en la adaptación a la nueva filosofía docente de las asignaturas troncales correspondientes al primer ciclo de Microeconomía impartidas en LE, LADE, Derecho-ADE y la Diplomatura en Ciencias Empresariales. En concreto, se ha profundizado en el conocimiento de las competencias requeridas por los titulados en estas titulaciones, que se pueden encontrar en el Libro Blanco sobre los Estudios de Grado en Economía y en Empresa, y que puede considerarse como uno de los puntos de partida para las futuras titulaciones de Grado en Economía y Empresa. En segundo lugar, se ha llevado a cabo una valoración completa de la posición actual del estudiante frente a estas materias. El diseño y realización de una encuesta entre todos los alumnos que han cursado las asignaturas recientemente permite obtener información suficiente para contrastar la realidad actual con las competencias requeridas para los titulados y diseñar en el futuro la metodología docente que mejor se adapte en este nuevo contexto.

I. 2 Aplicación de metodologías basadas en el EESS para el diseño y propuesta de experiencias piloto en bloques temáticos de la titulación de Ingeniería de Telecomunicación y análisis de su repercusión en la carga docente del profesorado

Álvaro Alesanco Iglesias, Raquel Bailón Luesma, María Canales Compés, Pedro Luis Carro Cevallos, Santiago Cruz Llanas, Marcos Curty Alonso, José Ramón Gállego Martínez, José García Moros, Eduardo Gil Herrando, Carlos David Heras Vila, Alicia López Lucia,

Antonio Miguel Artiaga, María Dolores Peláez Coca, Esther Pueyo Paules, José Rufino Solera Ureña

Este trabajo se ha dirigido a tres grupos de asignaturas de Ingeniería de Telecomunicación, para las que se han elaborado las guías docentes siguiendo el modelo de la Universidad de Zaragoza (Teoría de Circuitos I y II, Señales y Sistemas II, Comunicaciones Digitales Avanzadas, Gestión de Redes de Comunicaciones en la Empresa, Protocolos de Comunicaciones, Antenas y Propagación, y Sistemas Radar). En las propuestas se ha considerado un papel más activo de los estudiantes tratando de fomentar el aprendizaje de capacidades no contempladas en la clase magistral. Como primera fase de un trabajo en curso, se ha analizado tanto el esfuerzo discente como el docente. El estudio se ha basado en estimaciones 


\section{Investigación Educativa e Innovación Docente en el proceso de Convergencia Europea}

de factores asociados a las diferentes propuestas metodológicas, también dependientes del número de alumnos que cursen cada asignatura, distinguiendo entre el primer año de implantación y la impartición en cursos sucesivos. Según este estudio, el rango de esfuerzo docente para un grupo de 50 alumnos supondría una dedicación de entre 22 y 55 horas semanales, durante el primer año de implantación, y entre 18 y 50 horas semanales, en años sucesivos. No obstante, para disponer de información más precisa actualmente estamos abordando la implantación real de estas propuestas.

\section{3 ¿Qué demandan las empresas a los ingenieros españoles? Guía para la formación universitaria}

Mercedes Marzo Navarro, Marta Pedraja Iglesias, Pilar Rivera Torres

El sector empresarial español está sufriendo diversos cambios relacionados con sus recursos humanos. En este contexto surge el interés de este trabajo, cuyo objetivo consiste en identificar el perfil formativo que las empresas demandan a los titulados en Ingeniería. Para ello, se han analizado las ofertas de empleo publicadas en dos periódicos españoles de tirada nacional. Los resultados obtenidos muestran que las empresas desean incorporar en su personal a titulados en Ingeniería con experiencia profesional y dominio del inglés. Además, se detecta una creciente demanda de competencias transversales, que perfilan al candidato como personas con iniciativa, comunicativas, capaces de trabajar en equipo que están dirigirlos y orientados a obtener resultados.

\section{4 Como introducir las competencias profesionales transversales en los currículos}

Carlos Hué García

Según un estudio reciente de Accentura y Universia el $77 \%$ de los profesores universitarios manifestamos estar satisfechos con respecto a las competencias profesionales desarrolladas por los titulados, mientras que los empresarios rebajan ese nivel de satisfacción al $47 \%$. Eso indica que existe un diferencial de un $30 \%$ entre las competencias profesionales que los titulados adquieren en nuestras universidades y aquellas que son demandas por los empleadores. Las competencias requeridas que se echan en falta en los titulados son de carácter transversal y tienen relación con competencias para el manejo de la información (expresión oral y escrita en la lengua propia y otra extranjera, análisis, síntesis, etc); competencias personales (trabajar bajo presión, motivación, ganas de aprender, etc.); y competencias interpersonales (saber relacionarse, trabajo en equipo, liderazgo, etc.). El objetivo de la presente comunicación es señalar cuáles son las competencias profesionales demandas por los empresarios a través de los resultados obtenidos en los estudios más recientes, presentar una propuesta curricular de 


\section{Investigación Educativa e Innovación Docente en el proceso de Convergencia Europea}

carácter transversal en la que se identifiquen los objetivos, contenidos, actividades de enseñanza-aprendizaje, materiales y evaluación para su inclusión en los diferentes diseños curriculares de los nuevos estudios de Grado. Se cuenta para ello, con la experiencia de formación del profesorado universitario en cursos impartidos en el ICE durante los últimos cinco cursos.

\section{5 Diseño del Título de Grado en Bellas Artes de la Universidad de Zaragoza}

Luis Diego Arribas Navarro

Diseño e implantación del nuevo Título de Grado en Bellas Artes de la Universidad de Zaragoza.

\section{6 Diseño Curricular de la Materia Finanzas}

Begoña Pelegrín Martínez de Pisón, Begoña Gutiérrez Nieto, Natividad Blasco de las Heras

En esta ponencia queremos reflejar el trabajo realizado para intentar adaptar todas las asignaturas actuales que pensamos formaran parte de la materia Finanzas de los nuevos estudios de grado de Administración de Empresas. Tres profesores de dichas materias han analizado cúal debería ser el contenido lógico y coherente que deberiamos acercar al estudiante para que fuera capaz de obtener todas las competencias requeridas por la sociedad para nuestros egresados. Al realizar este estudio se han diseñado los programas correspondientes analizando las clases a impartir, el reparto entre actividades presenciales y no presenciales y entre cases de teoría y de práctica, así como los sistemas de evaluación continua y de autoevaluación tanto del profesor como del estudiante. Parte de este programa de Finanzas se viene experimentando en los últimos años por lo que ya se han venido haciendo modificaciones en el mismo en función de las necesidades que se han ido observando. Se aporta información sobre la aplicación de distintos criterios de impartición de clases y de evaluación.

I. 7 Diseño curricular de las guías de las asignaturas: Actividades Físicas Organizadas y Deportes de Equipo en la Diplomatura Magisterio de Educación Física

Joaquín Reverter Masia, Diego Moliner Urdiales

Este proyecto de innovación educativa tenía como objetivo el diseño de las guías docentes de las asignaturas "Actividades Físicas Organizadas" y "Deportes de Equipo", impartidas en la titulación de Magisterio en Educación Física de la 


\section{Investigación Educativa e Innovación Docente en el proceso de Convergencia Europea}

Facultad de Educación de la Universidad de Zaragoza. Este diseño se ha confeccionado en base a las directrices marcadas por el EEES, estimando la carga de trabajo según los ECTS y estableciendo las competencias en base a los Libros Blancos.

\section{8 Diseño curricular y Guías docentes ECTS en Información y Documentación}

Mª del Carmen Agustín Lacruz, Genaro Lamarca Langa, Ma Adelaida Allo Manero, Miguel Ángel Esteban Navarro, Manuel J. Pedraza Gracia, Ma Pilar Pueyo Colomina, José Antonio Salvador Oliván, Ana I. Sánchez Casabón, Jesús Tramullas Saz, Esperanza Velasco de la Peña

Se describe el proceso y los resultados obtenidos por un grupo de trabajo que durante el curso 2006-2007 desarrolló el Proyecto de Innovación Docente "Diseño y armonización curricular de las asignaturas de $2^{\text {a }}$ curso de la Diplomatura en Biblioteconomía y Documentación según la metodología de los ECTS". El objetivo es la armonización curricular y el rediseño con la metodología didáctica del EEES de las asignaturas de segundo curso del título de Diplomado en Biblioteconomía y Documentación, impartidas por el equipo de profesores participantes, integrado por 10 componentes, que afectan a nueve asignaturas. Este objetivo general se concreta en 10 objetivos específicos y pone en marcha un proceso de análisis y reflexión con repercusiones en los siguientes ámbitos: a) El Proyecto curricular de cada asignatura; b) El Plan curricular del curso; c) La metodología docente utilizada y; d) El diseño y uso de recursos didácticos. Entre los resultados obtenidos destacan: a) la identificación de las principales lagunas y solapamientos de contenidos existentes en plan curricular del curso; b) el diseño curricular según la metodología ECTS de cada una de las asignaturas tratadas; c) la redacción de las "Guías docentes" de cada una de las asignaturas desarrolladas, según un modelo común.

\section{9 Diseño de prácticas en la Geometría para maestros}

Pillar Bolea, María Consuelo Cañadas, Eva Cid, Rafael Escolano, José María Gairín, Raquel lbáñez, José María Muñoz, Julio Sancho

En este trabajo se describe un proyecto de innovación docente implementado durante el curso $2006-07$ y subvencionado en la convocatoria de ayudas PIIDUZ/2006. El ámbito docente del proyecto fueron las asignaturas de Matemáticas y su Didáctica II de las distintas diplomaturas de Maestro. En la experiencia intervinieron profesores del área de Didáctica de las Matemáticas de las Facultades de Huesca, Teruel y Zaragoza en las que se imparten estas asignaturas. El objetivo del trabajo es diseñar, implementar y evaluar las prácticas de estas asignaturas con la finalidad de que los futuros maestros alcancen una mayor competencia en su tarea de enseñar Geometría en Educación Primaria. De este modo, continuamos la labor de diversificación y adecuación al EEES de nuestra práctica docente, tratan- 
do de hacerla más compatible con los procesos de aprendizaje del estudiante. También nos mueve el deseo de coordinar la docencia de asignaturas que, aun perteneciendo a distintas especialidades de Maestro e impartiéndose en diferentes facultades, responden a unos mismos objetivos didácticos. Además, pretendemos que los estudiantes mejoren sus concepciones sobre la Geometría y que se familiaricen con aquellos procedimientos y recursos didácticos que, en su futuro como maestros, les ayuden a desarrollar su tarea profesional con mayor pertinencia y eficacia.

\section{10 del Master Internacional "Marco Legal de la Sociedad de la Información"}

Fernando Galindo Ayuda, María Pilar Lasala Calleja, Francisco Javier García Marco

Se describe el diseño de un Master Internacional “ Marco Legal de la Sociedad de la Información” coordinado por la Universidad de Zaragoza y en el que participan todas las Universidades del Proyecto de la Unión Europea LAW\&ICT Shared Virtual Campus.

\section{11 Diseño del Master Oficial en Dirección y Planificación del Turismo}

Carmen Elboj Saso, Vitelio Tena Piazuelo

Esta comunicación se refiere a la implantación de los estudios de Master oficial en el ámbito del Turismo en la Escuela Universitaria de Estudios Empresariales de Huesca dentro del marco del Espacio Europeo de Educación Superior. El objetivo de dicha titulación es la formación de profesionales de alto nivel para la dirección y planificación de empresas, actividades e instituciones turísticas, así como la formación de expertos que orienten su carrera profesional hacia el ámbito de la investigación y el desarrollo del conocimiento en Turismo. Este proyecto arranca de la preocupación por los estudios de turismo adaptados al nuevo escenario de la ordenación de las titulaciones universitarias en la estructura de Grado y Postgrado. Esta inquietud ha sido compartida por 14 universidades españolas (alguna de las cuales ya contábamos con un estudio propio de Segundo Ciclo en Turismo) y como consecuencia de la participación en los trabajos preparatorios del Libro Blanco del Grado en Turismo auspiciado por ANECA. La colaboración ha cristalizado en la constitución de la Red Interuniversitaria de Postgrados en Turismo (RED-intur) mediante convenio entre todas ellas. Y en ese marco se elaboró una propuesta común de diseño del Master Oficial en Dirección y Planificación del Turismo, basada en los perfiles profesionales y las competencias de los egresados. Cada universidad ha implantado, sobre esta base, una titulación que responde a un criterio unitario de troncalidad común y a una diversidad de especialidades en función de las características del entorno turístico. Junto a estas cuestiones estructurales, presenta interés el nuevo modelo de ordenación de la docencia desarrollado para la adecuación a las exigencias del EEES. 


\section{12 Diseño del título de Grado en Información y Documentación}

Luisa Orera Orera, Esperanza Velasco de la Peña, Ma del Carmen Agustín Lacruz, Mª Adelaida Allo Manero, Miguel Ángel Esteban Navarro, Francisco Javier García Marco, Pilar Gay Molins, Genaro Lamarca Langa, Manuel J. Pedraza Gracia, José Antonio Salvador Oliván, Ana I. Sánchez Casabón, Jesús Tramullas Saz, Antonio P. Ubieto Artur, Mª Isabel Ubieto Artur

Se describe la metodología seguida por los profesores del Área de Biblioteconomía y Documentación del Departamento de Ciencias de la Documentación e Historia de la Ciencia para la planificación y diseño en la Universidad de Zaragoza del título de Grado de Información y Documentación de acuerdo a los requisitos establecidos en el RD 1393/2007, de 29 de octubre, por el que se establece la ordenación de las enseñanzas universitarias oficiales. El objetivo general del proyecto es redactar la memoria justificativa que recoja el Plan de Estudios del título de Grado de Información y Documentación, mediante la adaptación de la actual Diplomatura de Biblioteconomía y Documentación, impartida actualmente por los profesores del Área. Como metodología de trabajo se propone la constitución de un grupo de trabajo con estructura de seminario, integrado por todos los profesores del Área. Las sesiones de discusión tienen una duración de 2 horas y se celebrarán con la periodicidad que requiera el desarrollo del proyecto. Como principal resultado se pretende redactar la memoria de dicho título para su aprobación en las instancias pertinentes, de manera que sea posible la puesta en marcha de dichos estudios en la Universidad de Zaragoza septiembre de 2008.

\section{13 El Máster BDI: una nueva perspectiva docente}

Eladio Domínguez Murillo, Inés Escario Jover, María Jesús Lapeña Marcos, José Carlos Ciria Cosculluela, Ángel De Miguel Artal, Ángel Francés Román, Jorge Lloret Gazo, María Antonia Zapata Abad

En el marco del Máster Bases de Datos e Internet (MBDI), Estudio Propio de la Universidad de Zaragoza, se trabaja con una metodología innovadora, y cada nuevo curso incorpora nuevos elementos didácticos tendentes a favorecer la integración de los titulados en el mundo de la Empresa. Teniendo como objetivo la formación de expertos en diseño y desarrollo de bases de datos con acceso a través de Internet, el MBDI se constituye desde un primer momento como un Sistema de Aprendizaje Profesional donde los alumnos hacen desarrollos reales encargados por entidades externas bajo una estructura empresarial. Así, conseguimos que los alumnos desarrollen las habilidades y capacidades propias de los profesionales de una empresa tecnológica a la vez que se familiarizan con la estructura departamental y con las funciones y responsabilidades propias de los profesionales de una empresa. La última innovación en nuestra estrategia de aprendizaje contempla la incorporación de empresas que colaboran con el Máster, dotándolo de una nueva dimensión que permite diseñar una es- 
tructura de formación permanente que se proyecta más allá del curso académico; los egresados del MBDI, contratados bajo esta estructura, pueden continuar su formación a la vez que colaboran en la formación profesional de los nuevos alumnos.

I. 14 El módulo de habilidades de comunicación del Curso Cero de la Facultad de Educación: Diseño y resultados

Santos Orejudo Hernández, Ezequiel Briz Villanueva, Teresa Fernández Turrado

Las competencias de comunicación oral forman parte de la mayor parte de taxonomías de formación de estudiantes universitarios. En el mismo proyecto Tuning aparecen como parte de las competencias transversales que todos los estudiantes han de adquirir en su paso por la Universidad. Una de las dificultades más importantes para alcanzar este logro es superar el miedo a hablar en público, uno de los temores más frecuentes entre los universitarios, que aparte de condicionar el desarrollo de la competencia oral, puede interferir igualmente en la puesta en marcha de otra de las líneas de la actual reforma universitaria, las metodologías activas, ya que todas ellas requieren en mayor o menor la interacción del alumnado. En el presente trabajo se expone una experiencia desarrollada en la Facultad de Educación de Zaragoza a lo largo de dos cursos académicos en la que se ha pretendido mejorar la competencia oral y el miedo a hablar en público en estudiantes de nuevo ingreso dentro del Curso Cero de este centro. Los resultados ponen de manifiesto que los estudiantes perciben como útil este tipo de experiencias y que mejoran su competencia percibida para hacer frente a las situaciones de este tipo.

\section{15 El Tuning y el Libro Blanco de Enfermería, dos procesos simultáneos}

Concha Germán Bes, Luis Bernués Aznar

En Mayo de 2003 la titulación de Enfermería se incorporó al estudio Tuning, siendo la representante española la profesora Germán de la Universidad de Zaragoza. En el curso 2004-05 se inició el desarrollo del libro blanco coordinado por el profesor Bernués de la Universidad de Zaragoza y director de la Escuela Universitaria de Ciencias de la Salud en esas fechas. En ambos procesos se utilizó el cuestionario de competencias generales del Tuning para todos los estudiantes universitarios y el de competencias específicas que desarrollo el grupo Tuning de Enfermería y que fue utilizado para el estudio español. El uso de los mismos instrumentos nos han permitido comparar los resultados de ambos estudios los cuales están publicado en la Web de la Escuela. Esta oportunidad de realizar ambos estudios simultáneamente nos permite contribuir a construir la Europa del siglo XXI. 


\title{
Investigación Educativa e Innovación Docente en el proceso de Convergencia Europea
}

\section{16 En defensa de la clase presencial en la Termodinamica-EEES}

\section{Francisco Javier Collado Giménez}

Se presentan los documentos "plan de la asignatura" y "agenda del estudiante" de la asignatura Termodinámica, una asignatura de base, dentro del Espacio Europeo de Educación Superior (EEES). La metodología docente en la que se basan dichos documentos se considera activa e híbrida: se da preeminencia a las aplicaciones tecnológicas sobre el puro contenido teórico (sin obviarlo en absoluto), mediante la adquisición de procedimientos (competencias) en el planteamiento y resolución de problemas termodinámicos prácticos. Se busca provocar la motivación espontánea del trabajo del alumno mediante la constatación diaria de que con una cantidad de trabajo razonable por su parte es factible aprobar. La clase magistral en los primeros cursos de los futuros grados se considera muy importante, no sólo como medio primordial de transmisión de información, sino también como elemento motivador del alumno. La estructuración de la información suministrada al alumno mediante el Anillo Digital Docente de la Univ. Zaragoza (ADD) es una tarea crucial y en permanente evolución. Como conclusión, se constata que la conjunción de la estructuración del material académico con una metodología docente claramente definida es clave en el planteamiento de dichos documentos. Destacar que no se pretende dar una visión cerrada y única de un problema que atañe a toda la educación superior, estando abierto a todo tipo de sugerencias y críticas.

\section{17 Enseñando en Responsabilidad Social, una perspectiva de las necesidades actuales de las empresas}

\author{
José María Agudo Valiente
}

La sociedad está demandando cada vez más modelos de desarrollo sostenibles, lo que supone la incorporación de los diferentes aspectos de Responsabilidad Social de la Empresa a la vida cotidiana. En vistas al proceso de convergencia europea hacia el Especio Europeo de Educación Superior, es necesario que desde los sistemas de enseñanza y aprendizaje sea contemplada esta necesidad a la hora de realizar el rediseño de la enseñanza universitaria. En esta comunicación se recogen los resultados de un estudio que refleja como las empresas están siendo conscientes de su falta de formación en estos aspectos y por ello están demandando formación relativa en estas competencias. 


\title{
I. 18 Finanzas, innovacion docente y Espacio Europeo de Educación Superior: Una aproximacion
}

\author{
Luis Ferruz Agudo, Isabel Marco Sanjuán, Fernando Muñoz Sanchez
}

La Universidad española está en la actualidad viviendo una época de cambio y evolución como consecuencia del Espacio Europeo de Educación Superior (EEES), cuyo origen está en la declaración de Bolonia. Inmersos en el proceso de adaptación al EEES, el nuevo diseño de las titulaciones en este novedoso contexto, las metodologías aplicadas al aprendizaje, estudio, control y evaluación de los estudiantes están cambiando para adaptarse a esta nueva forma de operar, que debe verse apoyada con el uso de nuevas tecnologías de la información y la comunicación. En este contexto, lo que se busca es implicar más al alumno en el proceso del aprendizaje. Para ello es necesario incidir no sólo en la formación sino también en la evaluación y la incentivación. En esta comunicación se presenta una propuesta de desarrollo de programa de una asignatura básica de Finanzas (Matemáticas Financieras) en base a los créditos europeos (ECTS) profundizando en todos los aspectos relacionados con las actividades presenciales y no presenciales así como su cuantificación en créditos europeos. Se detallan de una manera más pormenorizada los aspectos relativos a la evaluación del aprendizaje de tipo práctico, con especial énfasis en los trabajos individuales y en grupo.

I. 19 Implantación de la metodología ECTS en los dos primeros cursos de la titulación de Filosofía y su evaluación

Alberto Carreras Gargallo, Ana Samper Francín, Leyre Pastrana Blanco

Informaremos sobre el proceso de implantación de todo el segundo curso de la titulación de Filosofía con la metodología ECTS y de la continuación del primer curso con la misma metodología. Daremos cuenta de los cambios que hemos introducido tras la experiencia del año anterior, así como de los procesos que hemos seguido, de la evaluación de la experiencia y de sus resultados.

\section{20 Implantacion de un plan educacional para el desarrollo sostenible en asignaturas de la Universidad de} Zaragoza

Javier Domínguez Hernández, Enrique Cano Suñén, Beatriz Rodríguez Soria, José María Pérez Bella

Nuestra sociedad está tomando conciencia de que el actual modelo de crecimiento es insostenible, pero las generaciones actuales no han sido educadas para responder a los retos que supone la globalización y la eficiencia en la utili- 


\title{
Investigación Educativa e Innovación Docente en el proceso de Convergencia Europea
}

zación de recursos. Como ponen de manifiesto distintas entidades y organizaciones que advierten de los graves riesgos para la humanidad (UNESCO), al no haber una modificación en nuestros hábitos, se considera necesario introducir cambios educativos para que las nuevas generaciones sean conscientes de los problemas que las actuaciones irresponsables causan en el medio ambiente. En esta situación de valores, se pretende que los años 2005-2014 sean la "década de la educación para el desarrollo sostenible en una sociedad internacional" Tomando como base educativa la "carta de la tierra", se desarrollan en España diferentes "planes educativos", orientados a distintas tipologías sociales. Basándose en dichos planes se pretende implantar un nuevo programa en la asignatura Construcciones y Servicios Industriales, que recoja tales planteamientos. Para ello, se describirán metodologías activas de aprendizaje basadas en la experiencia, que faciliten la exploración creativa de formas de desarrollo más sostenibles y socialmente responsables, incluyendo objetivos, planificación de actividades concretas y métodos de evaluación que favorezcan la reflexión crítica del alumno y la toma de decisiones responsables y sostenibles en sus futuros puestos en la sociedad.

\section{21 Implementación curricular de la Diplomatura en Magisterio de Educación Física}

Joaquín Reverter Masia, Diego Moliner Urdiales, Julio Latorre Peña, José Antonio Ferrando Roqueta, Enrique Lizalde Gil, Manuel

Lizalde Gil, Raquel Martínez Jiménez, Paula Gelpi Fleta, Manuel Iguacel Linares, Inmaculada Tena Porta,

El proyecto que se presenta tiene como objetivo ver el grado de establecimiento de las competencias genéricas y especificas de la titulación de Magisterio en Educación Física en base a los Libros Blancos y estimar la carga de trabajo, medida en créditos ECTS, que supone para los estudiantes de Educación Física de la Facultad de Educación.

\section{22 Ingeniería Técnica de Telecomunicación: primeros pasos hacia la convergencia}

\author{
Raquel Lacuesta Gilaberte, Guillermo Palacios Navarro, Jesús Bella, Pablo Bueso, Carlos Hernanz, Amador Marín, Carlos Catalán
}

En este trabajo se expone el modelo de adaptación al Espacio Europeo de Educación Superior (EEES) desarrollado en la Escuela Universitaria Politécnica de Teruel para un curso completo de Ingeniería Técnica de Telecomunicaciones; modelo planteado durante el curso 2005/2006 y puesto en marcha a lo largo del curso $2006 / 2007$. 


\section{23 Interés de la materia de afecciones médico-quirúrgicas I-II para la futura profesión de la Terapia Ocupa-} cional

\section{Ana Luisa Caballero Navarro, Manuel Bueno Lozano}

Reconocemos esta asignatura de Afecciones Médico-Quirúrgicas I-II como materia substantiva, dentro de la titulación de Terapia Ocupacional, necesaria para la adquisición de conocimientos y formación de contenidos y competencias específicas de la profesión, aunque también podemos considerarla materia de especialización en el estudio de la patología de determinados órganos y aparatos, como el sistema nervioso y locomotor. El conocimiento de las enfermedades, especialmente aquellas que generan un grado importante de discapacidad, minusvalía o pérdida de la autonomía personal (procesos crónicos, degenerativos, congénitos, evolutivos) permitirá al futuro terapeuta enfrentarse a situaciones específicas en cada caso y desarrollar las competencias profesionales aplicadas con diversas técnicas y actividades a cada enfermo. Es por ello una asignatura troncal fundamental e imprescindible en este plan de estudios que permite concatenar o vertebrar las materias básicas introductorias con el estudio de técnicas, terapias o actividades propias en cada patología, que permitirán especializar y alcanzar las competencias propias del terapeuta ocupacional. Esta materia se refleja en el plan de estudios de otras universidades europeas con un peso troncal y de carga crediticia muy importante.

\section{24 La adquisición y desarrollo de competencias profesionales}

Pedro Manuel Aguado Benedí, Emilia Muñoz Langa, Asunción Paricio Miravete, Elisa Gomez de Mena, Irene Serrano Roldán

La comunicación expone la importancia de la Orientación Profesional como impulsor en el aprendizaje y mejora de competencias profesionales. Según la Declaración de Bolonia: "La Europa del conocimiento está reconocida como un factor irreemplazable para el crecimiento social y humano...capaz de dar a sus ciudadanos las competencias necesarias para afrontar los retos del nuevo milenio...". Es evidente que, para conseguir este importante objetivo, la Orientación Profesional, junto con otras estrategias (un Prácticum adecuado, el desarrollo de acciones relacionadas con la difusión de los estudios, investigaciones, información sobre mercado de trabajo, salidas profesionales, técnicas de búsqueda de empleo, etc.) debe poner en funcionamiento acciones educativas y orientadoras esenciales que permitan a los alumnos ver su futuro profesional como algo certero para lo que han sido formados. Conscientes de esto, los autores de la comunicación pertenecientes al grupo de Orientación de Universa de la Universidad de Zaragoza, consideran como una misión prioritaria la formación de profesionales competentes y cualificados para el desempeño de las funciones y puestos de trabajo demandados por la sociedad actual. Por ello el conjunto de actividades realizadas y propuestas debería constituir un elemento de ayuda a la toma de decisiones por parte de la Institución Universitaria. 


\section{Investigación Educativa e Innovación Docente en el proceso de Convergencia Europea}

I. 25 La asignatura Derecho mercantil diseñada para estudios de empresa y adaptada a las nuevas metodologías

\section{Cristina Fernández Fernández}

La comunicación que se presenta recoge el diseño actual de la asignatura Derecho Mercantil en la Diplomatura en Ciencias Empresariales en la EUEEH. Después de varios años durante los cuales la profesora ha ido encuestando a los propios alumnos, se ha llegado ha un determinado ajuste de la carga de trabajo del alumno que se puede trasladar sin problema al nuevo sistema de créditos ECTS.

\section{26 La Educación literaria en la Titulación de Maestro: Elaboración de guías docentes}

José Domingo Dueñas Lorente, Milagros Llorente Mayor, Elvira Luengo Gascón, José-Angel Sánchez Ibáñez, Marta Sanjuán Álvarez,

Rosa Tabernero Sala

En la comunicación se reflexiona acerca de la "guía docente" como instrumento didáctico adecuado en lo que respecta a la educación literaria en la Titulación de Maestro en el marco del EEES. Se establecen algunas pautas teóricas acerca de la elaboración de guías docentes y se proponen los componentes de algunas de ellas.

\section{27 La materia de Dirección Financiera en el marco del EEES: Una propuesta}

\section{Luis Vicente, Cristina Ortiz, Laura Andreu}

Esta propuesta de trabajo recoge la programación de la materia de Dirección Financiera de acuerdo a los criterios establecidos por el Espacio Europeo de Educación Superior y que van a ser implantados en la Universidad de Zaragoza. A partir de un análisis de las competencias profesionales requeridas por el estudiante, se estructura el programa de dicha materia integrando las diferentes metodologías y cuantificando las correspondientes cargas de trabajo del estudiante a partir de la unidad de análisis del ECTS. 
I. 28 Las materias de Afecciones Médico-Quirúrgicas I-II de la titulación de Terapia Ocupacional en otras universidades europeas. Objetivos y competencias

Manuel Bueno Lozano, Ana Luisa Caballero Navarro

Queremos destacar en esta comunicación la importancia de las Afecciones Médico-Quirúrgicas I-Il de la Terapia Ocupacional, en el marco Universitario Europeo, donde se imparte dicha titulación. También se comentan las materias que se suelen impartir cada curso académico en la mayoría de las universidades europeas que imparten la titulación de Terapia Ocupacional y se finaliza con los objetivos y competencias de las materias reflejadas en el Libro Blanco de la Titulación, publicado por la ANECA.

\section{29 Movilidad estudiantil, aprendizaje de idiomas y diseño de nuevos grados}

$M^{a}$ Victoria Sanagustín Fons, José Antonio Moseñe Fierro, Ruth Vallejo Dacosta, Carlos Gómez Bahillo, Jesús Tricas Oliván, Carmelo

López Lacambra, Ma Carmen Galán López

El aprendizaje de idiomas es una de las herramientas básicas para poder realizar experiencias de movilidad estudiantil en el ámbito europeo, tal y como emana de los objetivos del Proceso de Bolonia. En esta comunicación planteamos una reflexión en torno al papel que puede jugar la enseñanza de idiomas en el diseño de los nuevos Grados.

\section{30 Pautas y materiales para la renovación metodológica en la docencia universitaria}

Ana Isabel Escalona Orcao, Blanca Loscertales Palomar

La comunicación presenta la página web (http://ice.unizar.es/gidocuz/calidad) elaborada en el marco del proyecto Diseño, aplicación y difusión de estrategias ECTS para la mejora docente en Geografía, seleccionado en la convocatoria 2006 de proyectos de innovación docente de la Universidad de Zaragoza. Sus potenciales usuarios encontrarán en ella pautas para la programación de sus asignaturas, ejemplos de técnicas de aprendizaje, propuestas de actividades, materiales para su realización y herramientas para la evaluación. El formato de presentación permite la descarga de materiales en forma de fichas o plantillas para que el profesor las utilice directamente en su actividad docente. Destaca la incorporación de enlaces a documentos del máximo interés de cara a la renovación docente en la Universidad. Los contenidos recogidos como aportación en esta web son perfectamente aplicables a todas las materias, disciplinas y titulaciones. 


\section{Investigación Educativa e Innovación Docente en el proceso de Convergencia Europea}

I. 31 Planificación y desarrollo de un Curso Cero transversal secuenciado en niveles en el título de Grado en Información y Documentación en la Universidad de Zaragoza

José Antonio Salvador Oliván, Pilar Gay Molins, Esperanza Velasco de la Peña, Mª del Carmen Agustín Lacruz, Genaro Lamarca Lan-

ga, Luisa Orera Orera, Ana I. Sánchez Casabón, Antonio P. Ubieto Ubieto, Mª Isabel Ubieto Artur

Se describe la metodología para la planificación y desarrollo de un Curso Cero a tres niveles integrado en el proyecto de diseño y armonización curricular de las enseñanzas de grado en Información y Documentación en la Universidad de Zaragoza. Los objetivos propuestos son: a) Resolver las lagunas formativas de los alumnos de nuevo ingreso a la Universidad para afrontar con mayores garantías y en mejores condiciones los estudios universitarios. De esta manera se intenta conseguir un aumento del éxito académico. b) Ofrecer contenidos transversales de múltiples asignaturas para evitar la duplicación de contenidos. c) Guiar y facilitar al estudiante en su inserción laboral. Entre los resultados destaca la programación completa del Curso Cero incluyendo los contenidos específicos en cada nivel, su secuenciación a lo largo del tiempo, responsables, lugar y duración, así como el sistema de evaluación y los instrumentos utilizados. La principal conclusión es la mejora de la coordinación de las enseñanzas al proporcionar conocimientos y destrezas necesarias básicas para el aprendizaje del estudiante en la universidad, y proporcionar conocimientos transversales específicos de la titulación de Información y Documentación que eviten la repetición de contenidos en múltiples asignaturas, de manera que se optimiza la eficiencia en la organización y programación de las asignaturas.

\section{32 Postgrado en microsistemas e instrumentación inteligente. Estudio propio de la Universidad de Zara-} goza

Concepción Aldea, José Barquillas, Belén Calvo, Santiago Celma, Pedro A. Martínez, Nicolás Medrano, Aránzazu Otín, María Teresa Sanz

Este documento expone la justificación académica y social, los objetivos y las líneas básicas que fundamentan la elaboración de un Estudio Propio en Microsistemas e Instrumentación Inteligente. No sólo presenta un elevado interés desde la perspectiva de las titulaciones científicas e ingenierías, demostrando un marcado carácter transversal, sino que recoge la necesidad de formación continua y adquisición de competencias específicas de los nuevos egresados y profesionales en ejercicio. 


\section{Investigación Educativa e Innovación Docente en el proceso de Convergencia Europea}

I. 33 Puesta en marcha del máster oficial de postgrado sobre Sanidad y Producción Porcina: experiencia de trabajo entre tres universidades

Victoria Falceto Recio, Daniel Babot Gaspa, Jordi Casal y Fabrega, Emilio Espinosa Velázquez, Joseph Gasa Gaso, Eduardo Angulo Asensio, Joaquim Segales i Coma, Fernando Forcada Miranda, Clara Santamarina Gonzalez, Daniel Villalba Mata, Juan Luis Ubeda Echarte

El organigrama de trabajo entre tres universidades para poner en marcha un estudio oficial de postgrado de tipo profesionalizante tiene como ventaja que hay un mayor numero de profesores expertos en diferentes aspectos. Esto permite programar un master que integra todos los conocimientos sobre el tema desde diferentes puntos de vista, ofreciendo al alumno un aspecto global de la profesion. Sin embargo, no cabe duda que tambien tiene ciertas dificultades, que no inconvenientes, para poder poner de acuerdo las ideas e intereses de tres universidades. En esta comunicación se resume el proceso de más de cuatro años de trabajo y un objetivo ya cumplido, comenzando en febrero del 2008 la tercera edicion del master y la primera como estudio oficial de postgrado en la Universidad de Zaragoza.

\section{34 Una propuesta para la adaptación de la asignatura Derecho Administrativo I al EEES}

Elisa Moreu Carbonell, José Luis Bermejo Latre, Victor Escartín Escudé, Miguel Angel Bernal Blay, Carmen de Guerrero Manso

La comunicación pretende dar a conocer la metodología utilizada y los resultados obtenidos al elaborar una propuesta de adaptación de la asignatura Derecho Administrativo I al EEES. La propuesta comprende los siguientes aspectos: Selección de contenidos, competencias a adquirir, metodologías docentes y cómputo en términos ECTS. 


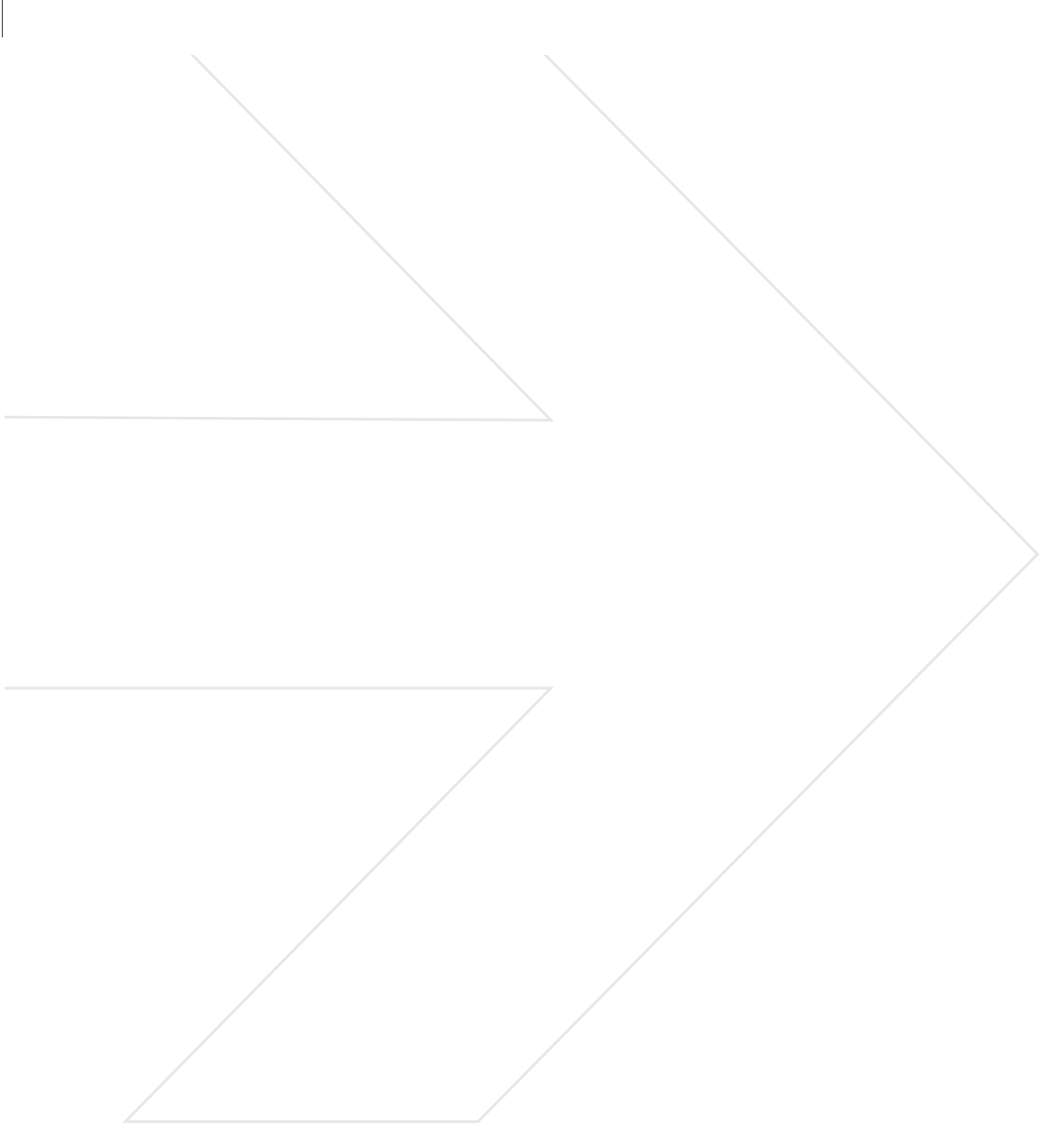




\section{EVALUACIÓN, INNOVACIÓN Y FACTORES DE CALIDAD}




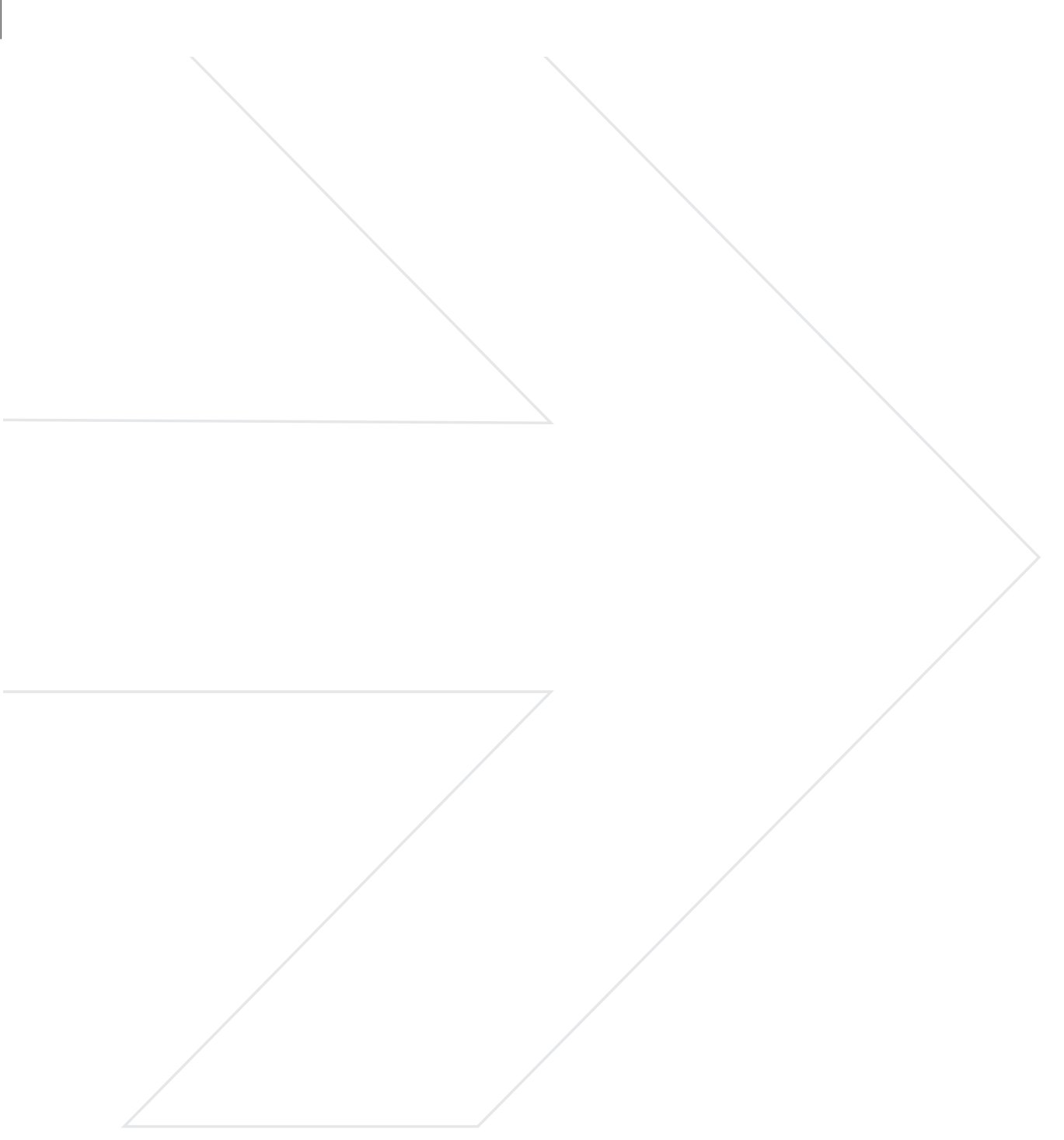




\section{1 Análisis de resultados de la metodología de triangulación de la docencia}

Carmen Berné Manero, Pablo Lozano Chavarria, Mercedes Marzo Navarro

La motivación de los alumnos es imprescindible para optimizar su aprendizaje, formación y desarrollo de habilidades. Persiguiendo estos fines, la metodología de triangulación de la docencia convierte a los estudiantes en activos directamente implicados en la elaboración del material de trabajo de las clases, proporcionando así un primer valor añadido. El alumno convive con los otros dos agentes del "triángulo": El profesor/es de la asignatura y las empresas, cuya participación es el otro valor añadido clave; su colaboración constituye una verdadera novedad y es una forma de conseguir la reclamada relación empresa-universidad. Después de describir brevemente el proceso de la metodología, premiada en 2007 con el segundo premio a la innovación docente de la Universidad de Zaragoza, el objetivo de esta comunicación es analizar los resultados obtenidos tras su aplicación efectiva en las aulas. Hasta el momento, el resultado más tangible es la publicación de tres informes de actuación empresarial con su correspondiente grabación en DVD, donde se dramatiza cada caso. Otros resultados son intangibles y se miden a través de las percepciones de los estudiantes sobre aspectos relativos a la metodología. Su análisis pone de manifiesto que la posibilidad de réplica en otras materias, la aproximación a la realidad empresarial que proporciona al estudiante, el fomento de la adquisición de competencias transversales y específicas y los escasos problemas que supone su efectiva puesta en marcha, son sus principales ventajas.

II. 2 Aspectos de calidad en el proceso de enseñanza y aprendizaje: Motivación, comprensión y utilidad en un sistema semipresencial

Fco. Javier Pérez Sanz, Ana Gargallo Castel, Luisa Esteban Salvador, Ma Angeles Soriano Paola

En la Facultad de Ciencias Sociales y Humanas se trabaja en la reformulación de los perfiles de las carreras de Relaciones Laborales y Ciencias del Trabajo de acuerdo a las necesidades del mercado y las directrices del EEES, todo ello bajo la perspectiva de preocupación e incorporación de los aspectos relacionados con la calidad en las universidades. En este proceso, el sistema de evaluación resulta altamente complicado desde la perspectiva de considerar que lo importante es que nuestros alumnos estén evaluados en una etapa o periodo concreto del curso académico (momento del tiempo) y en función de las respuestas que atribuyen el éxito de un examen a la buena suerte o al esfuerzo de los estudiantes. A esto debemos añadir las dificultades propias de la modalidad de enseñanza semipresencial. Una línea de este trabajo consiste en la elaboración de los nuevos curricula, centrados en la atención en el alumno para fortalecer estas enseñanzas, fijando como objetivo de esta comunicación evaluar el recurso "módulo de autoaprendizaje" de diversas asignaturas a través de 


\section{Investigación Educativa e Innovación Docente en el proceso de Convergencia Europea}

la opinión de los alumnos. La muestra se escogió en forma aleatoria simple, incluyendo alumnos de las citadas titulaciones que contestan una encuesta de opinión de forma voluntaria y anónima. Partiendo de otros trabajos previos, las respuestas se han categorizado en una escala de cinco posibilidades y recogen aspectos como organización de contenidos, utilidad, calidad de la información y cantidad de material empleado, motivación, tiempo utilizado y dificultad de comprensión. El resultado final revela el papel relevante de estos módulos en cuanto a la motivación e integración de los conocimientos de estas disciplinas.

\section{3 ¿Es serio estudiar con Internet en la Universidad?}

Ana de Echave Sanz, Pedro L. Domínguez Sanz, J. Javier Sarsa Garrido, Francisco J. Serón Arbeloa, Alberto Lekuona Amiano

Esta comunicación presenta los resultados del estudio realizado en la Universidad de Zaragoza, dentro del programa de enseñanza semipresencial, PESUZ (período 2004-2007), sobre las preferencias del alumnado en torno a asignaturas virtuales como es el caso de "Internet: Una herramienta útil a la hora de estudiar" Esta asignatura fue diseñada con el objeto de posibilitar la adquisición de habilidades informáticas básicas al alumnado de nuevo ingreso y facilitar así la incorporación de estas tecnologías a las actividades cotidianas de aprendizaje a lo largo de sus estudios universitarios.

\section{4 Comparativa entre el aprendizaje basado en proyectos y el aprendizaje basado en problemas}

José Antonio Domínguez Navarro, Eva Sara Carod Pérez, Ma Jesús Velilla Marco

Tanto el aprendizaje basado en problemas como el aprendizaje orientado a proyectos son dos tendencias del aprendizaje constructivista que se han utilizado ampliamente en el campo de la enseñanza técnica. En este trabajo se presentan las experiencias de la aplicación de ambas tendencias en una misma asignatura.

II. 5 Criterios de evaluación de la asignatura de Afecciones Médico-Quirúrgicas I-II siguiendo los modelos de la convergencia europea

\footnotetext{
Manuel Bueno Lozano, Ana Luisa Caballero Navarro
} 
Antes de entrar a definir nuestro criterios de evaluación, realizamos una pequeña introducción de cómo debe plantearse o cómo se debe entender la evaluación dentro del contexto de la Convergencia Europea. Se finaliza la comunicación, incluyendo los criterios de evaluación que se van a aplicar en las asignaturas, siguiendo las directrices de los Modelos de Convergencia Europea y del Libro Blanco de Terapia Ocupacional publicado por la ANECA.

\section{6 El "homo academicus" y la docencia: Nuevas estrategias de evaluación en un contexto realista de me- todologias activas}

Javier Usoz Otal, Jesús Astigarraga Goenaga

En el campo de la metodología docente dominan las reflexiones normativas sobre cómo debería ser la enseñanza. Los autores de esta aportación ven necesario un enfoque teórico positivo en el que la realidad se haga más presente. Al hilo de los avances en las Ciencias Sociales, proponen el recurso de un "homo academicus" que incorpore las hipótesis sobre el comportamiento de los agentes implicados en la docencia universitaria, así como valorar mejor las condiciones reales en que dicha figura decide y actúa. Apuntado este escenario y conforme a la enorme función formativa de la evaluación en el ámbito de las metodologías activas propias del ECTS, se incorpora la cualidad de incentivo y el posibilismo a la caracterización que la literatura hace de la evaluación excelente y se refieren algunas estrategias de evaluación experimentadas en un contexto masificado y precario que necesita un cambio efectivo en el aula y no una reforma en papel mojado.

II. 7 El alumno como protagonista: Conocimiento de los factores que intervienen en el proceso de adquisición de una L2

\section{Carmen Solsona Martínez}

La adquisición de una L2 es un fenómeno que comprende un complejo abanico de aspectos y problemas y tiene lugar en una situación concreta, es decir, en un contexto social y lingüístico determinado. El elemento central de este fenómeno es el sujeto que aprende; por tanto, cuanto mejor conozcamos al aprendiz y los factores que condicionan su aprendizaje, mejor orientaremos el proceso de enseñanza. En nuestra comunicación queremos hacer un repaso a los distintos factores que intervienen en el proceso de aprendizaje de una L2, tanto los factores lingüísticos (lengua materna, lengua extranjera) como los no lingüísticos (edad, estudios, motivación, aptitud para el aprendizaje de idiomas, personalidad, estilo cognitivo, estrategias de aprendizaje y comunicación) para pasar, a continuación, a analizar la importancia de estos factores y a conocer el perfil del aprendiz de italiano/LE de la Universidad de Zaragoza a partir de las respuestas de los alumnos a un cuestionario creado ad hoc. 


\section{Investigación Educativa e Innovación Docente en el proceso de Convergencia Europea}

\section{8 El portafolio como sistema de evaluación: Experiencia piloto en el Máster oficial de Estudios Textuales}

y Culturales en Lengua Inglesa

Mª Carmen Perez-Llantada Auría

La presente ponencia valora el seguimiento de la evaluación mediante el portafolio docente en la asignatura ECTS "How to write a research article in English" del Máster Oficial de Estudios Textuales y Culturales en Lengua Inglesa de la Universidad de Zaragoza. En primer lugar, la ponencia describe los objetivos curriculares trazados para dicha asignatura, así como sus aspectos metodológicos y los materiales didácticos diseñados para la misma. Seguidamente, la ponencia detalla cómo se realiza el seguimiento y la evaluación de los estudiantes mediante el portafolio docente, valorando tanto las ventajas como las dificultades que el sistema de evaluación continua mediante el portafolio docente ofrece a los estudiantes y al profesor de la asignatura. Finalmente, la ponencia valora los resultados académicos obtenidos por los estudiantes con este sistema de evaluación y constata el fomento de competencias interpersonales (i.e., capacidad de intercambio de información, capacidad crítica, capacidad de trabajar en equipo, habilidades en las relaciones interpersonales), competencias sistémicas (i.e. aplicación de los conocimientos en la práctica, búsqueda, análisis y síntesis de la información, capacidad de trabajo autónomo, toma de decisiones) y competencias profesionales (formación en técnicas y recursos lingüístico-retóricos y de traducción que permita a los estudiantes dedicarse tanto a labores de investigación como labores profesionales de apoyo al personal universitario e investigador que necesite/deba publicar en inglés).

\section{9 El portafolio-etnográfico de evaluación de competencias: Cuestiones metodológico-operativas por re-} solver

\section{Ana Arraiz Pérez, Fernando Sabirón Sierra, Alejandra Cortés Pascual, Concepción Bueno García, Tomás Escudero Escorza, Alfredo} Berbegal Vázquez

Cuando en el curso 2004-2005 iniciábamos la experiencia de innovación docente, nuestra ocupación se centraba en modular la enseñanza en las asignaturas vinculadas al área MIDE en la titulación de Psicopedagogía, propiciar procesos constructivistas de aprendizaje y desarrollar la consiguiente alternativa en evaluación que operativizara una y otra intencionalidades iniciales. El portafolio-etnográfico de evaluación de competencias refleja los logros de la experiencia; pero a la vez, la pretensión de generalizar la innovación nos sitúa -es obvio- ante la tesitura de los componentes a mejorar. Son las cuestiones metodológico-operativas que se circunscriben a tiempos y dedicaciones por consensuar, estructuras y actitudes por propiciar, tareas a realizar, plataformas virtuales por personalizar, entre otros 
componentes tratados en la comunicación que se presenta. El grueso de la experiencia está recogido en la publicación colectiva elaborada por el Grupo de Investigación Aplicada en Etnografía de la Educación (2007): El portafolioetnográfico: un instrumento para la evaluación de competencias. Zaragoza. Prensas Universitarias. La comunicación afina en los aspectos señalados con la finalidad de facilitar la viabilidad de la herramienta en las nuevas titulaciones.

II. 10 Ensayo de una metodología activa para la enseñanza de un curso básico de Electricidad y Magnetismo para ingenieros

Joaquín Mur Amada, Sergio Artal Sevil, Antonio Usón Sardaña, Jesús Letosa Fleta

El experimento de innovación docente que se presenta en esta comunicación se ha ensayado durante el primer cuatrimestre del curso 2006-2007 en una asignatura de primer curso de la titulación de Ingeniería Técnica Industrial, especialidad Electrónica Industrial. Tiene como precedente un ensayo similar en la misma asignatura el segundo cuatrimestre del curso anterior. Consiste en comparar los resultados académicos obtenidos, al utilizar distintos procedimientos de enseñanzaaprendizaje, para impartir la misma materia. Para ello se parte de una asignatura con tres grupos de docencia. Uno de ellos se toma como referencia y en él se sigue el procedimiento de años anteriores (enseñanza de la teoría y problemas basada fundamentalmente en clases magistrales). En los otros dos grupos se cambia el procedimiento de enseñanza/aprendizaje por otro activo y cooperativo. En los resultados obtenidos, en cuanto a número de aprobados de la convocatoria, el porcentaje de aprobados de los grupos con el nuevo procedimiento dobla los aprobados en el grupo de referencia. No obstante, cuando se compara el porcentaje de aprobados en un examen de conocimientos común los porcentajes de aprobados son similares. Se requieren más pruebas para establecer las posibles ventajas de este tipo de docencia en el contexto que nos ocupa.

\title{
II. 11 Evaluación de los alumnos de la asignatura optativa “Bioquímica Clínica” a través del portafolio
}

\author{
Mª Soledad Soria Aznar, M ${ }^{\mathrm{a}}$ Carmen González Sinde, Jesús Fernando Escanero Marcén
}

En la implementación de la asignatura optativa "Bioquímica Clínica", realizada durante el curso 2006-2007, se diseñó una evaluación formativa (retroactiva), sumativa, continuada y por actividades a través del portafolio del alumno, donde se consideraron y evaluaron todas las actividades realizadas (del trabajo individual y en grupo), tanto en lo que a competencias propias o específicas de la asignatura se refiere, como de las competencias transversales. La puntuación se repartió de la si- 


\section{Investigación Educativa e Innovación Docente en el proceso de Convergencia Europea}

guiente forma: Mapas conceptuales $20 \%$, preguntas escritas $20 \%$, casos prácticos $20 \%$ y evaluación de trabajos orales 20 \%. La evaluación de actitudes y autoaprendizaje fue del 10 \% cada una. Se planeó un sistema de seguridad para los alumnos que no asistieran o cumplieran con los requisitos ordenados que consistió en un examen tradicional de preguntas cortas. Las conclusiones obtenidas son las siguientes: 1. La totalidad de alumnos optó por este método de evaluación. 2 . El trabajo personal fue muy constante en todos los alumnos. 3. El portafolio fue reflejando el creciente interés de los alumnos, en el estudio y manejo de la asignatura. 4. La actitud de los alumnos evolucionó hasta la total participación y disfrute de la asignatura. 5. La relación profesor-alumnos fue más fluida. 6 . Se requirió mayor compromiso de trabajo de profesores y alumnos.

II. 12 Evaluación de los factores que condicionan la implantación de planes y metodologías innovadores en la docencia universitaria

$$
\text { Javier Paricio Royo }
$$

A partir del análisis de la experiencia llevada a cabo en el Instituto de Ciencias de la Educación en el apoyo a proyectos de innovación docente durante los últimos años, se realiza una sistematización de los diferentes factores que condicionan el desarrollo de planteamientos innovadores en la docencia universitaria. El estudio se centra en las condiciones para la puesta en práctica de metodologías activas o el desarrollo de programas por competencias, posiblemente, los dos aspectos que definen de forma más sintética la dirección del cambio de la docencia universitaria en España. Se analizan tanto aspectos de la cultura, la formación y las condiciones de trabajo de los docentes como la organización académica y las políticas institucionales o la definición y desarrollo de los propios proyectos.

II. 13 Evaluación por los alumnos de la implementación de las nuevas herramientas docentes en la asignatura optativa "Bioquímica Clínica"

\footnotetext{
M ${ }^{a}$ Carmen González Sinde, Ma Soledad Soria Aznar, Jesús Fernando Escanero Marcén
}

Durante el curso 2006-2007 se han implementado en la asignatura optativa "Bioquímica Clínica" la utilización de nuevas tecnologías (enseñanza por módulos y utilización del ADD) y de metodologías activas de aprendizaje (elaboración de mapas conceptuales y aprendizaje basado en problemas), con objeto de adaptar la materia al Sistema de Créditos Europeos (ECTS) y al Espacio Europeo de Educación Superior (EEES). Se han evaluado dos aspectos en el proceso docente: 1. La satisfacción con las actividades educativas 2. La satisfacción del estudiante con la actuación del profesor. Los resultados 
encontrados muestran: a) La asignatura cumplió sus expectativas en 12 de 18 alumnos y fue superior en los 6 restantes. b) 15 de 18 alumnos consideran haber alcanzado objetivos relacionados con los contenidos de la asignatura.c) De los 18 alumnos, 15 señalan haber alcanzado objetivos relacionados con las competencias y habilidades. d) Los aspectos que más han gustado de la asignatura han sido los casos prácticos (8/18), los temas (4/18) y la aplicación práctica de la asignatura (4/18). e) Los aspectos más negativos se han relacionado con el exceso de trabajo (8/18) y la elaboración de los mapas conceptuales (6/18). f) La evaluación de la satisfacción del estudiante con la actuación del profesor ha sido muy positiva.

\title{
II. 14 Experiencias de sistemas de aprendizaje y evaluacion competitivos
}

\author{
José María Yusta Loyo, Miguel Ángel García García
}

Aunque el trabajo cooperativo capta un gran interés en la innovación docente actual, los autores de este trabajo defienden la validez de los modelos de trabajo y evaluación competitivos como recurso de la docencia, siempre que éstos estimulen adecuadamente el proceso de aprendizaje del alumno. La experiencia de los autores abarca seis cursos académicos completos, a lo largo de los cuales se ensayó una nueva estrategia de desarrollo del proceso de aprendizaje y evaluación en la asignatura optativa "Instalaciones eléctricas y Luminotecnia", correspondiente al plan de estudios de la titulación de Ingeniería Industrial, impartida en el Centro Politécnico Superior de la Universidad de Zaragoza. La muestra fue aproximadamente de 50 alumnos por curso. Los resultados obtenidos demuestran que los alumnos alcanzaron buenas soluciones en casos prácticos de Ingeniería mediante el estímulo de una evaluación competitiva, donde la nota final asignada a cada alumno está indexada respecto a la mejor solución obtenida por alguno de los alumnos del grupo de docencia y calculada a partir de varias notas parciales y distintos índices paramétricos en cada una.

\section{15 Implicaciones transversales en el primer empleo: Resultados}

\author{
Pedro Manuel Aguado Benedí, Octavio Ratia Serrano, Mª Ángeles Yagüe Serrano
}

Las empresas acuden al mercado de trabajo solicitando titulados universitarios que cumplan unos determinados requisitos para cubrir una necesidad puntual en un puesto de trabajo concreto; además de la titulación, que garantiza el conocimiento técnico, científico o social, aparecen requerimientos sobre aspectos con una componente importante de transversalidad, tales como competencias profesionales personales o conocimientos técnicos interdisciplinares, que resultaran determinantes en la resolución de la oferta a favor de uno u otro candidato. Desde el Observatorio de Em- 


\title{
Investigación Educativa e Innovación Docente en el proceso de Convergencia Europea
}

pleo Universitario de UNIVERSA se ha querido conocer la opinión del titulado, como participante activo en el proceso, mediante la realización de una encuesta que aborda una buena parte de los interrogantes abiertos en el primer acceso al mercado de trabajo. La interpretación de los datos de dicha encuesta constituirá el núcleo principal de la comunicación, poniendo énfasis en las características marcadas por las empresas como hecho diferencial entre candidatos.

\section{16 La evaluación continua en el marco del Espacio Europeo de Educación Superior: Principales desafíos}

\author{
Luisa Esteban Salvador, Ana F. Gargallo Castel, Fco. Javier Pérez Sanz, Ma Angeles Soriano Paola
}

La evaluación continua posibilita al profesor conocer la evolución del alumno a lo largo de todo el proceso de enseñanza-aprendizaje, pero además permite informar a los alumnos de sus debilidades y fortalezas por lo que este permanente "feed-back" se convierte en una importante fuente de información tanto para el profesor como para el alumno y facilita la adopción de acciones correctoras. En esta comunicación se presenta la aplicación de la evaluación continua en diversas asignaturas de la Licenciatura en Ciencias del Trabajo a lo largo del pasado curso y del actual. Para conocer la opinión de los estudiantes que han elegido esta evaluación se ha diseñado una encuesta de cuyo análisis se extraen diversas conclusiones. Si bien destacan que la evaluación continua ha favorecido su mayor implicación en el desarrollo de las asignaturas también apuntan que los trabajos y actividades exigidos requieren excesivo tiempo, aspecto señalado también por aquellos alumnos que no optaron por la evaluación continua. Así pues, ahora el reto para los profesores consiste en revisar las estimaciones sobre los tiempos de trabajo del alumno y la distribución equilibrada de los mismos en línea con el desarrollo de los ECTS.

\section{17 La opinión de los estudiantes universitarios sobre su evaluación}

Ana F. Gargallo Castel

El objetivo de este estudio es conocer la opinión de los alumnos sobre las distintas tipologías de evaluación. El interés por este aspecto surge de la concepción de la evaluación como un instrumento de mejora dentro del proceso de enseñanza-aprendizaje. Por tanto, resulta imprescindible reflexionar sobre el mismo dentro de un entorno de mejora continua y de búsqueda de la calidad en la docencia. Para ello se realizó una encuesta a los alumnos con preguntas sobre: 1) Método evaluativo preferido y 2) Nivel de utilización de los diferentes modelos evaluativos por parte de los docentes. Los resultados confirman las preferencias de los alumnos en relación con su evaluación y reflejan algunas diferencias con respecto a los modelos evaluativos actuales. 


\section{18 Los métodos de innovación docente. Perspectiva de los estudiantes}

\section{Gema Pastor Agustín, María Vargas Magallón}

En este trabajo se realiza un análisis de las técnicas de innovación docente de mayor actualidad. Para ello se parte del concepto teórico de las mismas y se evalúa la percepción que de dicho concepto tienen los alumnos, diferenciándose entre ellos en base al nivel académico alcanzado. A tal efecto los autores elaboran una encuesta que cumplimentan alumnos de $1^{\circ}$ y $4^{\circ}$ de carrera y alumnos de un curso postgrado. El objetivo del trabajo es determinar si la percepción acerca de las técnicas de innovación docente utilizadas en el aula varía en función de elementos tales como la experiencia, la edad o el grado de participación de los estudiantes en la universidad.

II. 19 Los sistemas de evaluación y calificación para el EEES en asignaturas del ámbito de la Expresión Corporal

Paula Gelpi Fleta, Ma Rosario Romero Martín, Inmaculada Tena Porta, Nerea Cristina Estrada Marcén

Con el objetivo de diseñar y aplicar un sistema de evaluación más acorde con el logro de las competencias de las asignaturas establecidas en trabajos realizados en cursos anteriores, un grupo de profesoras del ámbito de la Expresión Corporal hemos realizado una profunda reflexión sobre nuestras experiencias en las materias impartidas, para lograr las competencias en todos los alumnos de forma similar, tanto en aquellos que pueden venir a las clases, como en aquellos que por circunstancias personales o profesionales no pueden venir. En la presente comunicación se presentan los sistemas de calificación utilizados en las materias, haciendo especial hincapié por un lado, en la participación del alumno en este proceso de evaluación e incluso de calificación y por otro lado en las estrategias que como docentes tenemos que utilizar para que todos los alumnos/as logren las competencias establecidas, incluso aquellos alumnos que no vienen a clase.

II. 20 Primera evaluación de un proyecto de innovación docente para la implantación del crédito ECTS en la asignatura de Derecho Penal, Parte General

Mª Ángeles Rueda Martín, Miguel Ángel Boldova Pasamar, Asier Urruela Mora

A lo largo de este estudio se presenta una primera evaluación de un proyecto de innovación docente que tiene como finalidad la implantación del crédito ECTS en la asignatura de Derecho Penal, Parte General. Esta evaluación aborda las nece- 


\title{
Investigación Educativa e Innovación Docente en el proceso de Convergencia Europea
}

sidades docentes, el contexto, el diseño y la ejecución del programa de innovación docente en dicha asignatura. Además se presentan los resultados de una primera encuesta realizada a los estudiantes durante el curso académico 2006/2007, que han trabajado este programa de innovación docente en la que se incluye la valoración de los estudiantes sobre distintas actividades como la asistencia a sesiones presenciales en el aula (teóricas y prácticas), el estudio individual, el trabajo en el seno de grupos o equipos, la búsqueda de información y la utilización de las TICs en dicha búsqueda, etc. Estos resultados se refieren, en primer lugar, a la dedicación que los estudiantes han destinado para realizar las diversas actividades propuestas y en segundo lugar, estos resultados también recogen la valoración efectuada por los estudiantes en torno a la adquisición de las concretas competencias generales y específicas que se pueden trabajar desde la asignatura de Derecho Penal, Parte General.

\section{21 Tiempo dedicado a la resolución de problemas en Farmacología Veterinaria. Una perspectiva de cua-} tro años

Ana Rosa Abadía Valle, Ma Jesús Muñoz Gonzalvo, Miguel Angel Bregante Ucedo

Desde el curso 2003-2004 se incluye en la docencia de Farmacología de la Facultad de Veterinaria la resolución de problemas. La metodología se describió en las I Jornadas de Innovación docente de la Universidad de Zaragoza. La presente comunicación, basada fundamentalmente en las encuestas realizadas a los estudiantes tras la resolución de cada caso, se plantea el estudio de las horas dedicadas por los alumnos a tal fin, la evolución de las mismas y su relación con otros parámetros como el número de tutorías o la memoria final presentada, a lo largo de los cuatro años de experiencia con esta metodología. El análisis de esta información es fundamental para organizar la docencia de la asignatura en el marco de la Convergencia Europea de acuerdo con los ECTS.

\section{22 Tras cuatro cursos de adaptación a los ECTS: Opiniones del profesorado y de los estudiantes}

\author{
Begoña Pelegrín Martinez de Pisón, Begoña Gutierrez Nieto, Javier Benito Colón
}

Tras cuatro cursos en los que se ha realizado la adaptación de las asignaturas a los ECTS, con las limitaciones existentes, se presenta una síntesis de las experiencias vividas por el profesorado tanto durante la preparación y estructuración de las materias como posteriormente en su implementación. Además es importante reflejar cuáles han sido los resultados apreciados por los grupos de estudiantes, tanto en cuanto a las nuevas metodologías como a los sistemas de evaluación continua realizados. Se considera de gran importancia haber impartido dos asignaturas de la misma materia y lectivamente en dos cursos consecutivos para permitir tanto a los profesores como a los estudiantes observar la 
influencia de experiencias anteriores con la misma metodología. También se ofrecen resultados obtenidos mediante la encuesta realizada a los estudiantes, que se creó para servir de elemento de corrección y ayuda en cursos posteriores.

II. 23 Una experiencia docente en el uso de metodologías activas y TICs ante un nuevo modelo de aprendizaje

\section{María Jesús Lapeña Marcos, Inés Escario Jover, Áurea Rodríguez Villanueva, María Antonia Zapata Abad}

Ante el nuevo reto del Espacio Europeo de Educación Superior, se ponen en práctica nuevos métodos y modelos de enseñanza-aprendizaje que van a ser fundamentales en el desarrollo de los nuevos títulos de grado; con estos nuevos métodos se intenta favorecer la implicación del alumno en el desarrollo de las asignaturas mediante el uso de las nuevas Tecnologías de la Información y la Comunicación. Se trata de crear sistemas orientados a una mayor participación del alumno, que faciliten el trabajo colaborativo, que favorezcan la formación asíncrona y que exploten las posibilidades de las múltiples herramientas que facilitan la comunicación no sólo entre profesor y alumno sino también entre los propios alumnos. En este sentido, se realiza un análisis de la utilización del Anillo Digital Docente en las asignaturas impartidas, valorando las ventajas y limitaciones observadas.

II. 24 Utilización de las tecnologías de la información y la comunicación (TICs) en las Licenciaturas de Medicina y Veterinaria de la Universidad de Zaragoza

Mª Victoria Ejea Arquillué, Beatriz Puisac Uriol, Ma Angeles Sáenz Galilea, Javier Lanuza Jiménez, Ana Isabel Alcalde Herrero, José

Emilio Mesonero Gutiérrez, Ángeles Pié Juste, Marga Logroño Ejea, Feliciano J. Ramos Fuentes, Juan Pié Juste

El uso de las TICs aparece como una herramienta docente destacada en el proceso de convergencia de la Universidad al Espacio Europeo de Educación Superior (EEES). La integración de las TICs en el aula requiere una organización específica que tenga en cuenta las necesidades y actitudes del alumnado. En este trabajo se compara la disponibilidad, uso y actitudes en relación a Internet de los estudiantes de $2^{\circ}$ de Medicina y de $2^{\circ}$ de Veterinaria. Se trata de un estudio transversal llevado a cabo en el curso académico 2005-2006 mediante una encuesta que consta de 13 preguntas cerradas. Los datos han sido procesados mediante el programa estadístico SPSS v.11.5. Aunque en ambos grupos el nivel de conocimiento del uso de los recursos disponibles en la red es superior al $80 \%$, los alumnos de Medicina parecen disponer de más recursos propios, tanto ordenador como conexión a Internet, que los de Veterinaria. 


\section{Investigación Educativa e Innovación Docente en el proceso de Convergencia Europea}

Ello podría guardar relación con el mayor número de estudiantes foráneos en esta última licenciatura. A pesar de que todos los estudiantes muestran una actitud positiva ante las TICs, los alumnos de Veterinaria parecen haberlas usado menos a petición del profesorado y los alumnos de medicina las valoran más como herramienta de autoevaluación. 


\section{TeCnologías apLICADAS AL MUNDO DE LA ENSEÑANZA SUPERIOR}



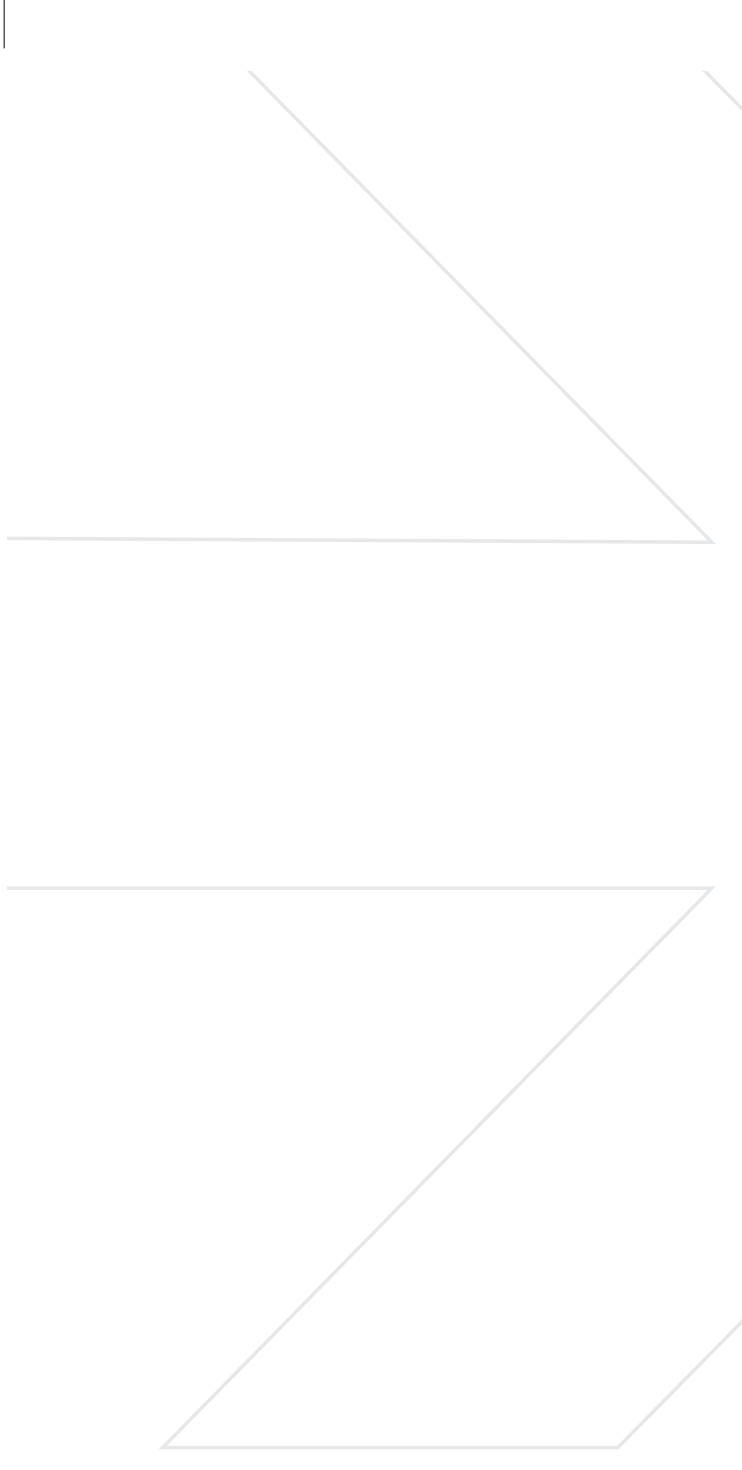
III. 1 Implantación de nuevas tecnologías en el estudio propio de Master en Fisioterapia Manual Ortopédica OMT. Modelo extendido

José Miguel Tricas Moreno, Mª Orosia Lucha López, Elena Estébanez de Miguel, Santos Caudevilla Polo, César Hidalgo García, Elena

Bueno Gracia, Blas García Rivas, Félix Herranz Bercedo

Seanalizala puestaen marchadelmodelo extendido delMasterdeFisioterapia ManualOrtopédicaOMT.ElconceptoKaltenbornEvjenth ha supuesto un cambio en la metodología docente de los contenidos del Master con respecto a ediciones anteriores bajo el modelo intensivo. En un principio se diseñó una base de datos a través de un servidor interno entre los profesores del Master para organizar el material docente. Posteriormente y todavia en fase de diseño, se pretende que a través de una nueva estructuración por niveles, no sólo los docentes tengan acceso al material elaborado sino también los alumnos matriculados en dicho Master. El acceso se realizará a través de una web docente que permitirá el seguimiento de los módulos y la resolución de dudas.

III. 2 'Biolinks': Web interactiva para el aprendizaje de herramientas de búsqueda de información biomédica online

Álvaro Sebastián Yagüe, María Ángeles Álava Martínez de Contrasta, María Iturralde Navarro, Fermín Lampreave Palacios

La era postgenómica se caracteriza por la ingente cantidad y diversidad de datos de que disponen biólogos, médicos y bioquímicos para sus estudios. Secuencias génicas, protéicas, artículos científicos y otros muchos tipos de información biológica se encuentran almacenados en bases de datos públicas y accesibles vía web. Según aumenta su número se hace más importante saber cúales son estas fuentes de información y cómo consultarlas adecuadamente. Sin embargo, son pocos los estudiantes que han oído hablar de ellas y las usan para su aprendizaje. Con la presente aplicación se pretende animar a los estudiantes a conocer y aprender a manejar herramientas de búsqueda de información online. La web, llamada 'Biolinks' (http://biolinks.unizar.es), ofrece tutoriales interactivos, así como la posibilidad de ampliarlos o generar otros nuevos por parte del profesorado y de responder a cuestiones planteadas por los estudiantes. Para dotar a la interfaz de diferentes posibilidades, tanto para profesores como para alumnos, se ha hecho uso de Drupal, una plataforma de software libre para la administración y publicación de contenidos web. 


\section{Investigación Educativa e Innovación Docente en el proceso de Convergencia Europea}

III. 3 Adquisición de competencias en información: Punto de encuentro entre el proceso de aprendizaje y las nuevas tecnologías

\section{Ramón Abad Hiraldo}

Durante los últimos años las bibliotecas universitarias han desempeñado un papel activo -y en algunos casos pionero-en la formación de estudiantes e investigadores en el uso de las tecnologías y recursos necesarios para acceder a la información existente en cualquier materia. Este trabajo explica los nuevos conceptos ALFIN (Alfabetización informacional o adquisición de competencias en información) y CRAl (Centro de recursos para el aprendizaje y la investigación) y los analiza en el contexto de los cambios que se están produciendo en la universidad con la introducción del nuevo EEES. Se hacen propuestas concretas de trabajo conjunto de los bibliotecarios con los docentes para conseguir unos usuarios/alumnos más autónomos y mejor preparados para afrontar los retos de la sobreabundancia de información y el cambio tecnológico continuo.

\section{4 ANAGRAMA, nueva herramienta para el análisis gramatical}

\section{Celia Florén Serrano, Rosa Lorés Sanz, Ignacio Guillén Galve, Silvia Murillo Ornat}

Esta herramienta ha sido creada para facilitar el aprendizaje de la gramática sistémica funcional del inglés, asignatura troncal de la Licenciatura de Filología Inglesa. Es un complemento necesario para la parte práctica de la asignatura y la aplicación al análisis de textos específicos. Ofrece al usuario el acceso a: 1. El aprendizaje individual asíncrono 2. La explicación y clarificación tanto de conceptos como de términos, evitando la confusión de términos próximos 3. La secuenciación del aprendizaje, que favorece la creación de los nexos, al separar las tomas de decisiones 4. Una visión holística del análisis.

III. 5 Aproximación al desarrollo del portafolio para la docencia de la asignatura Medicina Preventiva de la Licenciatura de Veterinaria

\section{Carmelo Ortega Rodríguez, M Marmen Simón Valencia}

El trabajo presenta el formato y opiniones sobre el uso de una aproximación al desarrollo del portafolio clásico en la asignatura Medicina Preventiva de la licenciatura de Veterinaria. En él se exponen los diferentes apartados que integran el portafolio propuesto, la forma de trabajar en cada uno de esos bloques, la intervención de los alumnos y el profesorado 


\section{Investigación Educativa e Innovación Docente en el proceso de Convergencia Europea}

y la evaluación que se realiza del mismo. Se presenta como aproximación al portafolio pues es una experiencia iniciada en el curso 2007-08, está en desarrollo y evolución y será una herramienta totalmente operativa en los años próximos.

\section{6 Autoevaluación formativa mediante el uso de la herramienta Moodle}

\section{Reyes Torres Sánchez, Mª Angeles Franco Sierra, Enrique Bardina Tremps, Mª Pilar Domínguez Oliván}

Se expone la utilización de los recursos integrados en la herramienta de docencia virtual Moodle en el proceso de enseñanza-aprendizaje del alumno en relación con la evaluación y la autoevaluación formativa y la experimentación de la metodología colaborativa de evaluación y autoevaluación en las asignaturas Valoración en Fisioterapia, Psicomotricidad como método complementario de intervención en Fisioterapia, Psicosociología de la salud y la discapacidad, Procedimientos de intervención en Fisioterapia y Fisioterapia en Especialidades Clínicas.

\section{7 Bioquímica Clínica: Adaptación al Espacio Europeo de Educacion Superior. Un camino por etapas}

\section{Armando Giner Soria, Jesús F. Escanero Marcén}

En la adecuación de la Universidad al Espacio Europeo y al cambio de paradigma, la asignatura de Bioquímica Clínica ha iniciado un camino por etapas. En primer lugar, se ha planteado la introducción de una metodología activa y continuada,teniendo el problema/caso clínico en el centro del aprendizaje. La materia consta de 30 temas y 20 problemas ligados. Cada uno de éstos es realizado por el alumno, corregido por el profesor y devuelto al mismo para su inclusión en al portafolio. La evaluación se realiza a través del portfolio, desapareciendo el exámen tradicional que queda relegado para los alumnos que no realizan los problemas o aquellos que desean mejorar su calificación. En posteriores etapas se implementarán otras tecnologías activas (mapas conceptuales, etc.).

III. 8 Código de buenas prácticas docentes para la asignatura de Teoría y Técnica Fisioterápica Especial I a través de la puesta en marcha de un registro informatizado de casos clínicos

José Miguel Tricás Moreno, Mª Orosia Lucha López, Elena Estébanez de Miguel, Santos Caudevilla Polo, César Hidalgo García, Blas García Rivas, Félix Herranz Bercedo, Elena Bueno Gracia 


\section{Investigación Educativa e Innovación Docente en el proceso de Convergencia Europea}

El objetivo de este trabajo es la presentación de una aplicación informática diseñada para el registro de casos reales en la asignatura Teoría y Técnica Fisioterápica Especial I. El registro permitirá que el alumno adquiera las capacidades de gestión y atención fisioterápica. Dicha registro se encuentra alojado en la pagina web docente www.unizar.es/uif. El registro recoge de forma exhaustiva el proceso de exploración, diagnóstico, tratamiento y reevaluación fisioterápico. Los alumnos tienen acceso a él durante las prácticas clínicas y la preparación de sesiones clínicas. El profesorado puede supervisar el registro o base de datos para poder hacer una valoración global de las prácticas, realizar el seguimiento de las mismas y evaluar al alumno.

III. 9 Cuando el propio estudiante diseña, elabora, implementa y resuelve WebQuest: Un paso más para la integración de asignaturas en el entorno del EEES

Ana Isabel Allueva Pinilla, Jose Luis Alejandre Marco, Chelo Ferreira González

En este trabajo presentamos una experiencia de integración de las asignaturas de Matemáticas y Herramientas Informáticas desarrollada durante el curso 2006-07 en la titulación de Veterinaria dentro de un proyecto del Programa de Incentivación de la Innovación Docente para la adaptación de las titulaciones de la U.Z. al EEES. El objetivo ha sido diseñar un escenario de enseñanza-aprendizaje en el que los estudiantes trabajan desde el plano de la adquisición de conocimientos en Matemáticas y de modo trasversal desde el plano del manejo, aplicación y transmisión de dichos conocimientos, aprovechando las herramientas que lo posibilitan con las TICs, en la asignatura de Herramientas Informáticas. Concretamente, los estudiantes en grupos colaborativos han estudiado, en el primer cuatrimestre del curso, diferentes temas de la disciplina de Matemáticas, efectuando un desarrollo y análisis teórico-práctico del mismo. Posteriormente, en el segundo cuatrimestre, los mismos estudiantes, en el marco de la asignatura de Herramientas Informáticas, han diseñado, desarrollado, implementado y resuelto una WebQuest o actividad de enseñanza-aprendizaje basada en Internet para cada uno de estos temas. Los resultados han sido excelentes. Además, esta experiencia se ha integrado en una plataforma colaborativa en Red basada en BSCW instalada y gestionada en un servidor propio.

III. 10 Desarrollo de un simulador multimedia para la mejora del aprendizaje del diagnóstico de cojeras en caballos

Francisco José Vázquez Bringas, Antonio Romero Laceras, Javier Gómez-Arrue Aspiazu, Ignacio de Blas Giral, Américo Josué Viloria González 
Este simulador ha sido desarrollado en el Hospital Clínico Veterinario de la Universidad de Zaragoza (HCV-UZ) para proporcionar a los alumnos una herramienta que facilite la adquisición de competencias diagnósticas ante cojeras equinas. La docencia tradicional se realiza mediante clases teóricas y prácticas usando casos clínicos reales. Sin embargo, este método de enseñanza presenta limitaciones y, aunque la utilización de casos reales afecta positivamente al grado de adquisición de conocimientos, el diseño docente puede mejorarse para evitar la gran dependencia de la casuística y particularidades de cada cojera, así como las limitaciones temporales, ya que un diagnóstico completo requiere más tiempo del disponible en las prácticas. Para superar estas limitaciones se desarrolló una aplicación que incluye elementos diagnósticos obtenidos de fichas clínicas de caballos atendidos por cojera en HCV-UZ en los últimos 3 años. La utilización de esta aplicación interactiva permite al alumno un aprendizaje autónomo y rápido mediante la selección de distintos parámetros: anamnesis, zonas de exploración, observación de locomoción en distintas circunstancias (movilización, anestesias diagnósticas, ...), radiografías, ecografías, etc... Al finalizar cada caso el alumno emite un diagnóstico que es evaluado por la aplicación. La calificación obtenida puede utilizarla el alumno como autoevaluación o el profesor como criterio de evaluación continuada.

\section{11 Diseño de un módulo docente sobre “Fundamentos de Diagnostico Serológico” con animaciones de Powerpoint}

Rafael Benito Ruesca, Javier Benito Colón, Joaquina Gil Tomás, Cristina Benito Colón, Francisco Javier Castillo García, Mª Carmen Rubio Calvo

El módulo docente "Fundamentos del Diagnóstico Serológico" es un material diseñado para facilitar el aprendizaje de las asignaturas "Microbiología Médica" y "Diagnóstico Microbiológico de las enfermedades infecciosas de aparatos y sistemas" de los cursos $3^{a}$ y $4^{a}$, respectivamente, de la Licenciatura de Medicina. El diagnóstico de las enfermedades infecciosas mediante pruebas serológicas es un procedimiento habitual. El fundamento de estas técnicas es de difícil comprensión, pero necesario para interpretar sus resultados. La explicación de dicho fundamento, basada en su descripción escrita, acompañada o no de imágenes bidimensionales, no es "amigable" para el alumno. Este módulo docente pretende atajar este problema con el diseño de presentaciones de PowerPoint que representan, de forma animada, coloreada y con sonido, las secuencias de las reacciones serológicas. Las presentaciones han sido convertidos a formato "avi", que puede ser insertado en presentaciones tipo Microsoft PowerPoint. Dichas animaciones pueden ser "colgadas" en el ADD de la Universidad de Zaragoza con el objetivo de: 1. Hacer más atractivo el proceso enseñanza-aprendizaje de unos conceptos abstrusos. 2. Ofrecer un material autoexplicable y asimilable de forma no presencial. La combinación de animación, color y sonido supone un enfoque original de la enseñanza de conceptos complejos de la Microbiología, en Medicina y en otras disciplinas. 


\section{Investigación Educativa e Innovación Docente en el proceso de Convergencia Europea}

\section{12 Diseño y puesta en servicio de una aplicación informática para el análisis de la carga discente}

Mª Milagros Gil Ruiz, Mª Dolores Lerís López, Jesús Mª Montaner Lavedán, Alfonso Ortega Jiménez, Mª Laura Ruberte Sánchez

La experiencia de anteriores trabajos, realizados conjuntamente por la EUITI y el CPS, sobre la evaluación del trabajo total que cada estudiante invierte en preparar una asignatura, y su cómputo en créditos ECTS, nos llevó a pensar en la idoneidad de crear una aplicación informática que soportara la base de datos generada por las encuestas, así como el análisis, la obtención de resultados y su visualización por los usuarios. Además, dicha aplicación podría ser útil en el futuro para realizar las revisiones y ajustes necesarios a los créditos ECTS una vez implantados y ser exportada a otros centros de la Universidad. La aplicación, desarrollada por una empresa externa, está plenamente operativa en su fase de adquisición de datos y gestión de gráficos. La aplicación permite visualizar, en los gráficos correspondientes tanto la evolución semanal del trabajo del estudiante, como el reparto de éste en las diferentes tareas (teoría, problemas, prácticas, estudio, trabajos, exámenes, tutorías, etc..) que comporta la preparación de las asignaturas. Con ella se puede hacer el estudio tanto de una asignatura, como de un curso o de una titulación completa.

\section{13 Documentos interactivos en pdf: Envío de información a bases de datos en Internet}

Manuel Calvo Pinilla, Juan Ignacio Montijano Torcal, Luis Rández García

Los autores llevan varios años desarrollando documentos interactivos en pdf en varias titulaciones universitarias. Este tipo de documentos puede resultar bastante interesante ya que el estudiante dispone de una herramienta muy sencilla para profundizar en las materias que disponen de este tipo de apuntes. En esta comunicación se hace hincapié en la generación de ejercicios que pueda completar el estudiante con fecha límite y enviar los resultados de dichos ejercicios via Internet. Un script en php se encarga de recolectar los datos de cada alumno y almacenarlos en una base de datos mysql.

\section{14 E-finance, experiencias desde la docencia y la investigación}

Luis Ferruz Agudo, Isabel Marco Sanjuán, Fernando Muñoz Sánchez

El Espacio Europeo de Educación Superior configura un nuevo marco de actuación que conlleva importantes novedades para que los estudiantes universitarios consigan la meta perseguida cuando se matriculan en la Universidad. En este con- 
texto, se pretende poner en común y comentar la positiva experiencia que ha supuesto la utilización de una página web desarrollada en el seno del grupo de investigación de los autores, que trata de combinar la información, con la formación de los estudiantes y con el suministro de fuentes de información relacionadas con las finanzas a través de un mismo portal financiero. En esta dirección electrónica se recoge la información sobre las asignaturas impartidas en el marco de las titulaciones oficiales, los cursos de doctorado y los estudios de tercer ciclo, así como otro tipo de información relacionada con las investigaciones y links de interés, información complementaria, noticias financieras, conferencias y actividades, revistas especializadas en finanzas, etc...

III. 15 El aprendizaje de los procesos geológicos a través de juegos de simulación en Internet: El proyecto OIKOS

Ángel Luis Cortés Gracia, Begoña Martínez Peña, José Miguel Calvo Hernández, Maria José Gil Quílez

La enseñanza y aprendizaje de la Geología requiere una importante aportación de recursos textuales y gráficos de distinto tipo que permitan al estudiante una adecuada comprensión no sólo de los objetos geológicos sino también de los procesos que los generaron. A través del proyecto europeo OIKOS (www.e-oikos.net), en el que participaron investigadores de la Universidad de Zaragoza, se ha desarrollado una completa herramienta didáctica accesible a través de Internet. OIKOS proporciona un conjunto de módulos de contenido sobre diversos riesgos geológicos (volcanes, terremotos, inundaciones, deslizamientos y dinámica costera) que incluyen vídeos y fotos de los procesos y/o sus resultados; información variada sobre los mecanismos que explican esos fenómenos; estrategias de prevención y mitigación; y simulaciones de casos reales o creados por el usuario (en los que el estudiante puede modificar los distintos parámetros implicados). Todo ello, aprovechando además el potencial de herramientas externas, conocidas como Mashups, como YouTube, Wikipedia, Google Earth \& Maps, etc. Paralelamente, OIKOS contiene un juego didáctico que representa una simulación de gestión de riesgos aplicado a la ordenación del territorio. De esta forma, el estudiante puede aprender sobre los riesgos naturales en un escenario de gestión complejo que incluye parámetros científicos, sociales y económicos.

III. 16 El Portafolio Europeo de Lenguas como herramienta para el desarrollo de metodologías activas en la docencia de asignaturas de francés e inglés empresarial

$\mathrm{M}^{\text {a }}$ Lourdes Cadena Monllor, Manuela Ruiz Pardos 


\section{Investigación Educativa e Innovación Docente en el proceso de Convergencia Europea}

Ante el inminente proceso de convergencia al EEES y la necesidad de adaptar el diseño curricular de las asignaturas de francés e inglés empresarial que impartimos al sistema de créditos ECTS, se propone la utilización del Portafolio Europeo de Lenguas como marco didáctico en la enseñanza-aprendizaje de idiomas con fines específicos en las nuevas titulaciones universitarias. Partiendo del modelo de metodología activa que supone trabajar con el portafolio del estudiante, el principal objetivo ha sido favorecer un proceso de aprendizaje más autónomo y reflexivo. Para diseñar un plan docente que permitiese la implementación del Portafolio Europeo de Lenguas en las asignaturas se ha colaborado con profesorado de varios centros con el fin de valorar las distintas formas de llevar a la práctica esta metodología activa. La experiencia docente presentada ha sido el resultado de varios proyectos de innovación docente que han permitido planificar los cambios introducidos. En la comunicación, se describe con ejemplos prácticos el diseño del programa de las asignaturas, la dinámica de las clases y el sistema de evaluación y se comentan los resultados iniciales obtenidos al aplicar este modelo didáctico en enseñanzas universitarias.

\section{17 El proyecto LAW\&ICT Shared Virtual Campus}

\section{Fernando Galindo Ayuda, María Pilar Lasala Calleja, Francisco Javier García Marco}

Con los nuevos entornos económicos y comerciales creados después de la incorporación de nuevos países a la Unión Europea es esencial la armonización de los marcos legales para el comercio electrónico y la administración electrónica. Los objetivos del proyecto LAW\&ICT Shared Virtual Campus son: 1. Creación de un Campus Virtual Europeo Compartido sobre Derecho y TICs para proporcionar un espacio virtual para el debate y la construcción de la política europea; una plataforma tecnológica educativa para ofrecer en toda Europa enseñanzas de grado, postgraduado y educación continua. 2 . Desarrollo de un programa completo de enseñanza internacional que comprende un Programa de Grado internacional en Derecho y TICs; Programa de Master internacional en Derecho y TICs; Programa de enseñanza continua en Derecho y TICs. 3. Identificación de buenas prácticas en la enseñanza de Derecho y TICs. 4. Creación de una red Europea de expertos en Derecho y TICs para compartir el conocimiento y diseminar los resultados y experiencias. 5. Animar la movilidad de profesores, estudiantes y profesionales entre los países, para compartir el conocimiento sobre los aspectos similares y divergentes en Derecho y TICs.

\section{18 Entorno de simulación didáctico de una Ingeniería Técnica Industrial}

Pedro Ubieto Artur, César García Hernández, Fernando Cebollada Pras, Alberto Fernández Sora, Bernardino Callejero Cornao, Pedro Ibáñez Carabantes 
La comunicación muestra el trabajo realizado por los profesores del Área de Expresión Gráfica en la Ingeniería de la Escuela Universitaria de Ingeniería Técnica Industrial de Zaragoza para el desarrollo de un entorno de simulación didáctico del puesto de trabajo del alumno en una Ingeniería. Con él se relaciona el trabajo de diseño y presupuesto de la Oficina Técnica y el proceso de producción con el acopio de material y la gestión de almacén y la gestión del departamento de administración. Como base del trabajo, se está adaptando un Sistema de Gestión de Información Documental de Proyectos Técnicos Industriales desarrollado por los profesores del Área.

\section{19 Gestión automatizada de los Proyectos Finales de Carrera de la Universidad de Zaragoza}

Piedad Garrido Picazo, Francisco José Martínez Domínguez, Jesús Tramullas Saz, Miguel Angel Esteban, Fernando Naranjo Palomino, Lucía Calvo Medrano

Esta contribución versa sobre la descripción de un proyecto de software libre desarrollado en la propia Universidad de Zaragoza para la gestión interna de los Trabajos Finales de Carrera (TFCs). Este proyecto fue respaldado por la línea de trabajo de utilización de herramientas TICs especializadas en metodologías activas del PESUZ-2006 y se fundamenta en la construcción de un entorno de gestión de los TFCs "ad-hoc" haciendo uso de workflow. Para su desarrollo se montó un equipo de trabajo multidisciplinar e interdepartamental (PAS, PDI y alumnado de la UZ), cuyos miembros se encuentran trabajando de forma activa en la adaptación de sus asignaturas al EEES, y entornos semipresenciales, consiguiendo finalmente una herramienta de gestión de gran utilidad tanto para al profesorado como para el alumnado, puesto que dispondrán en un único espacio de trabajo de toda la documentación relativa al desarrollo de un TFC y una biblioteca digital con TFCs de años anteriores con la propiedad intelectual cubierta por una licencia Creative Commons.

\section{20 Gestión de fondos de inversión en tiempo real mediante el uso del cuadro de mando}

Luis Ferruz Agudo, Isabel Marco Sanjuán, María Vargas Magallón

En este trabajo los autores destacan el uso del "balanced scorecard" o cuadro de mando como sistema de tratamiento de la información que permite al gestor de fondos de inversión una gestión en tiempo real de la relación existente entre un conjunto de variables macroeconómicas y la rentabilidad esperada de los fondos de inversión. Los autores parten de la consideración de un conjunto de variables macro representativas del ciclo económico y que poseen un alto poder predictivo de las rentabilidades de los distintos activos financieros. Evalúan el uso de estas variables de 


\section{Investigación Educativa e Innovación Docente en el proceso de Convergencia Europea}

información por los gestores en la gestión que realizan de sus carteras y plantean la utilidad de las finanzas electrónicas como un medio de provisión de información sobre estas variables macro, de manera que permitan mantener información actualizada sobre las mismas que será utilizada como sistema de alarma, llamado cuadro de mando, que informará a los gestores de los valores críticos que tomen estas variables permitiéndoles, por tanto, implementar una gestión en tiempo real de los fondos de inversión tal que se consiga una anticipación a los movimientos del mercado.

III. 21 Implantación de nuevas metodologías de aprendizaje y evaluación en las asignaturas Estancias Clínicas de los estudios de Enfermeria

Mercedes Blasco Solana, Ana Gascón Catalán, Ana Belloso Alcay, Juan Francisco León Puy, Mª Carmen Larroche Garcés, Mª José

Lacaustra Bueno, Cándida Serna Porro, Ana Vecino Soler, Virginia Aznar Rico, Javier Paricio Royo, Fernando Cruz Bello, Armando

Colomer Simón, José Manuel Granada López, Carmen Muro Baquero

El objetivo de este trabajo es promover el auto-aprendizaje y evaluación del alumnado, utilizando nuevas tecnologías, siendo estas un nexo docente continuo entre los alumnos y el profesorado de la Escuela de Ciencias de la Salud de Zaragoza, Escuela Universitaria de Enfermería de Huesca y profesorado docente-asistencial. El método utilizado ha sido el aprendizaje activo basado en la reflexión, que permite al alumnado adquirir competencias en la "resolución de problemas enfermeros", prestando cuidados individualizados al usuario enfermo/sano, familia, comunidad, uniendo teoría y práctica de forma continuada a través de una aplicación web creada en PHP y que utiliza una base de datos MySQL. Al concluir los modulos prácticos el alumno podrá juzgar las competencias adquiridas en su aprendizaje metodológico, basado en el modelo de Virginia Henderson. Al profesorado le permitirá realizar una retroalimentación al poder comparar y medir los resultados del aprendizaje con los objetivos formulados en la programación. El método utilizado refuerza el proceso de comunicación y evaluación objetiva.

\section{22 Implementación de un diseño activo y colaborativo de la asignatura Herramientas Informáticas en} Ciencias Experimentales mediante la plataforma BSCW

\section{José Luis Alejandre Marco, Ana Isabel Allueva Pinilla, José Miguel González Santos}

Se presenta una experiencia de innovación docente desarrollada en la titulación de Veterinaria que ha consistido en la implementación de un diseño activo y cooperativo de la asignatura optativa Herramientas Informáticas en Ciencias Experimentales utilizando una plataforma colaborativa en red como instrumento de aprendizaje informático colaborativo que proporciona un 
escenario de enseñanza-aprendizaje basado en CSCL (Computer Supported Collaborative Learning), concretamente BSCW (Basic Support of Cooperative Work), que permite publicación en red, versionado de documentos, repositorio, gestión de eventos, de personas y grupos, establecimiento de roles, etc.... instalado y gestionado completamente en un servidor propio. La experiencia se ha desarrollado en el segundo cuatrimestre del curso académico 2006-2007 con 101 alumnos en el marco de un proyecto concedido dentro del Plan de Mejora Docente y Académica en el apartado de Utilización de Herramientas TIC especializadas en Metodologías Activas. Los resultados han sido excelentes y hay un alto grado de satisfacción de los profesores y estudiantes, tanto desde el punto de vista metodológico, como desde el derivado de la utilización de la plataforma BSCW.

\section{23 Información y lectura crítica a través de las TICs de información científica y divulgativa en Salud y Medio Ambiente}

\section{Concha Germán Bes}

En la asignatura de Enfermería Comunitaria que se imparte en $3^{\circ}$ de la diplomatura de Enfermería desde hace 6 años se desarrolla un método activo de búsqueda de información en los módulos de Promoción de Salud y Salud Ambiental. El cognitivismo propone diversas estrategias como el aprendizaje por descubrimiento y el trabajo cooperativo. En la era de la información y con el uso de las TICs se propone que el alumnado realice búsquedas activas de información tanto en bases documentales científicas como en prensa divulgativa. Se trata de que adquieran competencia en la búsqueda, lectura crítica y fichado de documentos. Durante el cuatrimestre en que se desarrolla la materia deben recopilar información y realizar lecturas crítica, que se recogen en las fichas que deben entregar al profesorado. Esta información con la aportada en clase y en las guías didácticas son incorporadas en el desarrollo de la evaluación tipo ensayo de forma que se potencia el espíritu crítico y el contraste de tendencias tanto en el ámbito científico como entre la opinión de los ciudadanos recogida en la prensa. Este tipo de metodologías, si bien resulta novedosa para el alumnado, resulta enormemente gratificante y efectiva en la evaluación en la que se obtienen buenos resultados. La evaluación de la asignatura se completa con test de respuesta múltiple, trabajos y estudio de casos.

\section{24 La creación de una revista digital de Lingüística Aplicada: “Desde Macondo”}

\section{Alberto Hijazo Gascón}

Una revista electrónica puede suponer grandes avances en la difusión de la investigación, la creación de materiales didácticos y la comunicación en la gestión de un centro académico. Se presentan aquí los pasos que deben seguirse para crear 


\section{Investigación Educativa e Innovación Docente en el proceso de Convergencia Europea}

una a partir de la experiencia de "Desde Macondo", una revista electrónica dedicada a la Lingüística Aplicada a la enseñanza de Español como Lengua extranjera.

III. 25 La formación sobre energías renovables en la Universidad de Zaragoza. Innovación docente en el Master en Energías Renovables

Amaya Martínez Gracia, Eva Llera Sastresa, Sabina Scarpellini

La formación específica en materia de energías renovables ha venido desarrollándose en paralelo al crecimiento del sector y a la evolución de las competencias profesionales que lo integran. La formación a distancia facilita el acceso a la formación a colectivos distantes geográficamente o con poca disponibilidad de tiempo. No obstante, su desarrollo requiere una planificación específica de la materia a impartir así como de los medios más adecuados para la consecución de los objetivos docentes. Aunque la plataforma WebCT, sobre la cual se construye el Anillo Digital Docente de la Universidad de Zaragoza, posee la flexibilidad necesaria para el aprendizaje a distancia, se impone un amplio conocimiento de sus posibilidades con el fin de seleccionar la herramienta metodológica más adecuada para la consecución de cada propósito docente. En esta comunicación se presenta la experiencia del Master en Energías Renovables de la Universidad de Zaragoza como ejemplo de adaptación de un estudio ya existente en modalidad presencial a su versión on line, se analizan las particularidades observadas y finalmente se proporcionan datos comparativos de la evolución de ambos estudios en los últimos cinco años.

\section{26 La Web como recurso y exposición en la clase de Nuevas Tecnologías aplicadas a la Educación}

\section{Mari Carmen Montolío Tena}

Se presenta el sitio Web diseñado y actualizado con las aportaciones de las clases de "Nuevas Tecnologías aplicadas a la Educación" por parte de alumnos de $2^{\circ}$ curso de Magisterio y la profesora. Dicha herramienta se utiliza como recurso para el aprendizaje, la práctica de aula y la publicación de trabajos en Internet. 
III. 27 Las argumentaciones de los estudiantes como punto de partida para la valoración del patrimonio natural

José Miguel Calvo Hernández, José Carrasquer Zamora, Ángel Luis Cortés Gracia, Milagros de La Gándara Gómez, Mª José Gil Quilez, Begoña Martínez Peña

Dentro de las actividades del grupo de investigación Beagle (Didáctica de las Ciencias Naturales) se ha diseñado y puesto en funcionamiento una web dinámica que permite la participación de los estudiantes en la elaboración de una base de datos escolar, asociada a la propia web de la Universidad de Zaragoza, sobre lugares de interés natural: Naturaragon (www.unizar.es/naturaragon). Esta herramienta permite proponer nuevos puntos de interés patrimonial, apoyados en las argumentaciones de los estudiantes, mediante la introducción de textos y gráficos que ayuden a identificar y resaltar los principales valores de las zonas seleccionadas: descripciones, explicaciones, sugerencias, fotos y mapas. El entorno informático consiste en una aplicación PHP con un sistema de base de datos MySQL. El principal objetivo de Naturaragon es incluir el punto de vista del estudiante y, a través de su propio lenguaje, utilizar el entorno próximo como elemento de análisis y discusión a la hora de hacer propuestas o tomar posturas frente a problemas ambientales, aprovechando el potencial de las TICs y contribuyendo a la valoración del patrimonio natural. En este momento está siendo utilizado en varias asignaturas impartidas en la Facultad de Educación de Zaragoza.

\section{28 Personajes virtuales: una nueva herramienta para la enseñanza de la Informática Gráfica}

\section{Sandra Baldassarri, Eva Cerezo, Francisco Serón}

Este artículo presenta el uso de personajes virtuales para mejorar el aprendizaje de los estudiantes de las asignaturas de Informática Gráfica, en la carrera de Ingeniería Informática. Para este propósito se ha desarrollado una potente plataforma de enseñanza llamada Maxine. Maxine permite la creación y manipulación de entornos 3D y el desarrollo de aplicaciones que utilizan agentes virtuales animados. Esta plataforma, basada en librerías de código abierto, permite la interacción multimodal con el usuario en tiempo real a través de texto, de la voz, de imágenes y gestos. Los personajes virtuales de Maxine establecen una comunicación emocional con el usuario a través de sus movimientos corporales, expresiones faciales, modulación de la voz y signos conversacionales. De este modo, los agentes virtuales pedagógicos animan a los estudiantes a ser conscientes de sus propios progresos, transmiten entusiasmo en el aprendizaje de la materia, y, simplemente, hacen el aprendizaje más divertido... En este trabajo se presentan los resultados de la utilización de esta herramienta para la exposición de ciertos temas que suelen ser particularmente difíciles de aprender por parte de los alumnos. 


\section{Investigación Educativa e Innovación Docente en el proceso de Convergencia Europea}

\section{29 Realización de una publicación Web tipo revista especializada para Ciencia y Tecnología de los Ali- mentos}

Ignacio Alvarez Lanzarote, Javier Raso Pueyo, Santiago Condón Usón, Rafael Pagán Tomás, Pilar Mañas Pérez, Pedro Roncalés Rabinal, José Antonio Beltrán Gracia, Miguel Calvo Rebollar, Mª Dolores Pérez Cabreras, Ana Cristina Sánchez Gimeno, Lourdes Sánchez

Paniagua, Pascual López Buesa, Rosa Oria Almudí, José María Peiró Esteban, Agustín Ariño Moneva, Susana Bayarri Fernández, Domingo Blanco Parmo, Juan José Carramiñana Esteban, Mª Pilar Conchello Moreno, Regina Lázaro Gistau, Susana Lorán Ayala, Consuelo Pérez Arquillué, Ma Carmen Rota García, Javier Yangüela Martínez, Antonio Vercet Tormo, Ana Ferrer Mairal, Iva Marques Lopes,

Cristina Yagüe Ruiz, Sara Remón Oliver, Diego García Gonzalo, Mª Eugenia Venturini Crespo

En el contexto de la construcción del EEES, la utilización de metodologías activas adquiere un especial valor. A ello se suma la necesidad de dotarlas de la flexibilidad que ofrecen los entornos de aprendizaje virtuales especializados. Entre las muchas herramientas que existen, la edición de una publicación Web tipo revista especializada puede resultar de gran utilidad para la aplicación del proceso enseñanza-aprendizaje que requiere el EEES. En este trabajo, se presenta la puesta en marcha de la publicación Web, CTAMagazine (www.catedu.es/ctamagazine), tipo revista especializada para Ciencia y Tecnología de los Alimentos (CTA). La revista tiene como objetivo servir de soporte para que los propios alumnos puedan publicar sus noticias, trabajos realizados, páginas Web de interés, anuncios de cursos, viajes, infografías, etc., siempre bajo la supervisión de distintos profesores. De esta forma, el alumno es el motor y elemento activo dentro del proceso de innovación y mejora de la docencia, potenciando además la relación alumno-profesor. Hasta el momento, se han publicado más de 200 artículos, ha recibido un total de unas 4.500 visitas desde su lanzamiento oficial (marzo 2007) y se ha formado un grupo de estudiantes voluntarios que participa en el equipo editor de CTAMagazine.

\section{30 Uso de las TIC en la docencia universitaria: Asignatura de Diseño e Ingeniería Electrónica Asistida} (CAD/CAM/CAE) en la Universidad de Zaragoza

\footnotetext{
Miguel Ángel Torres Portero, Manuel Torres Portero
}

La progresiva complejidad que han ido adquiriendo los proyectos electrónicos, así como la obligada reducción en los tiempos de desarrollo para lanzar al mercado nuevos equipos electrónicos, han impulsado extraordinariamente la utilización intensiva de las TICs, y más concretamente de las herramientas de Diseño e Ingeniería asistida por ordenador. La vigencia comercial de los equipos y sistemas electrónicos es cada día más corta y resulta paradójico que la misma capacidad innovadora que facilita la rápida penetración en el mercado de los nuevos desarrollos electrónicos es la que 
propicia su pronta obsolescencia y su desaparición. En este entorno de constante y vertiginoso cambio tecnológicocomercial, al técnico o ingeniero de desarrollo no le queda más opción que emplear constantemente estas herramientas informáticas, como forma de acortar el tiempo transcurrido entre la concepción de un equipo y su realización práctica. En el marco de esta realidad industrial se presenta el enfoque didáctico implementado por los autores para la asignatura optativa de CAD/CAM/CAE, desde su inclusión en el plan de estudios de Ingeniería Técnica en Electrónica Industrial. El modelo propuesto pretende servir de guía tanto para la enseñanza presencial como virtual; aunque en este último caso el uso intensivo del ordenador y de los soportes digitales interactivos (CD-ROM e Internet), obliga a redefinir la estructuración y navegación dentro de los contenidos, el sistema de búsqueda, el seguimiento del aprendizaje y la realización de los ejercicios y prácticas de autoevaluación. Se pretende presentar sucintamente las potencialidades ofrecidas por el paquete CAE (Diseño e Ingeniería electrónica asistida) Protel 99 SE, utilizado por los autores y para la impartición completa de la asignatura CAD/CAM/CAE dentro del plan de estudios de Ingeniería Técnica en Electrónica Industrial.

\section{31 Utilización de los recursos web como herramienta para fomentar el auto-aprendizaje de Postgrado en Genética Forense}

Begoña Martínez Jarreta, Ignacio de Blas, Miguel Bolea, Miriam Baeta, Yolanda Casalod, Carolina Núñez Domingo, Cecilia Sosa Misuraca, Santiago Gascón

Respondiendo a los nuevos estándares de calidad educativa que exige el Espacio Europeo de Educación Superior, el Laboratorio de Genética Forense de la Universidad de Zaragoza ha implementado un curso on line de Capacitación en Genética Forense con el fin de otorgar una formación básica en Genética Forense que permita realizar labores de investigación pericial dentro de la Criminalística Biológica e Investigación Biológica de la Paternidad. La ventaja de un curso no presencial es la posibilidad de adaptarse a las necesidades individuales de aprendizaje de cada estudiante y la optimización de los recursos universitarios ya que es posible abarcar un universo mayor de estudiantes. El curso, cuyo contenido ha sido desarrollado por especialistas de reconocido prestigio, ofrece tutorías electrónicas y establece requisitos específicos para su superación a través de pruebas de autoevaluación. La superación da derecho a un Certificado Oficial de Curso Propio por la Universidad de Zaragoza y se oferta además como curso de Doctorado en la Universidad de Zaragoza y de Master y Doctorado en la UCLM. El curso ha tenido una acogida muy satisfactoria por parte de los estudiantes, lo que viene avalado por el alto número de inscripciones y la alta tasa de superación del mismo. 


\section{Investigación Educativa e Innovación Docente en el proceso de Convergencia Europea}

\section{32 Videoconferencias con metodología C.L.I.L. en el marco de la convergencia europea}

\section{Enrique García Pascual, Eugenio Climent López, Javier Sarsa Garrido}

Se muestra la experiencia desarrollada durante los cursos 2005-06 y 2006-07 para implementar la metodología CLIL (AICLE, en español) a través de la videoconferencia. La metodología CLIL (Content Language Integrated Learning) o AICLE (Aprendizaje Integrado del Contenido y la Lengua Extranjera) consiste en que los estudiantes aprovechan el tiempo que dedican al aprendizaje de un contenido curricular para aprender simultáneamente una lengua extranjera. En esta experiencia se ofrece la oportunidad de aprender un contenido curricular a través de video clases impartidas por un profesor especialista en el contenido y que actúa como profesor de "lengua madre" Los idiomas utilizados fueron español e italiano. En la experiencia participaron la Katedralscholl de Vaxjo (Suecia), el Instituto Giorgi de Milano (Italia) y la Universidad de Zaragoza (España). Además de la descripción de la experiencia, se ofrecen algunas consideraciones metodológicas, técnicas y organizativas como resultado de la reflexión colaborativa de la experiencia.

\section{33 WebQuests para un aprendizaje activo y colaborativo en la asignatura de Inglés Técnico}

\section{María José Luzón Marco, Sonia Baelo Allué,}

Una de las directrices básicas para adecuar la enseñanza superior al Espacio Común Europeo es una metodología basada en el aprendizaje, en la que el estudiante adopta un papel activo. Entre las técnicas usadas en las asignaturas de Inglés Técnico del Centro Politécnico Superior para fomentar un aprendizaje activo, autónomo y colaborativo está la realización de una WebQuest que esté basada en el contenido de la disciplina. Una WebQuest es una actividad orientada a la investigación en la que la mayor parte de la información y recursos que se usan están en Internet. Esta actividad se basa en técnicas de trabajo en grupo por proyectos, por lo que promueve el trabajo cooperativo. Además, desarroIla habilidades cognitivas de alto nivel y potencia la creatividad y la toma de decisiones. El resultado de las WebQuests que se proponen en las asignaturas de Inglés Técnico es la producción de un texto específico (un informe, una propuesta, etc.) por parte de los alumnos, dando respuesta a la situación o problema real que se le plantea en la tarea. 
IV. EXPERIENCIAS DE tRABAJO COOPERATIVO Y TRABAJO EN GRUPO 

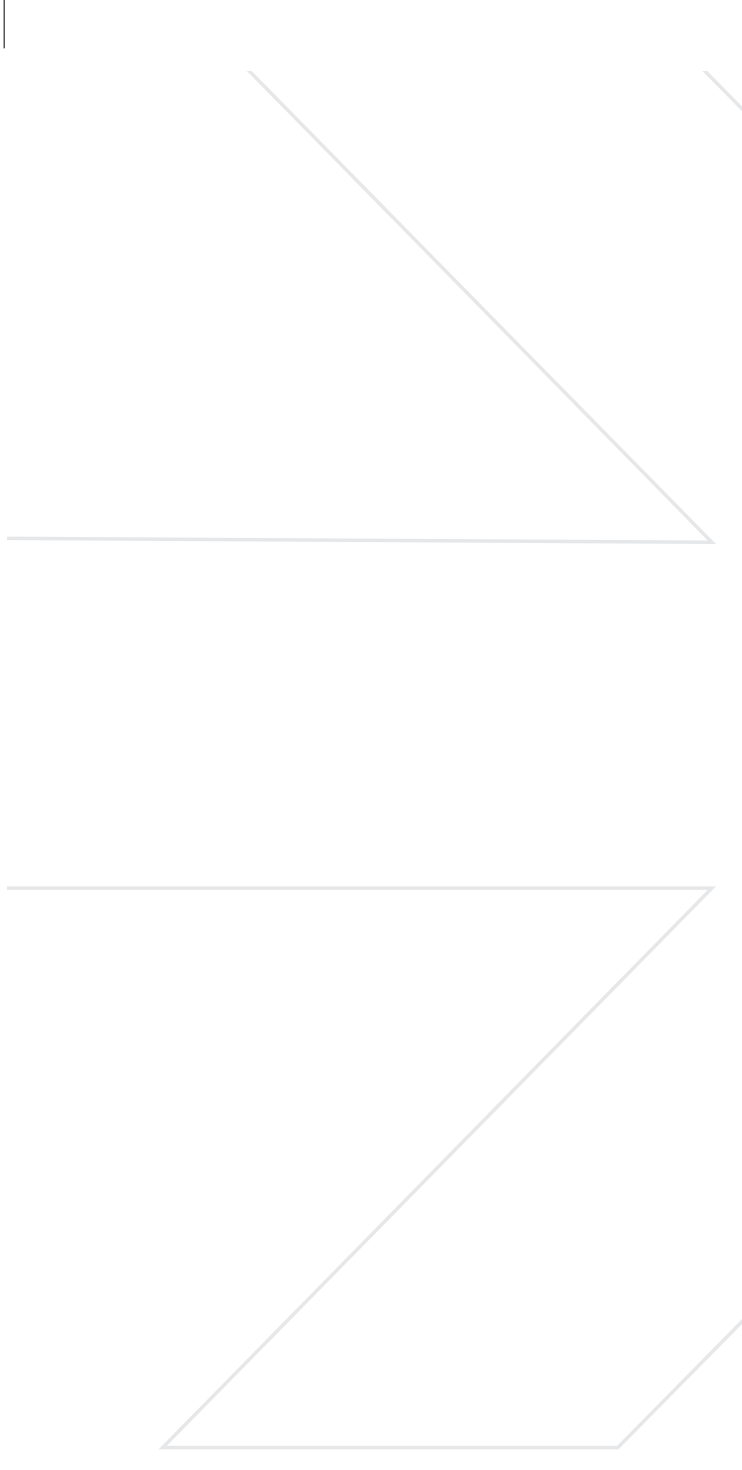


\section{1 Curso de Orientación a las Matemáticas en Ingeniería, una experiencia de innovación docente}

Natalia Boal Sánchez, Mercedes Arribas Jiménez, Ma Dolores Lerís López, Mª Luisa Sein-Echaluce Lacleta

El Curso de Orientación a las Matemáticas en Ingeniería (COMI) es una experiencia formativa llevada a cabo por las autoras dirigida a estudiantes de nuevo ingreso de las distintas titulaciones de Ingeniería e Ingeniería Técnica de la Universidad de Zaragoza. En el COMI se pone en práctica nuevas metodologías docentes activas sustentadas por el trabajo cooperativo. El fin perseguido es mejorar las habilidades matemáticas de estos estudiantes para amortiguar el desnivel con el que se encuentran en su incorporación a la Universidad y para conseguir que se involucren en su propio proceso de aprendizaje.

\section{2 Adaptación a la estructura ECTS con tutoría entre iguales}

\section{Pilar Arranz Martínez, Enrique García Pascual, Javier Sarsa Garrido}

Esta comunicación hace referencia a la experiencia de innovación llevada a cabo durante el curso $2006-07$ (y también, con algunas modificaciones, en el presente curso) y en la que participaron estudiantes de la Facultad de Educación pertenecientes a distintas carreras (Psicopedagogía y Magisterio) y a distintos cursos $\left(1^{\circ}\right.$ y $2^{\circ}$ ) de la diplomatura de Magisterio de la especialidad de Educación Especial. La experiencia innovadora se planteó y desarrolló con dos pretensiones: a) Analizar las posibilidades de la tutoría entre iguales de diferentes cursos y, por tanto, con diferente grado de formación y experiencia universitaria (participaban estudiantes de una asignatura de $1^{\circ}$, otra de $2^{\circ}-$ Magisterio- y de $4^{\circ}-P s i c o p e-$ dagogía-). b) Conocer las horas que los alumnos invertían e invierten en los trabajos autónomos. Los resultados han reflejado las ventajas y los inconvenientes de la tutoría entre iguales, así como el número de horas que las estudiantes utilizaron para realizar la tarea encomendada y que hace exceder notablemente el tiempo que se valora en cada asignatura. Igualmente, se señalan los problemas de coordinación entre grupos de estudiantes y profesores de distinto curso. Se puede concluir afirmando que, aún con las debidas cautelas propias de una primera experiencia, este modo de trabajo ha logrado que las estudiantes participantes en el proyecto hayan desarrollado actitudes básicas en un universitario y futuro profesional; colaboración, autonomía y responsabilidad. Al respecto, subráyese que se pretende que no sólo que el estudiante sea más autónomo en su proceso de aprendizaje, sino que perciba la necesidad de fomentar el trabajo en grupo en pro de mayores logros académicos y personales y perciba la importancia e influencia positiva de las sinergias. 


\section{Investigación Educativa e Innovación Docente en el proceso de Convergencia Europea}

\section{3 Adecuación del concepto MEFN en el nuevo curriculum de Medicina}

Jesús Fernando Escanero Marcén, María Soledad Soria Aznar, Ana Isabel Cisneros Gimeno, Jesús Obón Nogué, José Luis Nieto Amada, Jaime White, Carmen Pérez Castejón

Se plantea una estrategia docente para la distribución de los créditos y la elaboración curricular para la convergencia en el grado de Medicina. Se ha operado con el sub-bloque 4 del bloque I del Libro Blanco de la titulación de la Agencia Nacional de la Evaluación de la Calidad y Acreditación. Se analizan los porcentajes de cada uno de los apartados para Anatomía, Histología y Fisiología y se propone la discusión en grupos, que darán lugar a equipos docentes, para analizar la pertinencia de la fusión de los contenidos de dichas materias. A continuación se propone seguir, junto con otros agentes, para concluir con la pertinencia y créditos europeos del bloque que vendrán determinados con la elaboración concomitante de los aspectos metodológicos y evaluativos y se postula, finalmente, la creación de una comisión de gestión curricular.

\section{4 Aprendizaje activo de la interacción de radiación en materia}

Susana Cebrián Guajardo, José Manuel Carmona Martínez, Gloria Luzón Marco, Julio Morales Villasevil, José Angel Villar Rivacoba

La interacción de distintos tipos de radiaciones con la materia es uno de los contenidos más relevantes en Física Nuclear. Con el fin de facilitar su aprendizaje, se ha elaborado una aplicación interactiva con la que se trabaja de forma colaborativa en pequeños grupos. Los estudiantes, mediante simulaciones de la interacción de electrones, fotones y partículas alfa en materiales diversos, descubren las características esenciales de la interacción de estas partículas con la materia y se familiarizan con las magnitudes y parámetros que describen el fenómeno. El trabajo cooperativo enriquece ampliamente el aprendizaje extraído de la experiencia, sin aumentar proporcionalmente la carga de trabajo. Se justifica la motivación del trabajo, se describe las principales características de la aplicación y su uso, y sobre todo, se valoran las ventajas e inconvenientes de su utilización frente a otras formas convencionales de enseñanza, conforme a la experiencia acumulada en la asignatura Física Nuclear de Bajas Energías desde el curso $2004 / 2005$. 


\section{5 Aprendizaje colaborativo en el ámbito internacional}

Silvia Abella Garcés, José Antonio Moseñe, Helena Giné Abad, Laura Gállego Cortijo, Alberto Cáceres Sáenz, Miriam Pérez Legarda,

Marta Plumed Lasarte, Tamara Torrente Cera

Lo que aquí presentamos no es tanto un proyecto, sino una realidad que se basa en un acuerdo que tenemos en la EUEEH, para desarrollar temas turísticos junto con otras universidades europeas. Cada año, uno de los participantes organiza un proyecto semanal, en el cual los estudiantes trabajan bajo la dirección de profesores y profesionales sobre el tema propuesto. A los alumnos se les asignan unas tareas previas a realizar en las semanas anteriores a la semana del proyecto para realizarlas en grupo. Durante la semana del proyecto se les asignan nuevos trabajos que tienen que resolver en grupos compuestos por alumnos de diferentes países asesorados por diferentes profesores sobre un tema propuesto por el coordinador. Finalmente el último día tienen que realizar una exposición pública del tema tratado presentando la solución encontrada. Un jurado decide y evalua las diferentes alternativas. El objetivo de este trabajo es mostrar la experiencia de los profesores y alumnos participantes así como lo que el desarrollo de un aprendizaje colaborativo.

IV. 6 Aprendizaje de la Patología Médica de Animales de Compañía a través de una sistemática de repetición del método de toma de datos clínicos sobre animales enfermos y posterior desarrollo

Maria Teresa Verde, Laura Navarro, Araceli Loste, Carmen Marca, Silvia García-Belenguer Laita, Manuel Gascón, Pablo Gómez, Asier Basurco, Mª Carmen Aceña

La Patología Médica es una materia muy amplia en cuanto que los alumnos tienen que llegar a conocer una gran cantidad de procesos característicos de los diversos sistemas orgánicos. La asignatura incluye un elevado numero de de conceptos de diversas especialidades médicas (Gastroenterología, Cardiología, Nefrología, Urología, Oftalmología, Endocrinología) que se estudian de forma fundamentalmente memorística. Durante el curso 2006-07 se estableció un sistema de desarrollo de las prácticas clínicas trabajando sobre los casos reales, guiándo a los alumnos en la recogida de información sistematizada y en la organización de la misma. En grupos de 4 tuvieron que preparar una relación de todos los casos que habían tratado a lo largo del curso, organizando la información resumidamente en los apartados precisos para enfocar el diagnostico final. Posteriormente tuvieron que plasmar, discutiendo y analizando, sobre cuatro casos estándar, cada uno de los apartados que habían estado practicando de forma esquemática a 


\section{Investigación Educativa e Innovación Docente en el proceso de Convergencia Europea}

lo largo del curso. El objetivo fue favorecer su capacidad crítica, incrementar su autoestima al observar que son capaces de resolver los problemas clínicos más habituales y ayudarles a aprender de forma más racional la asignatura.

\section{7 Coordinación y evaluación de experiencias de metodologías activas de aprendizaje en Ciencia y Tec-} nología de Materiales

Hippolyte Amaveda, Luis Alberto Angurel Lambán, Miguel Artigas Álava, Miguel Castro Corella, Juan Carlos Diez Moñux, Mario Mora Alfonso, Neculai Plugaru, José Ignacio Peña Torre, Ricardo Ríos Jordana, José Antonio Rojo Martínez, Javier Rubín Llera, Anselmo

Villellas Malo

Ante el reto que supone el diseñar nuevas asignaturas en el marco del Espacio Europeo de Educación Superior, un grupo de profesores que imparten docencia en asignaturas relacionadas con la Ciencia y Tecnología de Materiales tanto en el C.P.S. como en la E.U.I.T.I.Z. decidieron compartir sus experiencias sobre aplicación de metodologías activas de aprendizaje con el fin de evaluar de forma conjunta estas experiencias y extraer aquellos aspectos positivos que conviene potenciar y entre todos definir nuevas estrategias que permitieran superar las deficiencias encontradas. Se están compartiendo experiencias desarrolladas en asignaturas troncales de primeros cursos en donde se imparte clase en grupos de unos 40 a 80 alumnos, una asignatura optativa de primer ciclo en la que se trabaja con grupos de aproximadamente 10 a 25 alumnos y cinco asignaturas optativas de la titulación de Ingeniería Industrial, en donde los grupos son más reducidos ( 8 a 15 alumnos). Además de este objetivo también se han desarrollado diferentes actuaciones tendentes a evaluar el tiempo que el estudiante está dedicando a cada una de las tareas propuestas.

\section{8 Diseño de casos desde una perspectiva interdisciplinar en Gerontología}

Carmen Muro Baquero, Dolores Azúa Blanco, Pilar Domínguez Oliván, Mª José Roche Asensio, Dolores de Pedro Herrera

La resolución de casos es una metodología activa propuesta para la adquisición de competencias profesionales. Este método de aprendizaje supone una aproximación a un estilo de aprendizaje más autónomo, más eficiente y que permite al alumno la adquisición de aquellas competencias profesionales que serán mas útiles en su práctica profesional. El trabajo interdisciplinar es de gran importancia en el campo de la Gerontología, ya que la persona mayor se puede beneficiar, tanto en estado de salud como afectada de diversas patologías, de la atención de múltiples profesionales. El beneficio que puede obtenerse de esos equipos es mayor si su actividad profesional la desarrollan de un modo interprofesional. Es decir, cuando los profesionales 
aprenden unos de los otros en su trabajo diario. Las prácticas clínicas parecen ser un medio donde este aprendizaje sería optimo, pero se ha visto que la percepción de los estudiantes en sus prácticas clínicas es que existe poca formación interdisciplinar. Por este motivo se propuso realizar el diseño de casos donde el alumno para resolverlos tuviese que trabajar en un equipo interdisciplinar. La elaboración corrió a cargo de un equipo interdisciplinar de profesores del Master en Gerontología Social.

\section{9 Dos modelos de enseñanza cooperativa}

Juan de Dios Escolar Castellón, Asunción Escolar Castellón, Julia Blasco Oquendo, Carmen Martínez Ciriano, María José Luesma Bartolomé

Se proponen dos tipos de enseñanza cooperativa: Los "grupos de base cooperativos", en los que un grupo grande y heterogéneo de alumnos brinda su apoyo durante un periodo largo de tiempo y se utiliza el foro de debate del ADD y la enseñanza cooperativa que se realiza en pequeños grupos de alumnos. Se presenta la experiencia en la enseñanza cooperativa tras haber trabajado con alumnos de $2^{\circ}$ de Medicina y $1^{\circ}$ de Óptica en las asignaturas de Anatomía. Los grupos de docencia de ambas carreras se dividieron en secciones de cinco alumnos. Dentro de cada sección un compañero asumía el rol de alumno instructor durante dos semanas. En cuanto a la utilización del foro, se colocaban dos apartados fundamentales relacionados con las posibles dudas que pudieran tener los alumnos. Los resultados de las experiencias fueron diferentes según el tipo de carrera. Los alumnos de Medicina mostraron en todo momento gran entusiasmo. El alumno que tenía el papel de jefe asumía la iniciativa preocupándose del aprendizaje de sus compañeros.

IV. 10 El calcio intracelular como conector inter e intramateria en el aprendizaje de la Fisiología y Farmacología orientada a la isquemia miocárdica

Ana Fanlo Villacampa, Blanca Sinués Porta, Ma Victoria Ejea Arquillué, Marisol Soria Aznar, Jorge Vicente Romero, Izaskun Arenaz

Villalba, Jesús Fernando Escanero Marcén

Ante el reto que supone el proceso de creación del Espacio Europeo de Educación Superior (EEES), un grupo de profesores de Fisiología y Farmacología han acometido este trabajo como fruto de una reflexión continuada sobre la docencia colaborativa en ambas materias que se va plasmando en una metodología que permite al alumno un aprendizaje significativo e integrado tomando como guía los movimientos del calcio intracelular. El trabajo asume los siguientes principios: a) Adaptación del aprendizaje por esquemas, ya que éste es el sistema de respuesta de los expertos ante problemas, b) El/Los principio/s de aprendizaje 


\section{Investigación Educativa e Innovación Docente en el proceso de Convergencia Europea}

colaborativo y continuado, c) Aceptación de elementos guía o conectores de diversas partes intra e intermateria, en este caso se ha adoptado el calcio. En este trabajo se presenta la fisiología de las arterias coronarias y la farmacoterapia antianginosa explicada alrededor de los procesos que moviliza el calcio dentro de la pared vascular y de la célula cardiaca. Este sistema de trabajo abre diferentes vías a la elaboración de nuevo material (guías, textos etc) basado en los principios antes enumerados.

IV. 11 El trabajo en pequeños grupos como aplicación de metodología activa en la asignatura de Patología General de la Licenciatura de Veterinaria

Mª del Carmen Marca Andrés, Araceli Loste Montoya, Aurora Ortín Pérez, Manuel Gascón Pérez, Ma Teresa Verde Arribas, Mª del

Carmen Aceña Fabián, Silvia García-Belenguer Laita, Joaquín Pastor Meseguer

La Patología General es una asignatura cuatrimestral del tercer curso de la Licenciatura de Veterinaria, que sirve de introducción al resto de asignaturas clínicas. Para fomentar el trabajo activo y cooperativo de los estudiantes, se decidió aplicar el trabajo en pequeños grupos para el desarrollo de dos temas del programa teórico. El número total de alumnos fue de 160, que se dividieron en 10 grupos (16 alumnos / grupo de seminario) y en cada uno se formaron a su vez grupos de trabajo de 2-3 estudiantes. La actividad se desarrolló a lo largo de tres seminarios. En el primero se explicaron las normas y se presentaron dos problemas clínicos, a partir de los cuales se formularon las cuestiones a las que se debía responder. Los dos seminarios siguientes se dedicaron a la presentación oral por parte de los estudiantes de los trabajos realizados por cada uno de los grupos de trabajo. Al final, se pasaba una encuesta para recabar su opinión en relación a esta forma de trabajo. Un alto porcentaje coincidió en reconocer que este método les facilitó el estudio, pero les obligaba a invertir mucho más tiempo y, debido a lo cargado de sus programas, les resultaba muy costoso.

IV. 12 Espacio Cooperativo en Internet para promover la Innovación Educativa en el Centro Politécnico Superior y la Escuela Universitaria de Ingeniería Técnica Industrial de Zaragoza

Fernando Tricas García, Jesús Vela Rodrigo, Mª Luisa Sein Echaluce Lacleta, Mª Dolores Lerís López, Natalia Boal Sánchez, José Manuel Correas Dobato, Milagros Gil Ruíz, Pedro Jodrá Esteban

Los equipos directivos del CPS y EUITIZ, junto con varios profesores de ambos centros, algunos de ellos integrantes del grupo Formación Matemática en Ingeniería, percibieron que son muchas y muy variadas las actividades de innovación docente que desarrollan diversos grupos de profesores con docencia en ambos centros. Se juzgó que, a la vez que se ponen 
en marcha experiencias innovadoras, es necesario darlas a conocer y compartirlas con la comunidad universitaria. Se muestra el espacio cooperativo creado en esta experiencia y configurado en Internet para ofrecer un escaparate "virtual" con las experiencias de innovación educativa desarrolladas en nuestros centros, crear foros para su debate, animar a compartir los materiales y las ideas y utilizar herramientas para desarrollar nuevos proyectos de forma colaborativa. Es muy interesante la existencia de foros permanentes que atraigan a participar a los 'innovadores' y que animen a los que podrían serlo

\section{13 La adquisición de la competencia del trabajo en equipo en el Master en Gerontología Social}

Carmen Muro Baquero, Dolores Azúa Blanco, Jesús Paniagua Royo

Una de las competencias genéricas que los alumnos deben adquirir en su formación en el Master en Gerontología Social es el trabajo en equipo. En el campo de la atención a mayores esta competencia es de vital importancia pues gran número de profesionales interactúan tanto en la promoción de la salud como en la atención de los diferentes estados patológicos en los mayores. En las últimas décadas la complejidad en la atención sanitaria y sociosanitaria ha aumentado enormemente y el trabajo en equipo ha demostrado ser eficaz en diferentes contextos, mejorando la atención a los mayores pero también mejorando la salud laboral de aquellos que utilizan el trabajo en equipo en su actividad profesional. Por todo ello, cuando se diseñó el plan de estudios de Gerontología Social se planteó trabajar esta competencia a diferentes niveles; a nivel teórico-práctico con una asignatura, en las prácticas asistenciales y con carácter transversal en los diferentes trabajos que se realizaban para la evaluación de asignaturas.

IV. 14 La formación de maestros de Educación Primaria: Valoración de una experiencia para el desarrollo de la competencia profesional de atención a la diversidad

Begoña Vigo Arrazola, José Luis Bernal Agudo, Antonio Bernat Montesinos, Carmen Julve Moreno, Juana Soriano Bozalongo

La atención a la diversidad constituye una de las competencias en la Orden ECl/3857/2007, de 27 de diciembre, por la que se establecen los requisitos para la verificación de los títulos universitarios oficiales que habiliten para el ejercicio de la profesión de Maestro en Educación Primaria En un momento de transición de las condiciones institucionales y curriculares respecto a la titulación de Maestro, un grupo de profesores de la facultad de Educación aborda la atención a la diversidad desde una perspectiva interdisciplinar a partir del análisis de las percepciones de los estudiantes. El contraste que resulta en relación con los estudios y reflexiones teóricas sobre el papel del profesor ante la atención a la diversidad 


\section{Investigación Educativa e Innovación Docente en el proceso de Convergencia Europea}

orienta el diseño de acciones comunes desde distintas asignaturas de la titulación. El desarrollo de una página web, talleres, conferencias o estudios de caso configuran este proceso. La evaluación posterior muestra mayor coherencia entre dichas percepciones y las orientaciones teóricas sobre el perfil del maestro para la atención a la diversidad en el momento actual.

IV. 15 La formación de maestros para la atención a la diversidad: Evaluación de una experiencia de reflexión conjunta entre futuros maestros de distintas especialidades

\section{Juana Soriano Bozalongo, Begoña Vigo Arrazola}

La experiencia que se presenta forma parte de un proyecto sobre "[la] innovación y la mejora interdisciplinar en la formación de profesionales de la educación para la atención a la diversidad". En este trabajo, con la intención de aproximar la práctica docente en la universidad a las exigencias de la práctica profesional, se analizan las potencialidades y limitaciones de una metodología basada en el trabajo colaborativo de estudiantes de maestro de distintas especialidades. Se valoran sus percepciones del proceso a partir de la resolución de un caso mediante el estudio y la reflexión conjunta de los aspectos organizativos y didácticos que intervienen en su desarrollo. Se combina la atención a las competencias que definen el perfil del maestro actual y las exigencias del Espacio Europeo de Educación Superior.

\section{16 La metacognición: Un camino para el éxito}

\section{Jesús Fernando Escanero Marcén, Ma Soledad Soria Aznar, Carlos González-Haro}

El nuevo paradigma centrado en el aprendizaje implica que el alumno asuma uno de los principios básicos de la educación continuada; ser aprendedor durante toda su vida, lo que supone que conozcan y usen estrategias de aprendizaje más sofisticadas que la pura repetición mecánica. En este trabajo se discute la clasificación de las estrategias de aprendizaje de acuerdo con los contenidos a aprender (cognitivas, metacognitivas y de apoyo del aprendizaje) y se profundiza en la enseñanza metacognitiva planteando una serie de propuestas al respecto entre las que se destaca un círculo metacognitivo para el estudio de la Fisiología con éxito. En esencia, se trabaja durante todo el curso (tres sesiones) con los alumnos. En la primera se les obliga a reflexionar y realizar una "tarjeta para el éxito" en los exámenes finales de Fisiología. Dicha tarjeta debe contener, al menos, cinco recomendaciones dependientes del alumno (no del profesor o de la materia) para obtener una alta puntuación. Cada tarjeta se intercambia posteriormente con los compañeros de sección (10 alumnos) que deben revisarla y añadir en una columna lateral alguna propuesta de modificación. 
Al final cuando vuelve al alumno autor, su tarjeta de éxito puede presentar distinto grado de variaciones con respecto al original. Dicha sesión se repite hacia mitad del curso y al final del mismo y se comparan las recomendaciones.

\section{17 La vocación cooperativa nacional e internacional de la Red del Master Interuniversiatario de Ciencias} de la Enfermería

\section{Concha Germán, Loreto Macia, Adela Zabalegui, Roser Ricomá, Isabel Mariscal, Josefa Marquez, Carmen Nuin, Azucena Pedraz}

Desde Abril de 2005, las Universidades de Alicante, Almería, Autónoma de Madrid, Internacional de Cataluña, Huelva, Lleida, Rovira i Virgili y Zaragoza, tienen firmado un convenio interuniversitario por el que se comparte la troncalidad de la titulación Master en Ciencias de la Enfermería. Parece que se trata de una vía que estimula el intercambio formativo al acordar por consenso las materias impartidas en cada itinerario ofrecido por cada universidad, que es coincidente con los intereses del alumnado. La primera Universidad que firmo un convenio internacional para el desarrollo de la formación superior fue la Universidad de Alicante con Hocheschool Zeeland; este convenio permitió la realización de estudios de Bachelor a los estudiantes españoles y continuar hacia el doctorado en momentos anteriores a la aprobación del actual Master Oficial de CC. de la Enfermería. Entre 1998 y 2002, la Universidad de Zaragoza trabajo el grupo del "European Master Nursing of Science", compuesto por las Universidades Humbolt (Alemania) Karlscrona (Suecia) entre otras. Cada Universidad, partiendo del programa Erasmus, ha ido incorporando nuevas experiencias de intercambio Actualmente, se sigue avanzando hacia los acuerdos europeos ya en la línea Master, que permitan iniciar la investigación conjunta entre estados miembros de la Unión. El proyecto más ambicioso es el de la doble titulación entre los estudiantes de la Red Interuniversitaria y la Universidad de Leuven con la que se firmó un convenio en 2006. Para ello los estudiantes deben realizar estancias de uno a tres meses, el proyecto de investigación del Master codirigido y presentado ante tribunal mixto. El intercambio entre alumnado y profesorado español y europeo es un hecho, estando en la actualidad varios alumnos y profesores implicados. .

\section{18 Participación del alumno en el proceso enseñanza-aprendizaje de la Anatomía Humana en Medicina}

Mª José Barral Morán, Manuel Lahoz Gimeno, Daniel Anadón Mateo, Irene Cid Jiménez, Alberto Dominguez Longás, Miriam Herrero

Traver, Pedro Lacarta García

Se presenta una experiencia que fomenta, por un lado, la participación activa de todos los alumnos matriculados en la asignatura en dos niveles: En primer lugar, como monitores de clases prácticas, asistiendo a la preparación de las mismas 


\section{Investigación Educativa e Innovación Docente en el proceso de Convergencia Europea}

y explicando posteriormente lo aprendido al resto de compañeros de su sección y en segundo lugar realizando seminarios presenciales dirigidos mediante tutorías ECTS, en los que grupos de 5-6 estudiantes elaboran y exponen públicamente un trabajo sobre temas relacionados con la materia de la asignatura y propuestos por el profesor y por ellos mismos. De cada seminario se extraen los puntos más importantes que constituirán materia de examen y posteriormente son evaluados por el resto de estudiantes y por el profesor constituyendo su calificación el 10\% de la calificación final. Por otro lado, se fomenta la relación y colaboración profesional entre estudiantes de distintos cursos, involucrando a alumnos de cursos superiores en el proceso de enseñanza-aprendizaje de los que comienzan sus estudios, trabajando como alumnos internos, elaborando y enseñando material de prácticas y tutorizando seminarios. Esta experiencia forma parte de la propuesta de transformación de créditos LRU a créditos ECTS de esta asignatura troncal que se imparte en los dos primeros cursos de Medicina. De esta transformación forman parte también los recursos de la metodología informática del ADD, las actividades tutoriales, individuales y grupales y la elaboración de materiales de evaluación de los seminarios.

\section{19 Proyecto FEDAl: Formación de Equipos para el Desarrollo de Aplicaciones Informáticas}

José Antonio Baldovín Oliver, José Carlos Ciria Cosculluela, Eladio Domínguez Murillo, Angel de Miguel Artal, Angel Francés Román, Beatriz Pérez Valle, Aurea Rodríguez Villanueva, María Antonia Zapata Abad

El proyecto tiene como objetivo básico la formación de estudiantes para el desarrollo de una aplicación informática mediante el trabajo en equipos. El proyecto involucra a tres asignaturas optativas de la licenciatura en Matemáticas: Métodos Matemáticos en Ingeniería del Software (optativa del primer cuatrimestre del $2^{\mathrm{a}}$ ciclo); Modelos Matemáticos de Bases de Datos (optativa del segundo cuatrimestre del $2^{\mathrm{a}}$ ciclo); Informática II (optativa del segundo cuatrimestre). En el proyecto se pretende hacer énfasis en el desarrollo de las competencias: Capacidad de comunicación oral y por escrito; manejo de distintos paradigmas de programación; adquisición de pautas para decidir cuál es el más adecuado para una situación dada; adquisición de una metodología para el desarrollo de aplicaciones que garantice la fiabilidad, eficiencia y buen estilo de programación.

IV. 20 Resultados de una experiencia de innovación docente en Termodinámica técnica e Ingeniería térmica con extension posterior a otras materias y universidades del país

Mª Carmen Velasco Callau, José Antonio Turégano Romero, Amaya Martínez Gracia, Tomás Gómez Martín, Javier Uche Marcuello 
Se presentan los resultados de una experiencia de innovación docente en la que se viene trabajando desde hace más de dos décadas, en las asignaturas de Termodinámica Técnica e Ingeniería Térmica en las que se ha puesto en práctica una metodología docente constructivista basada en el aprendizaje significativo con resultados muy positivos: Estudiantes que superan la asignatura en Junio en asistencia continuada a clase (en torno al $85 \%$ de los matriculados) e incremento del número de aprobados (hasta un 500\%). Se incorpora un análisis sociológico de la extracción de los estudiantes que han participado en la misma en el último periodo. Asimismo se presenta la extensión de dicho proyecto a lo largo de estos años a otras materias en la Universidad de Zaragoza, así como fuera de ella, con la incorporación de otras universidades a una propuesta de trabajo colaborativo entre el profesorado para producir y compartir materiales, metodologías y resultados en red con el desarrollo de un sistema de distribución y retribución de documentos de diversos tipos utilizados en la experiencia utilizando la plataforma Moodle como soporte. Se presentan los objetivos y el estado de desarrollo actual.

IV. 21 Trabajo colaborativo de un grupo de profesores para desarrollar metodologías activas. una experiencia de la Facultad de Educación

Teresa Fernández Turrado, Ma Ángeles Garrido Laparte, Santos Orejudo Hernández, Javier Nuño Pérez, Mª Luisa Herrero Nivela,

María Frontera Sancho, José Emilio Palomero Pescador, Ma Rosario Fernández Domínguez, Pilar Teruel Melero, María Carmen Gil Ciria, Miguel Puyuelo Sanclemente, Antonio Valero Salas, Teresa Ramos Cascón

En esta presentación queremos dar cuenta del proceso que un grupo de profesores del Departamento Psicología y Sociología con docencia en la Facultad de Educación, en las titulaciones de Magisterio y Psicopedagogía ha seguido en los últimos años en relación con los proyectos de innovación metodológica en que ha participado desde el curso 2004 , al hilo de la Convergencia al Espacio Europeo de Educación Superior. Se trata de un proceso continuado desde su inicio que abarca participantes en diferentes proyectos que de alguna manera han confluido al compartir un número significativo de sus integrantes y que ha permitido que las experiencias de unos hayan revertido y fluido hacia otros que han podido ampliar su perspectiva y devolver un trabajo reflexivo de mayor envergadura extendiendo su área de influencia al trabajo directo con estudiantes de diferentes titulaciones y asignaturas. El trabajo se ha centrado en la reflexión metodológica, el análisis de la actividad docente y la aplicación de metodologías activas (tipo caso, aprendizaje basado en problemas y proyectos, aprendizaje en grupo cooperativo, uso de diarios, cuadernos de bitácora y carpetas para el aprendizaje autónomo). 


\section{Investigación Educativa e Innovación Docente en el proceso de Convergencia Europea}

\section{22 Una experiencia de aprendizaje de trabajo en equipo en la asignatura de Espectroscopía (Técnicas}

Atómicas)

\section{Maria Teresa Gómez Cotín, María Sierra Jiménez García-Alcalá, Juan Ramón Castillo Suárez}

En este trabajo se presenta una metodología docente basada en fomentar el trabajo en equipo por parte de estudiantes de la asignatura de Espectroscopía (Técnicas Atómicas) de $4^{\text {a }}$ curso de la Licenciatura de Química. Es un trabajo diseñado y dirigido por los profesores de los distintos grupos docentes. Se trata de una actividad que los profesores participantes vienen realizando en cursos anteriores pero que, en esta adaptación progresiva hacia el EEES, va quedando reflejado en la asignatura. El trabajo desarrollado por los alumnos en "Espectroscopía", de carácter no presencial y común a grupos de cuatro estudiantes, es evaluado y valorado tanto por profesores como por los propios estudiantes. Son objetivos primordiales en el contexto de fomentar competencias transversales el desarrollo de la capacidad de trabajo en equipo, la capacidad de análisis y síntesis, la capacidad de comunicación oral y escrita en la lengua nativa, el conocimiento de una lengua extranjera (inglés), las habilidades en las relaciones interpersonales, la búsqueda de información y de documentación, la capacidad de discriminación de información relevante y la valoración del trabajo personal, tanto del propio como del resto de los alumnos. 


\section{Metodologías activas}



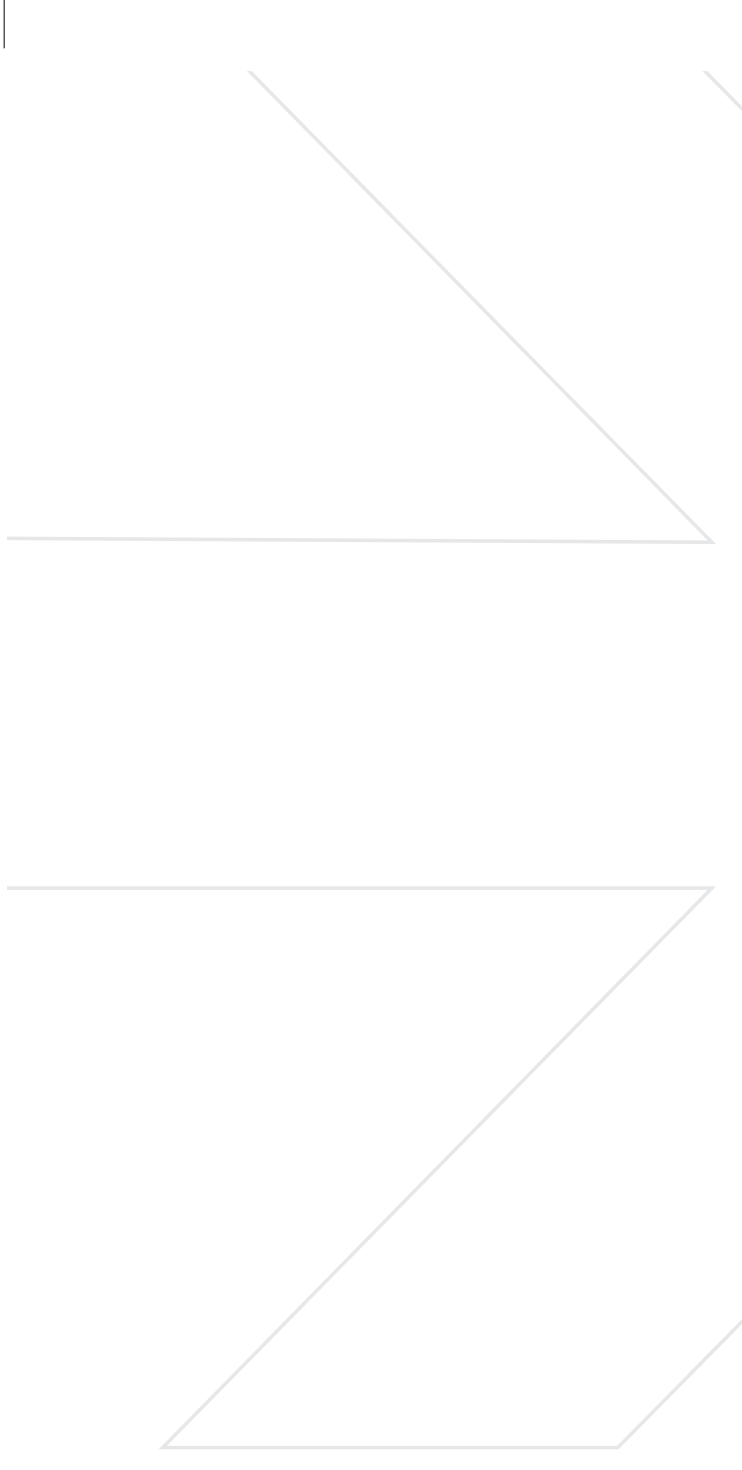


\title{
Investigación Educativa e Innovación Docente, en el proceso de Convergencia Europea
}

\section{1 Aplicación práctica del electrocardiograma en la valoración del estado sanitario de perros y caballos \\ F. Manuel Gascón Pérez, Pablo Gómez Ochoa, Aurora Ortin Pérez, Jorge Palacio Liesa}

Se presentan las conclusiones obtenidas al cambiar el método de una práctica de una asignatura troncal, Patología General, de la Licenciatura de Veterinaria. Facilitando al alumno material audiovisual antes de la práctica para que lo use como tutorial de la misma, se le proporcionan posteriormente los medios animales e instrumentales para que la realice en grupo, obteniendo un electrocardiograma, leyéndolo e informándolo, cumpliendo los objetivos planteados en el tutorial que se le entregó.

\section{2 Acciones para estudiantes de nuevo ingreso organizadas por la Facultad de Ciencias de la Universidad de Zaragoza}

\begin{abstract}
Ana Isabel Elduque Palomo, Concepción Aldea Chagoyen, Enrique Artal Bartolo, Manuela Artal Lerín, Blanca Bauluz Lázaro, Bienvenido Cuartero Ruiz, Javier Fernández López, Ángel Francés Román, Tomás Grande Ventura, Josefina Jiménez Villar, María Luisa Sarsa Sarsa, Belén Villacampa Naverac, Eva Villarroya Aparicio, María Antonia Zapata Abad, Eva Noriega Miguélez, Désirée Sánchez Ojanguren, Roberto Soriano García
\end{abstract}

La Facultad de Ciencias de la Universidad de Zaragoza, siguiendo las directrices planteadas en su Plan Estratégico, ha desarrollado en los últimos años un conjunto de acciones dirigidas a los alumnos de nuevo ingreso: Jornadas de Acogida, Cursos Cero de Matemáticas, Física y Química y Curso Básico de Utilización de Recursos Bibliográficos. El objetivo de estas acciones es facilitar la incorporación de los estudiantes de nuevo ingreso al entorno universitario ofreciéndoles variada información desde distintos puntos de vista; académico, curricular, de servicios de la Facultad, etc., así como la posibilidad de contactar con compañeros y profesores antes del comienzo de las clases. En esta comunicación se intenta valorar la experiencia acumulada, así como plantear posibles mejoras en el programa, para ello se cuenta con los resultados de las encuestas que, específicamente para cada una de las actividades, han sido realizadas al finalizar las mismas. Por primera vez, además, en este curso académico se dispone de datos sobre la satisfacción de los alumnos de $2^{\circ}$ curso, que tras haber cursado $1^{\circ}$, valoran la utilidad de las referidas acciones y las posibles cuestiones a mejorar. 
V. 3 Actividades de aprendizaje activo, profundo y significativo en Ciencias Sociales, Economía, e Ingeniería, y su evaluación competencial, para el Espacio Europeo de Educacion Superior

Luis Fernando Peña Tirado

El trabajo muestra las claves de una actividad docente que cumple el diseño, desarrollo y validación de los resultados de una actividad de enseñanza-aprendizaje en la misma dirección y sentido que la docencia representativa del EEES, basada en el aprendizaje y evaluación de/y por competencias, que supone aprendizajes activos, profundos, potentes y significativos y teniendo en cuenta en su programación el crédito ECTS (el trabajo real del estudiante en su proceso de aprendizaje). Pero también es un ejemplo de la implementación de un método de aprendizaje cooperativo (Método ICARO), que incorpora elementos de investigación y cooperación colaborativa entre los miembros del equipo y la cooperación colaborativa de los diferentes equipos entre sí, pero configurando todo ello en un conjunto coherente, cohesionado y sinérgico y no la simple agregación de un conjunto de tareas, permitiendo desde este segundo objetivo la consistencia y cumplimiento del primero.

\section{4 Aprendizaje activo de la Fisiología respiratoria y cardiovascular y sus adaptaciones durante el ejercicio}

Ma Pilar Arruebo Loshuertos, Ana Isabel Alcalde Herrero, Marta Castro López, Laura Grasa López, José Emilio Mesonero Gutiérrez, Mª Divina Murillo López de Silanes, Mª Jesús Rodríguez Yoldi, Miguel Ángel Plaza Carrión

La experiencia docente llevada a cabo desde la Unidad de Fisiología de la Facultad de Veterinaria consiste en la implantación de un sistema de aprendizaje para la Fisiología respiratoria y cardiovascular, en condiciones normales o en situaciones de adaptación al ejercicio físico, con diversas metodologías que requieren la participación activa de los alumnos. La explicación teórica en el aula se ve reforzada posteriormente por el manejo, en grupos reducidos, de programas informáticos interactivos que consolidan el aprendizaje teórico e integran los mecanismos reguladores de la función respiratoria y cardiovascular, así como las adaptaciones funcionales y metabólicas durante el ejercicio. Posteriormente se realizan en el laboratorio de forma individualizada diversas pruebas funcionales; espirometría, ciclo respiratorio, pulso, presión arterial y electrocardiograma. Algunas de estas pruebas se realizan también en animales, con objeto de establecer comparaciones funcionales y valorar diferencias interespecíficas. Las señales captadas en el laboratorio se procesan posteriormente mediante un programa de ordenador (Biopac Student Lab), que permite la cuantificación individualizada de diversos parámetros fisiológicos. Con este sistema docente basado en metodologías activas, se consigue un aprendizaje más profundo y consolidado de las funciones orgánicas. 


\section{5 Aprendizaje presencial y metodologías activas: Reflexiones sobre el manual docente}

José Antonio Mateos Royo

Este trabajo tiene por objeto promover una reflexión sobre los manuales utilizados de manera habitual en las universidades españolas ante los nuevos retos docentes que supone el Espacio Europeo de Educación Superior. Fruto de una perspectiva desfasada, muchos de estos manuales resultan por completo inadecuados para promover metodologías de aprendizaje activas y cooperativas. Auténticos contenedores de teoría, son concebidos más bien para la utilidad del profesor, al no adaptarse con frecuencia ni a los objetivos de la asignatura ni a la preparación de los estudiantes. Por este motivo, su utilización efectiva por parte de éstos se limita a su consulta apresurada durante los días previos al exámen sin convertirse en vehículo efectivo de su aprendizaje diario. Estos manuales rara vez permiten que los estudiantes sean capaces de gestionar y analizar por sí mismos al menos una parte de la información que se les aporta. Desde esta reflexión previa, este trabajo ofrece la experiencia propia de diseño de un manual docente vinculado a la asignatura de Historia Económica, impartida en la Facultad de Ciencias Económicas y Empresariales ( $1^{\circ}$ de LADE). Concebido para su empleo diario como actividad presencial, supone una revisión de los cometidos que el manual debe cumplir para promover estrategias de aprendizaje. Sus conclusiones también valoran las distintas capacidades que su utilización suscita frente a la dinámica más común basada en la clase magistral.

\section{6 Aún aprendo}

José Antonio Rojo

Uno de los objetivos fundamentales en el proceso de convergencia en el Espacio Europeo de Educación Superior es fomentar el trabajo continuo del estudiante como elemento clave en su proceso de aprendizaje. La finalidad de este proyecto fue conseguir dicho objetivo en los dos grupos de las asignaturas básicas del primer ciclo de Ingeniería Superior Industrial. Para ello, en el curso 2005-2006 se organizó el material docente, el proceso docente, el proceso de aprendizaje y el proceso de evaluación de dichas asignaturas con una referencia permanente hacia el fomento y la consecución del trabajo continuo del estudiante dentro y fuera del aula o laboratorio. Dos elementos claves fueron potenciar la participación del estudiante y usar con intensidad las tutorías. La respuesta conseguida por parte de los estudiante sfue muy buena, superior a las previsiones iniciales. Los resultados fueron mejores que los obtenidos en años precedentes. La metodología y estrategias desarrolladas pueden ser adaptables a cualquier otra asignatura, especialmente a las asignaturas donde mayor fracaso escolar se produce; asignaturas troncales y obligatorias de los primeros cursos. 


\section{Investigación Educativa e Innovación Docente en el proceso de Convergencia Europea}

\section{7 ¿Los mismos usos con distintos créditos? ECTS: Contabilizar tiempos, diversificar actividades, planifi- car por competencias}

Ángel Antonio Bayod Rújula, Alberto Carreras Gargallo, Ángel Gregorio Chueca Sancho, Nieves Cuadra Pérez, Antonio Eito Mateo, Gloria Luzón Marco, Carmen Marcuello Servós, Chaime Marcuello Servós, Amaya Martínez Gracia, José Mariano Moneva Abadía, Ana Leonor Navarro Soto, Javier Paricio Royo, Susana Torrente Gari, Manuel González Labrada

El llamado Espacio Europeo de Educación Superior, al menos sobre el papel, supone una transformación de las estructuras y de los hábitos docentes en la universidad. Más allá de la convergencia de planes y procesos o del impulso a la movilidad de estudiantes, la concepción general de la enseñanza superior pasa a enfatizar el papel del alumnado. El foco de atención se centra más en el discente y no tanto en el docente al potenciarse metodologías activas de aprendizaje, entre otras cuestiones. En el Grupo Interdisciplinar de Innovación Docente (GIDID) se ha propuesto para este curso un análisis/investigación/reflexión de las consecuencias del modelo ECTS tanto en estudiantes como en profesores. Una cosa es la contabilidad en ECTS, otra diferente es la diversificación de los tipos de actividades de aprendizaje realizadas con los estudiantes y otra distinta es la cuestión de la planificación curricular por competencias. Aunque las tres cuestiones están relacionadas en la práctica, es muy conveniente discriminarlas porque plantean problemas de orden diverso. Este trabajo es una primera aportación a esta cuestión utilizando como base el proceso de experimentación y la reflexión realizada en el seno del GIDID.

\section{8 Código de Buenas Prácticas Docentes basado en criterios de calidad}

Inmaculada Plaza García, Francisco Arcega Solsona, Ana Mª López Torres, Carlos T. Medrano Sánchez, Juan José Marcuello Pablo,

Tomás Pollán Santamaría, Montserrat Corbalán Fuertes, Ana Blanca Posa Gómez, Emiliano Aldabas Rubira

Entre la filosofía que subyace en los documentos básicos del Espacio Europeo de Educación Superior (EEES) destaca la importancia que se le concede al concepto de calidad. Esta filosofía ha sido adoptada así mismo por la Universidad de Zaragoza, donde se ha considerado la calidad como uno de los retos de su Plan Estratégico y la cultura de calidad como una de sus líneas de actuación prioritarias. Sin embargo, aplicar esta filosofía en la labor diaria docente no es una tarea que pueda considerarse trivial. En este contexto de trabajo, el presente documento muestra un proyecto que está siendo realizado en el seno de la Universidad de Zaragoza por el grupo EduQTech (Education, Quality, Technology / Educación, Calidad, Tecnología) dentro del programa de Incentivación Docente para la Adaptación de las Titulaciones al Espacio Europeo de Educación Superior (PIIDUZ). El principal objetivo es elaborar un Código de Buenas Prácticas Docentes basado en criterios de calidad. El proyecto, que fue iniciado durante el curso pasado, finalizará en junio de 2008. En él colaboran nueve profesores, cinco estudiantes y un profesional externo. El presente documento muestra los resultados obtenidos hasta el momento y las futuras líneas de actuación. 


\section{9 Código de Buenas Prácticas Docentes en el título de Grado en Información y Documentación}

Ana I. Sánchez Casabón, Mª del Carmen Agustín Lacruz, Esperanza Velasco de la Peña, Ma Adelaida Allo Manero, Pilar Gay Molins, Luisa Orera Orera, José Antonio Salvador Oliván, Jesús Tramullas Saz, Mª Isabel Ubieto Artur

El trabajo se propone como objetivo general, tomando como marco de referencia el concepto de "competencia docente" del profesorado universitario establecido por Zabalza Beraza (2003, 70-167), así como su análisis de las capacidades, conocimientos y destrezas que caracterizan el trabajo de los profesores universitarios, desarrollar un proceso de reflexión, análisis, discusión, acuerdo y elaboración de pautas de referencia en las actividades docentes, comunes y consensuadas, encaminadas a la consecución de la excelencia en las competencias profesionales docentes de los profesores del Ârea de Biblioteconomía y Documentación. El objetivo general se concreta en un conjunto de objetivos específicos orientados a identificar las "buenas prácticas" ya existentes y aquellas otras que se desean alcanzar. Se constituye un grupo de trabajo, organizado bajo la estructura de seminario, que celebra mensualmente sesiones de discusión, según un cronograma previamente establecido. En una segunda etapa, al seminario de trabajo se incorporan también alumnos de la titulación. Entre los resultados más importantes destacan: a) El inventario del estado de las "buenas prácticas docentes"; b) La redacción, publicación y difusión de un Código de buenas prácticas docentes en el Área de Biblioteconomía y Documentación y d) La propuesta de un modelo de autoevaluación del Código diseñado.

V. 10 Desarrollo y comunicación de proyectos en los que se destacan las Relaciones Ciencia, Tecnología y Sociedad. Colaboración de los estudiantes en entornos telemáticos

Ma Jesús Morales Lamuela, Ma Dolores Sánchez González

El alumnado de la asignatura "Relaciones Ciencia, Tecnología y Sociedad" ha intervenido en actividades colaborativas sobre temas de actualidad y problemáticas ambientales. Estas actividades forman parte de un proyecto de formación en el que los conocimientos y los valores están relacionados, para que den lugar a unos aprendizajes en los que se prioriza la responsabilidad individual y el compromiso social de la ciudadanía, en una sociedad en la que la toma de decisiones suele ser compleja. La perspectiva educativa prioritaria es una alfabetización científica cultural, lo que supone el uso de unas metodologías activas y colaborativas centradas en el aprendizaje del estudiante. Las TICs y los entornos telemáticos se han utilizado para favorecer la colaboración y para la realización del proyecto a lo largo del segundo cuatrimestre de 2007 en la Facultad de Educación de Zaragoza. 


\section{11 El Máster de Profesorado de Educación Secundaria: Un diseño participativo con la colaboración de} los estudiantes

\section{Enrique García Pascual, Javier Enrique Mur Isaiz}

Refiere el diseño y la planificación del currículum del Master de Profesorado de Educación Secundaria. A tal fin se describen los marcos físicos, temporal, educativo, institucional, profesional y el de los estudiantes para su contextualización. Se analiza la situación actual de la formación del profesorado de Secundaria y se realiza una propuesta en función de las directrices actuales. El diseño considera las competencias prescritas, así mismo el trabajo describe brevemente los contenidos, señal las actividades, la metodología y asigna los tiempos de trabajo presencial y de trabajo autónomo. Finalmente se realiza una propuesta de evaluación, indicando los instrumentos y los criterios de la misma.

\section{12 El uso de metodologías activas en los estudios de Finanzas en la Universidad: Análisis DAFO de una experiencia real}

Aurora Sevillano Rubio

Consciente de la necesidad de adaptar la docencia universitaria a las nuevas metodologías activas que se derivan de la integración al EEES, durante el curso 06-07 se diseñó una nueva estructura metodológica para el estudio de la asignatura “Operaciones Financieras" impartida en la Diplomatura de Ciencias Empresariales, a partir de las conclusiones extraídas de una encuesta realizada a los estudiantes de la asignatura. En el presente trabajo, además de exponer esta estructura metodológica, se plantea un análisis DAFO del uso de estas metodologías activas implantadas en el curso 07-08 para esta asignatura. Las debilidades son aspectos que limitan o reducen la capacidad de desarrollo efectivo de la estrategia aplicada. Las amenazas se definen como toda fuerza del entorno que puede impedir la implantación de una estrategia o reducir su efectividad. Las fortalezas son capacidades, recursos, posiciones alcanzadas y, consecuentemente, ventajas competitivas. Las oportunidades son todo aquello que puede suponer una ventaja competitiva en la aplicación de la estrategia, o bien representar una posibilidad para mejorar los aspectos positivos en su desarrollo. Las debilidades y fortalezas tienen su origen en influencias internas que son controlables. Las amenazas y oportunidades provendrán de influencias externas incontrolables. Finalmente se proponen unos cambios, en la forma de aplicar esta metodología, derivados de este análisis elaborando una nueva estrategia que cree nuevos puntos fuertes que permitan aprovechar las oportunidades, contrarrestar las amenazas y corregir las debilidades. 


\section{13 Experiencia de adaptación al EEES de la asignatura de Instrumentación Electrónica en fases}

Pilar Molina Agudo

La plena adaptación de una, o varias asignaturas al EEES requiere un esfuerzo elevado por parte de los docentes, así como una evaluación y análisis de los resultados obtenidos para, posteriormente, introducir nuevos cambios y mejoras. Este trabajo, resultado de dos proyectos de innovación docente, presenta una propuesta para modificar una asignatura anteriormente impartida de forma mayoritaria utilizando la metodología de la clase magistral (más o menos participativa) y transformarla en una asignatura que se basa fundamentalmente en metodologías activas. La primera fase contempla una modificación de las prácticas. Las dos segundas fases plantean el cambio en el aprendizaje de la teoría. Las fases pretenden implantarse en dos años. Se presentan también estrategias y resultados de evaluación por parte de alumnos y profesores.

\section{14 Experiencias docentes de metodologías activas en dos asignaturas técnicas con grupos reducidos}

\section{José Antonio Yagüe Fabra, José Antonio Albajez García, Jorge Santolaria Mazo, Miguel Ángel Lope Domingo}

El proceso enseñanza-aprendizaje está fuertemente unido al concepto de "aprender haciendo" o al "hands-on" tan fomentado por muchas universidades norteamericanas. No obstante, el elevado número de alumnos por clase no siempre permite llevar a cabo esta técnica de la manera adecuada. Por contra, un número reducido de alumnos en el grupo permite aplicar interesantes metodologías. Este caso se ha dado en las dos asignaturas "Medición por Coordenadas" y "Técnicas de Medición en Producción y Mantenimiento" en las que se basa este trabajo. Se describen las metodologías activas (en taller y laboratorio) empleadas en dichas asignaturas, especialmente interesantes al tratarse de asignaturas técnicas muy aplicables al ámbito empresarial. Se describen algunas de las metodologías empleadas, como el estudio del caso, en el que se coloca a los alumnos frente a situaciones de medición reales, se les enseña a medir, a descubrir los problemas que surgen, ir resolviéndolos e interpretar los resultados. Se analiza también el papel que la web de una de dichas asignaturas presente en el ADD ha realizado en el apoyo al aprendizaje, así como en la mejora continua de la materia. 


\section{15 Feedback desde la empresa}

Ana Isabel Elduque Palomo, Concepción Aldea Chagoyen, Enrique Artal Bartolo, Blanca Bauluz Lázaro, Javier Fernández, Ángel Francés, Josefina Jiménez, María Luisa Sarsa Sarsa, María Antonia Zapata

En una época de renovación de las enseñanzas universitarias para su adaptación al Espacio Europeo de Educación Superior, resulta imprescindible mirar hacia la sociedad y los agentes sociales para afrontar algunos de los cambios requeridos. La Facultad de Ciencias tiene un amplio programa de acciones encaminadas a potenciar la colaboración entre los distintos agentes, así como a buscar una mayor implicación de los mismos tanto en el proceso formativo como en la implantación de nuevas titulaciones. Se trata de obtener desde la empresa el feedback necesario para abordar la incorporación de los titulados al mercado laboral. En este trabajo se detallan las distintas acciones desarrolladas los dos últimos cursos académicos, entre las que destacan: Convenios de colaboración con asociaciones empresariales y organismos públicos, desarrollo de seminarios, conferencias y debates contando con la participación de profesionales externos al ámbito universitario para difundir los perfiles profesionales de los titulados en Ciencias e intercambiar información entre las empresas y la Universidad, organización de cursos y talleres que complementan la formación de los titulados y mejoran su empleabilidad, reuniones con representantes del entorno empresarial, colegios profesionales y personal académico y creación de una bolsa de empleo.

\section{16 Herramienta para la evaluación del funcionamiento de grupos de proyectos}

Juan Luis Cano Fernández, Iván Lidón López, Rubén Rebollar Rubio, Fernando París Roche, María Jesús Sáenz Gil de Gómez, Fernando Gimeno Marco

A lo largo de los dos últimos años (cursos 05/06 y 06/07) se ha desarrollado un cuestionario para la evaluación de distintas variables relacionadas con el funcionamiento de grupos de proyectos. Para su elaboración se ha contado con la participación de 113 alumnos de la asignatura Proyectos de la titulación de Ingeniería Industrial de la Universidad de Zaragoza, en la que grupos de 5-6 alumnos trabajan para resolver una necesidad planteada por un cliente real, a través de las realización de un proyecto. Del análisis de los resultados de este cuestionario durante el curso 06/07 se observó la correlación entre el funcionamiento del grupo y la calidad del proyecto que los alumnos desarrollaban, fundamentalmente en aspectos relativos a la coordinación dentro del mismo. A la vista de estos resultados en el curso 07/08 se ha desarrollado un cuestionario basado en 7 preguntas obtenidas del cuestionario anterior que mostraba una correlación estadísticamente significativa entre la calidad del funcionamiento como grupo y la calidad del proyecto. A través de dicho cuestionario se pide a los alumnos que, durante el desarrollo del curso, evalúen cómo está funcionando. Los resultados obtenidos han permitido detectar problemas de funcionamiento de grupo en 5 de los 18 grupos que están cursando esta asignatura. A partir 
de la detección de estos problemas, los profesores de la asignatura han llevado a cabo sesiones de reflexión con estos grupos al objeto de resolver, en la medida de lo posible, las dificultados que éstos están teniendo en su funcionamiento.

\section{17 La competitividad como factor para la mejora del aprendizaje}

\section{Emilio Larrodé Pellicer}

El establecimiento de un sistema competitivo entre los estudiantes en el proceso de aprendizaje ha de provocar sin duda un cambio en el concepto de la metodología tradicional de adquisición de conocimiento, que normalmente se realiza mediante la superación de pruebas que se resuelven de forma individual en la mayoría de los casos. Los parámetros que normalmente rigen esta metodología son diferentes a los que aparecen en un entorno competitivo colaborativo, en donde otros factores relacionados con otras capacidades del carácter afloran, en un momento especialmente indicado para el autodiagnóstico del estudiante. Las nuevas tecnologías de comunicación, los avances en la informática y las innovaciones en el proceso de aprendizaje colaborativo activo, son los factores que se plantean en este estudio para mostrar la capacidad de mejora del aprendizaje a través de la incentivación de la competitividad.

V. 18 Los valores en la educación de maestros dentro del contexto de la ciudadanía europea: El conocimiento y la relación cultural y social en la educación. Introducción a una metodología adaptada a los créditos ECTS

\section{María Jesús Vicén Ferrando, Lidia Isabel Bañares Vázquez, Ma Pilar Moreno Rodríguez, José Mª Nasarre López}

Se pretende aunar la doble vertiente educativa, por un lado la formación de profesionales capacitados para el ejercicio de su función (educativa o de cualquier otro ámbito científico-técnico) pero sin olvidar la dimensión humana, personal y social en la que tiene lugar el desarrollo de la educación en valores, en especial, la formación ciudadana. El objetivo es formar una ciudadanía responsable capaz de enriquecer y, a su vez, enriquecerse valorando el intercambio y la convivencia con otros modos de pensar y actuar, fomentando la participación de las minorías étnicas presentes en la comunidad educativa, sin perder de vista el contexto multicultural actual. Se aborda como tema de trabajo la propuesta de Francesco Tonucci en su obra: "La ciudad de los niños" en la que hace responsable a toda la sociedad para transformar el ambiente urbano y cívico. Se consideran las aportaciones de este documento un material facilitador para el tratamiento del tema en la formación de maestros y ciudadanos europeos. Se considera la educación para una sociedad democrática como eje fundamental de la actual legisla- 


\section{Investigación Educativa e Innovación Docente en el proceso de Convergencia Europea}

ción escolar, se analiza el marco legal desde el punto de vista de los valores y la ciudadanía, especialmente la LOE y los Reales Decretos que la desarrollan, así como las propuestas para una Ley de educación para Aragón. Por último, se ha valorado el proyecto y se han hecho propuestas desde el equipo de trabajo en relación al alumnado, al profesorado y a los espacios.

\section{19 Metodologías activas para el aprendizaje del Derecho Civil}

Carlos Martínez de Aguirre Aldaz, Sofía de Salas Murillo, Mª Victoria Mayor del Hoyo, Marina Pérez Monge

Este grupo de innovación docente viene desarrollando desde el curso 2002-2003 un modelo de docencia que pretende lograr una implicación diaria y activa del alumno, utilizando diversos modos de presentación (expositivo, argumentación, diálogo, discusión y debate) y que se apoya en el trabajo que el alumno debe realizar fuera del aula. El sistema se basa inicialmente en la puesta a disposición de los alumnos de un cronograma que les permite conocer los temas que van a ser desarrollados cada semana y prepararlos previamente. El papel de las clases teóricas es: 1) Proporcionar al alumno las claves conceptuales de cada tema, que faciliten su comprensión y estudio posterior, presupone el estudio previo del tema por parte del alumno; 2) Resolver las dudas que haya suscitado en los alumnos ese estudio previo; 3 ) Desarrollar actividades relacionadas con ese tema, dirigidas a la obtención de las destrezas y habilidades básicas del jurista. Estas actividades consisten tanto en resolución de casos prácticos, como en la lectura, comprensión, análisis y redacción de documentos jurídicos de distinta naturaleza (leyes, sentencias, contratos, dictámenes...), que permitan al alumno familiarizarse con ellos. En este planteamiento es clave el esfuerzo que se exige al estudiante en relación a la preparación de las materias que van a ser abordadas en la clase teórica ya al desarrollo y resolución de las actividades propuestas. Esta metodología enlaza con las características esenciales del Espacio Europeo de Educación Superior.

\section{20 Metodologías activas y uso de las TICs en el área de Lingüística}

\section{María del Carmen Horno Chéliz, Iraide Ibarretxe Antuñano}

Los nuevos tiempos sociopolíticos y económicos demandan nuevas estrategias en el ámbito de la educación, de tal modo que los esquemas tradicionales han de sustituirse paulatinamente por una nueva forma de entender el aprendizaje, más activa por parte del estudiante, de naturaleza colaborativa y que exceda ampliamente los límites del aula. Para ello, desde el área de Lingüística se aplican metodologías de aprendizaje más activas, favoreciendo el uso de las TICs y promocionando el trabajo colaborativo. El propósito de este trabajo es resaltar los logros obteni- 
dos y las dificultades afrontadas. Las asignaturas a las que se aplican las nuevas estrategias son variadas, tanto en el tipo de materia como en el tipo de alumnos. Se comentan dos marcos bien diferentes: Una asignatura general e introductoria denominada "Lingüística" que es troncal y está adscrita a la Facultad de Educación para los alumnos de $1^{\circ}$ de Magisterio y una asignatura más especializada, denominada "Lenguaje y Comunicación", que es optativa de segundo ciclo, ofertada en la Facultad de Filosofía y Letras para los alumnos de Filología Hispánica de $4^{\circ}$ y $5^{\circ}$ curso.

V. 21 Metodologías activas en la dirección estratégica de la empresa: Implicación de los alumnos en el análisis estratégico de la Universidad

Ana F. Gargallo Castel, Francisco Javier Pérez Sanz

En el marco del Espacio Europeo de Educación Superior se desea adaptar las actividades y prácticas desarrolladas en la docencia con los alumnos dentro y fuera del aula con el objetivo de que los estudiantes alcancen nuevas competencias y habilidades que le sean útiles es su posterior desempeño profesional. Entre las prácticas con las que se ha buscado lograr implicación y compromiso de los alumnos dentro de la asignatura Dirección Estratégica de la Empresa, se encuentra el estudio aplicado del análisis estratégico a empresas con las que tengan una relación directa, entre ellas la Universidad. De este análisis estratégico se desprende que la Universidad española se encuentra actualmente con importantes cambios en el entorno a los cuales debe responder con una adecuada planificación estratégica que englobe todos sus ámbitos de actuación y que apoye el fortalecimiento de una estrategia de diferenciación basada en la calidad y la excelencia.

\section{22 Metodologías colaborativas, activas y cooperativas en el Máster de Medicina de Urgencia en Montaña}

Mª Antonia Nerín Rotger, José Ramón Morandeira García de la Cruz, Pablo Vela Condón, Pedro Vas Esteban, Manuel Vázquez Martínez, Germán Martín Gardel, Emilio Serrano García

El Master de Medicina de Urgencia en Montaña es un Estudio Propio de la Universidad de Zaragoza estructurado en 3 niveles progresivos y selectivos de dificultad, cuyo objetivo es conseguir que los sanitarios (médicos y enfermeros) que los cursan posean una formación acreditada en tres aspectos fundamentales: 1) Práctica de una medicina de urgencia de calidad a realizar sobre el terreno, 2) Capacidad física y conocimientos técnicos necesarios para poder acceder hasta el lugar donde se encuentra el accidentado por difícil que sea el acceso, y 3) Formación necesaria para colaborar con los equipos de rescate haciéndose cargo por completo de los aspectos sanitarios y colaborando eficazmente en las tareas de 


\section{Investigación Educativa e Innovación Docente en el proceso de Convergencia Europea}

rescate, con la finalidad de mejorar la oferta a los usuarios de los servicios que se prestan en la asistencia a los enfermos y accidentados en el medio natural y en la montaña. Para ello se ha enfatizado la formación multidisciplinar (medicina, deportes de montaña y rescate) y el aprendizaje sobre el terreno. Se han incrementando los talleres teórico-prácticos y las clases prácticas sobre el terreno y se ha reducido la carga docente basada en clases teóricas y magistrales de presencia física en el aula. La aplicación de metodologías colaborativas, activas y cooperativas es de gran utilidad para alcanzar los objetivos docentes del Máster. Estos métodos participativos, en los que los alumnos exponen sus conocimientos, propuestas, dudas y sugerencias, ayudan a aprender de otros y con otros, haciendo y resolviendo problemas, estimulando el desarrollo y el uso de destrezas de colaboración, comunicación e interacción -tan importantes en la atención urgente a los accidentados en medio difícil, hostil y aislado-, así como el desarrollo de estrategias sociales y cognitivas.

\section{23 Nueva metodología para un eficiente proceso enseñanza-aprendizaje}

\section{Juan José Cubero Marín}

Este trabajo presenta una nueva metodología para reducir el tiempo de ejecución del proceso enseñanza-aprendizaje, debido a que en muchos casos, el tiempo de dedicación al estudio por parte de los alumnos, supera con creces la jornada semanal oficialmente establecida. Por medio del principio de "aprender haciendo" y aplicando sistemáticamente "autoevaluaciones“, se puede conocer el grado de aprendizaje alcanzado a lo largo del proceso formativo, permitiendo aplicar propuestas de mejora en el curso que se está impartiendo. La eficiencia de esta metodología se consigue por medio de la personalización de la enseñanza, la participación de los alumnos, la disponibilidad del profesor y todo ello bajo el criterio de "aprender en clase". Así se puede conseguir la mejor utilización del tiempo de estudio de los alumnos y los más positivos resultados académicos. Esta metodología ya ha sido aplicada (pensando en el concepto ECTS) y se ha conseguido alcanzar un $80 \%$ de rendimiento del aprendizaje durante una hora lectiva, en lugar del $20 \%$ obtenido con los métodos tradicionales.

\section{24 Organización de prácticas externas en entornos de inclusión social para estudiantes de Magisterio}

Elias Vived Conte, Marta Liesa Orús, Miguel Ángel Ascaso Laliena, Pilar Otal Piedrafita, Natividad Murillo Ros, Teodora Agudo Valiente

Uno de los mayores retos de la educación actual en la enseñanza obligatoria es la atención a la diversidad de los alumnos, de todos los alumnos. La atención a la diversidad de necesidades educativas en el marco escolar requiere planteamientos metodológicos y organizativos que, a partir de las especiales dificultades de aprendizaje de algunos alumnos, procuren un mayor y 100 
mejor aprendizaje a todos. Pero la atención a la diversidad requiere una preparación psicológica y metodológica del profesorado. Y a esta preparación contribuye la organización de las prácticas externas. Se determinan diferentes situaciones reales que permiten un aprendizaje más práctico y conectado con la realidad. Entre otras situaciones prácticas impulsadas desde la Facultad pueden mencionarse las siguientes: a) Medios de comunicación y diversidad (Programa de radio "Los Bandidos de la Hoya"); b) Proyecto "Vida Independiente"; c) Taller de Creación Literaria; d) Taller de elaboración de material didáctico; e) Seminario de Educación Especial. Además, se definen otros entornos inclusivos para la realización de prácticas formativas de los estudiantes, en colaboración con entidades vinculadas a distintos colectivos de diversidad: Cruz Roja (inmigrantes), Fundación Secretariado Gitano (población gitana) y Coordinadora de Asociaciones de personas con discapacidad de Huesca (CADIS).

\section{25 Participación activa del estudiante en su aprendizaje, un modelo de cómo reflotar una asignatura optativa}

José María Agudo Valiente, Teodora Agudo Valiente

En un entorno tan cambiante como el actual, las titulaciones universitarias deben estar realizando de forma permanente una adecuación de sus contenidos a las necesidades del mercado laboral. Esta adecuación todavía se manifiesta más necesaria y permanente en el desarrollo del nivel de competencias transversales adquiridas por el alumno durante su paso por una asignatura optativa. Esto es debido a que en el proceso de selección por parte del alumno interviene su percepción de la misma. En este trabajo se describe el proceso y los medios utilizados para el caso concreto de una asignatura de la titulación de Ingeniería Técnica Industrial, así como los resultados obtenidos en la aceptación de la misma por parte de los alumnos.

\section{26 Procedimientos terapeúticos en Atención Primaria}

Amor Melguizo Béjar, Francisco Gómez Bernal, María José Orta Costa, Arantxa Royo Ochoa, Ignacio Andrés Bergareche, Rut Águeda Rubio Cavero, María José Lahoz Mustiense, José Felix Magdalena Belío, Natividad González Viejo, David Ibáñez Muñoz

Se plantean como objetivos didácticos que los alumnos conozcan el Centro de Salud y sus principales actividades y que tengan contacto real y aprendan a manejar los principales instrumentos empleados en el Centro de Salud. La metodología propuesta incluye 7 unidades didácticas, cada una de ellas a cargo de uno o dos monitores (médico y/o enfermera), con materiales reales. Los alumnos forman grupos de 6 para poder realizar la mayoría de las técnicas de forma activa, bien real o mediante simulación. Se recogen sugerencias para la mejora en años sucesivos. 


\section{27 Querer aprender, saber enseñar: Retos docentes}

\section{Chaime Marcuello Servós, Carmen Marcuello Servós}

Este trabajo plantea un análisis del nuevo marco de las "enseñanzas superiores oficiales" y su correlación con nuestra experiencia docente en el ámbito de las Ciencias Sociales, tanto del horizonte como de los "bajos fondos". Sabemos que hay una vieja distinción que destaca la diferencia entre el "decir" y el "hacer", entre la "teoría" y la "praxis". Por eso, resulta interesante contrastar el texto de la ley con la experiencia cotidiana. Esto es, ¿cuál es el alcance de la afirmación "la nueva organización de las enseñanzas universitarias responde no sólo a un cambio estructural sino que además impulsa un cambio en las metodologías docentes, que centra el objetivo en el proceso de aprendizaje del estudiante, en un contexto que se extiende ahora a lo largo de la vida" (RD.1393/2007)? ¿Cómo se traduce esto en la práctica? Especialmente, cuando durante los últimos años percibimos un incremento del número de estudiantes que "están" en el aula porque se matricularon y poco más. A la par que, más allá de algunas lumbreras, nos topamos con quienes en tutoría llegan a decir: "es que yo no sé estudiar" o "quiero aprender pero no sé qué hacer". Si la falta de base no sirve de excusa y la docencia ha de centrarse en el discente, quizá estamos ante un reto casi imposible de superar. Aquí se explorarán estas cuestiones a través de diferentes apartados incluídos una introducción y las conclusiones. En primer lugar, se plantea un diagnóstico de la situación. Segundo, se formulan las aporías a las que nos enfrentamos. En tercer lugar, se postulan unas alternativas dentro del escenario del Espacio Europeo de Educación Superior.

V. 28 Recursos docentes de las materias del área de Economía Aplicada en el Grado de Empresa a partir de la experiencia en las Escuelas Universitarias de Empresariales

Jorge Infante Díaz, Marta Melguizo Garde, Melania Mur Sangrá

La incorporación de la universidad española al Espacio Europeo de Educación Superior requiere la adaptación de los procesos de enseñanza-aprendizaje de Economía Aplicada. La experiencia obtenida en la impartición de dos materias, Economía Española y Fiscalidad de la Empresa, en la diplomatura de Ciencias Empresariales, impartida en dos centros distintos permite diseñar una programación docente en la que utilizando los recursos tradicionales, se incorporan nuevas fórmulas que permiten al alumno adquirir los recursos prácticos suficientes para actualizar a lo largo de su vida profesional los conocimientos básicos adquiridos. Por su contenido, las asignaturas se caracterizan por su actualidad. Son materias que exigen del profesor la utilización de recursos didácticos que no se pueden considerar como permanentes en el medio/largo plazo. Las transformaciones legales, económicas y políticas de la sociedad obligan a incorporar al pro- 
ceso de aprendizaje la utilización de TIC's para la obtención de información actualizada (noticias en la prensa económica, fuentes estadísticas, disposiciones legales, ...). Las clases prácticas, además de resolver casos, se transforman en clases para potenciar la adquisición de herramientas de aprendizaje autónomo y permanente. Con esta programación del curso se consigue que además de saber, también se incorpore al aprendizaje el saber hacer y el saber ser/estar.

\section{29 Reflexión general de una disciplina a partir del análisis de las competencias}

\section{Ana F. Gargallo Castel, Fco. Javier Pérez Sanz}

En el presente trabajo se realiza un análisis pormenorizado de la asignatura Dirección Estratégica de la Empresa I, de la actual Licenciatura en Ciencias del Trabajo en la Universidad de Zaragoza, utilizando para ello los conocimientos y las habilidades adquiridos en diversos cursos dirigidos al profesorado universitario por el Instituto de Ciencias de la Educación en la Universidad de Zaragoza. Se comienza con una contextualización de la disciplina en el marco de la titulación en la que se encuentra enmarcada, revisando los perfiles profesionales y las competencias, distinguiendo entre competencias genéricas o transversales y competencias específicas, para posteriormente centrar la atención en la disciplina y las relaciones entre los diferentes bloques temáticos. Por último se ofrece una reflexión metodológica sobre el desarrollo y la evaluación del proceso de enseñanza-aprendizaje destacando las ventajas del enfoque por competencias para la formación y la transformación del papel del profesor como acompañante, guía, orientador y facilitador del aprendizaje.

V. 30 Retos de la implantación del Espacio Europeo de Educación Superior: Aprendizaje para nuevas profesiones en Derecho civil con TICs y otras metodologías activas. Redacción de "Guías para contratar"

Jesús Delgado Echeverría, María Martínez Martínez, José Antonio Serrano García, Carmen Bayod López, Elena Bellod Fernández de Palencia, Miguel Luis Lacruz Mantecón, Aurora López Azcona, Alfredo Sánchez-Rubio García

Se pretende que los estudiantes de las asignaturas indicadas confeccionen "Guías para contratar". Se propone a los estudiantes, con la dirección de los profesores, elaborar guías para los ciudadanos españoles y extranjeros en las que se contengan los derechos y deberes de las partes intervinientes, las garantías que deben cumplirse, las consecuencias de los eventuales incumplimientos de las partes, las responsabilidades para las partes derivadas del contrato, las cláusulas específicas, los pactos especiales, la interpretación, etc. Se proyecta que se refieran únicamente a la regulación en Derecho civil español. Se propondrá la redacción tanto de Guías didácticas sobre contratos entre particulares como en contratos del ámbito del Derecho 


\title{
Investigación Educativa e Innovación Docente en el proceso de Convergencia Europea
}

de consumo. En concreto se pretende la confección de: "Guía sobre compraventa de vivienda"; "Guía sobre arrendamientos"; "Guía sobre préstamo hipotecario". La supervisión de los contenidos queda a cargo del equipo de profesores del Grupo de Innovación coordinado po el Dr. Delgado Echeverría desde hace más de quince años. Se trata de ofrecer a la sociedad con la máxima sencillez posible pero sin perder el rigor jurídico necesario, el contenido de los contratos típicos en el Derecho español. La labor del equipo de profesores precisará la labor tutorial de modo muy señalado con un seguimiento específico. Es un modo de llevar a cabo una clara transferencia a la sociedad de los resultados de la docencia y el trabajo en la Universidad.

V. 30 Trabajando la indagación científica. Desde las aulas de la Facultad de Educación a las aulas de Educación Primaria

\author{
Mª José Gil Quílez, Mª Begoña Martínez Peña, Milagros De la Gándara, José Miguel Calvo Hernández, Angel Cortés Gracia
}

El objetivo de este trabajo es conocer qué aspectos de la enseñanza por indagación utilizan los maestros en formación, en diversas experiencias de laboratorio y cuáles utilizan posteriormente, en la transposición de esas experiencias a los alumnos de Educación Primaria.

\section{31 Trabajos académicamente dirigidos (TADs) en el marco del EEES: Experiencia Docente}

\section{Concepción Aldea Chagoyen, Santiago Celma Pueyo, Nicolás Medrano Marqués}

Los trabajos académicamente dirigidos (TADs) permiten al alumno la adquisición de competencias y destrezas mediante la utilización de metodologías compatibles con el sistema ECTS en el ámbito del EEES. En este artículo se describe la experiencia de los autores como supervisores de TADs en tecnologías electrónicas. En particular, el análisis se centra en TADs relacionados con el diseño microelectrónico y la instrumentación inteligente incluidos en los currícula de la Licenciatura en Física de la Universidad de Zaragoza, su valoración y, especialmente, la posible exportación del modelo a los nuevos estudios de Grado de Ingenierías y Ciencias Experimentales. 


\section{HerRamientas de Resolución de CASOS Y PROYeCto Tutor}



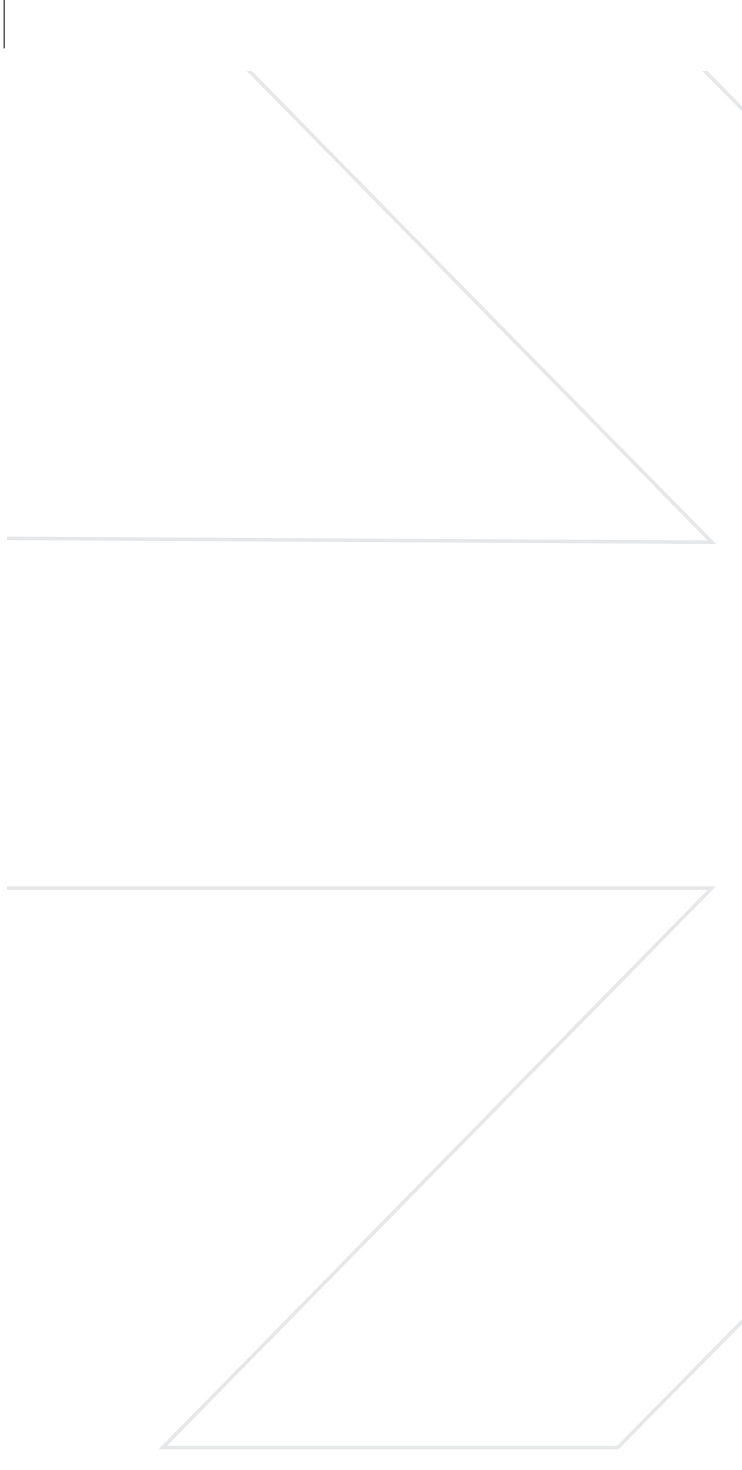


\title{
Investigación Educativa e Innovación Docente, en el proceso de Convergencia Europea
}

\author{
VI. 1 Aplicación de la metodología de aprendizaje basado en casos en Fisioterapia \\ Mª Ángeles Franco Sierra, Reyes Torres Sánchez, Ma Pilar Domínguez Oliván, Enrique Bardina Tremps, Celia López Tello
}

El estudio de un caso como método de aprendizaje activo proporciona a los estudiantes la oportunidad de aplicar conocimientos ya adquiridos, reflexionar y debatir con el resto de compañeros y profesores sobre diferentes problemas que se presentan y diseñar estrategias o propuestas encaminadas a la resolución de dichos problemas. La aplicación de esta metodología en Fisioterapia es idónea para la adquisición de competencias transversales, así como específicas profesionales y actitudinales. El diseño de esta actividad exige una planificación adecuada que se inicia con la presentación del caso, continúa con la formulación de preguntas y el diseño de actividades para el seguimiento y finaliza con la evaluación de la actividad tanto por parte de los profesores implicados como de los alumnos.

\section{2 Aplicación de una metodología activa a la enseñanza de la Electrónica Industrial}

\section{Jesús Sergio Artal Sevil, Joaquín Mur Amada, Jesús Letosa Fleta, Antonio Usón Sardaña}

Se describe de forma breve el ensayo de innovación docente llevado a cabo durante el curso 2006/07 en la asignatura de Electrónica Industrial. Dicha asignatura está adscrita al segundo curso de Ingeniería Técnica Industrial, especialidad Eléctricos, posee un único grupo de docencia con aproximadamente 160 alumnos. Es una asignatura anual, troncal y obligatoria con 10,5 créditos y para la mayoría de los estudiantes constituye el primer contacto con la materia en cuestión. El proyecto ha consistido en la aplicación de dos métodos de aprendizaje en la asignatura, basados en la resolución de problemas -aprendizaje cooperativo- y el problema del caso. La idea principal está basada en mantener los mismos objetivos de aprendizaje de conocimientos, que se evaluarán en un examen común, aunque a los estudiantes que se acogen a los nuevos procedimientos se les ofrece una evaluación "especial" en la que se tienen en consideración los resultados y calificaciones obtenidas en las diversas actividades. Cuando se efectúa la comparación de los porcentajes de aprobados en un examen de conocimientos común, los porcentajes son semejantes. Como conclusión se puede decir que se requieren más pruebas para establecer las posibles ventajas de este tipo de docencia en el contexto que nos ocupa. 


\section{3 Aprendizaje basado en problemas: Para actividad conjunta de Enfermería Geriátrica y Enfermería Psi-} quiátrica

Mª Dolores Guadalupe Azúa Blanco, Carmen Muro Baquero

El aprendizaje basado en problemas constituye una herramienta que ha demostrado una gran utilidad en el aprendizaje en las Ciencias de la Salud y encaja perfectamente en las metodologías docentes propuestas en el Espacio Europeo de Educación Superior, ya que favorece el aprendizaje activo del estudiante, enseña al estudiante a aprender y a integrar la teoría con la práctica. En este trabajo se recoge la experiencia diseñada conjuntamente en las asignaturas de Enfermería Geriátrica y Enfermería Psiquiátrica, en relación a la adquisición de algunas de las competencias que recoge el Libro Blanco de la titulación de Enfermería. Las competencias que deseamos trabajar son la 3, 9, 10, 16, 17, 26 y 27. En concreto la actividad que ha sido diseñada para los alumnos de estas asignaturas es realizar un plan de cuidados de enfermería a una persona ficticia, con el diagnóstico de Enfermedad de Alzheimer, con el objetivo de aplicar los conocimientos para la mejora de la calidad de vida.

\section{4 Aprendizaje basado en proyectos en asignaturas optativas de Física nuclear y de particulas}

Gloria Luzón Marco, José Manuel Carmona Martínez, Susana Cebrián Guajardo, Julio Morales Villasevil, José Ángel Villar Rivacoba

La resolución de problemas ha formado siempre parte de las estrategias de enseñanza en el campo de la Física. Sin embargo, la concepción actual del proceso de enseñanza-aprendizaje, exige ir un paso más allá. En el aprendizaje basado en problemas (PBL) un pequeño grupo se reune para analizar y resolver un problema complejo diseñado para el logro de ciertos objetivos de aprendizaje. Además del aprendizaje de los contenidos de la materia, los alumnos consiguen desarrollar, entre otras, habilidades de análisis y síntesis de información, competencias propias del trabajo colaborativo y un mayor compromiso con su proceso de aprendizaje. Se presentan experiencias piloto en asignaturas del Área de Física Atómica, Molecular y Nuclear impartidas en la Licenciatura de Física.

VI. 5 Aprendizaje basado en resolución de problemas por el sistema CASUS. Innovación docente y desarrollo de competencias en Medicina Legal Laboral dentro del Espacio Europeo de Educación Superior

Yolanda Casalod Lozano, Santiago Gascón Santos, Begoña Martínez Jarreta, Cecilia Sosa Misuraca, Carolina Núñez Domingo, Miriam Baeta Bafalluy, Miguel Bolea García 
Fomentar el aprendizaje continuado, la innovación docente, la calidad y la excelencia son objetivos fundamentales en el nuevo Espacio Europeo de Educación Superior. El aprendizaje basado en resolución de problemas constituye uno de los métodos que ha demostrado mayor eficacia en la consecución de objetivos docentes y en el desarrollo de competencias y habilidades clínicas. El uso de herramientas docentes "on line" que faciliten la incorporación de estos métodos y el autoaprendizaje tutelado no está muy extendido en el medio universitario español por las dificultades que entraña su desarrollo y validación. Pero han demostrado ser un buen instrumento de apoyo docente y un soporte de actividades comunes de formación en un contexto internacional. A fin de buscar esta convergencia en métodos docentes en Medicina Forense y Laboral en la Europa comunitaria, se puso en marcha una iniciativa dentro de la Cátedra de Medicina Legal de la Universidad de Zaragoza, integrada en el Proyecto NetWoRM financiado por la Unión Europea liderado por la Universidad Ludwig Maximilian de Munich desde1999. Este proyecto ha demostrado ser muy eficaz al permitir la creación y validación de herramientas docentes que completan y mejoran la formación tradicional que la Medicina del Trabajo ofrece a los alumnos de la licenciatura de Medicina. Los resultados obtenidos tras la incorporación del sistema CASUS demostraron que los estudiantes españoles que trabajan resolviendo los casos validados, comparados con los estudiantes de otros países de Europa, presentan un interés más alto. El Real Decreto de enfermedades profesionales publicado en España compromete a los médicos del sistema público de salud a la notificación de enfermedades profesionales. La formación en Medicina del Trabajo adquiere por ello una importancia indudable en el currículum de la licenciatura de Medicina. El sistema CASUS otorga la posibilidad de completar y mejorar la formación tradicional de la Medicina del Trabajo aprovechando los recursos que la red ofrece y las ventajas del aprendizaje basado en la resolución de problemas.

\section{6 Aprendizaje de Estadística a través de casos prácticos}

\section{Clemente A. Campos y Sáez}

Se presenta una experiencia de aprendizaje de diversas técnicas estadísticas de uso e interés en la Ingeniería basadas en el análisis y resolución de problemas y casos prácticos diversos relativos a diferentes ámbitos en la tecnología. En la enseñanza y aprendizaje de la Estadística en la Ingeniería se usa un libro de carácter aplicado con amplia difusión internacional y se realizan diversas resoluciones de casos reales con ayuda de programas de ordenador. Se intenta así mejorar aspectos que inciden en la calidad de la enseñanza y el aprendizaje (como son la motivación, los modos de aprendizaje, las metas y objetivos que los estudiantes se plantean) para así potenciar los factores que condicionan positivamente el aprendizaje, al colocar a los estudiantes ante casos y problemas reales referentes al mundo de la Ingeniería. Para trabajar con datos reales se tienen en cuenta los conocimientos que los estudiantes poseen de informática (como por ejemplo los programas EXCEL, MATLAB o MAPLE). 


\section{Investigación Educativa e Innovación Docente en el proceso de Convergencia Europea}

VI. 7 Construcción y resolución de problemas en el laboratorio como estrategia para la adquisición de competencias prácticas durante la formación de maestros

Ángel Luis Cortés Gracia, Milagros de la Gándara Gómez

La experiencia presentada ha sido aplicada en los últimos cursos en la asignatura Laboratorio Científico Escolar, de la especialidad de Maestro de Educación Primaria. Está enfocada como pequeñas investigaciones en las que el alumnado debe obtener respuestas a un problema (planteado por los estudiantes en clase, con ayuda del profesor) por medio de actividades prácticas de laboratorio. Este enfoque didáctico de planteamiento y resolución de problemas consta de dos partes diseñadas inicialmente con propósitos diferentes. La primera se plantea como una actividad aparentemente autónoma, para que se identifiquen problemas a partir de fenómenos de la vida cotidiana y emerjan ideas diversas (principios que aplican, hipótesis, creencias, líneas de argumentación, etc.). La segunda parte se diseña como un contexto donde se reflexiona y actúa dentro de un tipo de indagación dirigida, con objeto de aprender un modelo de ciencia caracterizada por la interacción explícita entre los enunciados teóricos que conocen y los procedimientos que ponen en juego a la hora de emitir juicios sobre los fenómenos estudiados. La aplicación de esta propuesta muestra las posibilidades didácticas de la misma, a la vez que pone de manifiesto las distintas dificultades que encuentran los estudiantes al enfrentarse a un modelo docente "no tradicional".

\section{8 El aprendizaje basado en casos clínicos: Del estudio y la discusión a la publicación}

Luis Miguel Ferrer Mayayo, Delia Lacasta Lozano, Antonio Fernández Casasnovas, Tomás Conde Ayuda, Araceli Loste Montoya, Juan José Ramos Antón

La mejora de la innovación docente implica una transformación profunda en los modos de concebir, planificar y llevar a la práctica la enseñanza y el aprendizaje. En esta línea, un grupo de profesores de la Facultad de Veterinaria iniciamos una experiencia a lo largo del año 2007, encaminada a mejorar el aprendizaje a través de la publicación de casos clínicos en la revista Albéitar. Se entiende la publicación como un medio y no como un fin. Esta metodología contribuye al desarrollo de competencias genéricas, a potenciar la figura del profesor-tutor y a acercar la Universidad a la sociedad. 


\section{Investigación Educativa e Innovación Docente en el proceso de Convergencia Europea}

\section{9 El aprendizaje basado en casos clínicos: Estudio, discusión y exposición pública}

Juan José Ramos Antón, Luis Miguel Ferrer Mayayo, Delia Lacasta Lozano, Mª Teresa Verde Arribas, Aurora Ortín Pérez, Luis Figueras Ara, $\mathrm{M}^{\mathrm{a}}$ Carmen Marca Andrés

En la línea marcada por el proceso de convergencia europea, se propone avanzar en el procedimiento basado en la discusión de casos clínicos reales mediante su difusión en un curso en el que son los propios alumnos quienes presentan los casos estudiados. Este paso adelante en la metodología del caso contribuye a potenciar la figura del profesor-tutor, el trabajo en equipo y la integración en el EEES. Las presentaciones realizadas superaban ampliamente las realizadas por los alumnos semanas o meses antes, en la sesión semanal de prácticas, tanto en la forma (diseño del Power Point y exposición oral) como en el fondo (discusión del caso), siendo conscientes ellos mismos del progreso realizado y valorando muy positivamente las presentaciones de sus compañeros. Asimismo, mejoró la interacción alumno-profesor, el clima de trabajo, la implicación de los estudiantes, el rendimiento del alumnado y el autoaprendizaje.

VI. $10 \mathrm{El}$ aprendizaje basado en problemas en la sala de demostraciones de la asignatura de Enfermería Fundamental: Experiencia piloto

Ana María Lample Lacasa, Pedro José Satústegui Dordá, Carlota Rodrigo Luna, María Isabel Herrando Rodrigo, José Antonio Tobajas Asensio

Un grupo de profesores motivados por la adecuación del Plan de Estudios de Enfermería al Espacio Europeo de Educación superior, han puesto en marcha el uso del Aprendizaje Basado en Problemas en el desarrollo de las clases prácticas en la sala de demostraciones de la asignatura de Enfermería Fundamental. En el trabajo se reflejan los resultados del estudio piloto, donde se aprecia la buena aceptación y valoración del método por los alumnos.

\section{11 El profesor tutor en la Licenciatura de Veterinaria: Variaciones y modificaciones a lo largo de la Li- cenciatura}

Ana Isabel Alcalde Herrero, Ma Pilar Arruebo Loshuertos, José Emilio Mesonero Gutiérrez, Mª Divina Murillo López de Silanes, Mª Cristina Barrios Adán

El Proyecto Tutor en la Licenciatura de Veterinaria se inició en el curso 2004-2005, con unos planteamientos específicos en función de la demandas para el desarrollo profesional y de la heterogeneidad poblacional presente entre el alumnado. En 


\section{Investigación Educativa e Innovación Docente en el proceso de Convergencia Europea}

su etapa inicial, con los nuevos alumnos universitarios, el proyecto se centró en la integración universitaria, la estimulación de la autonomía en el aprendizaje y la mejora del rendimiento académico de los estudiantes. Para ello se potenció la comunicación alumno-profesor, la formación de grupos de trabajo y la reflexión y análisis de los métodos de estudio y trabajo. En la facultad de Veterinaria, la figura del profesor tutor no se ha restringido a los alumnos de $1^{\circ}$ curso de la licenciatura, sino que se ha extendido a lo largo de la misma. Esto ha permitido adaptar el funcionamiento del Programa Tutor a los diferentes niveles educativos y a las dificultades y necesidades que se plantean. De esta manera, de las necesidades adaptativas y académicas iniciales se ha pasado a nuevas necesidades organizativas y profesionales, conforme se ha ido adquiriendo una formación personal y profesional. Ello ha permitido desarrollar una acción tutorial singular en función de la propia evolución del alumnado.

\section{12 El programa Tutor de la Facultad de Veterinaria: Experiencia comparada entre diferentes licenciaturas}

Jose Emilio Mesonero Gutiérrez, Jesús García Sánchez, Rafael Pagán Tomás, Maa Pilar Arruebo Loshuertos, Mª Cristina Barrios Adán

En el momento actual se persigue una mejora de la calidad de la enseñanza universitaria que puede conseguirse actuando sobre varios aspectos. Uno de ellos es la estimulación de la autonomía en el aprendizaje y la mejora del rendimiento académico de los alumnos, en el que se ha puesto un especial énfasis durante los últimos años. El Proyecto Tutor de la Universidad de Zaragoza, con la figura del profesor tutor, pretende incidir en dicha mejora académica. En la Facultad de Veterinaria, se implantó el Proyecto Tutor en el curso 2004-2005, primero en la Licenciatura de Veterinaria y posteriormente en la Licenciatura de Ciencia y Tecnología de los alimentos. Aunque breve, la experiencia acumulada en estas dos licenciaturas, una de las cuales es solamente de segundo ciclo, ha permitido observar, analizar y comparar las diferencias existentes entre las necesidades y demandas de un estudiante de primer ciclo, recién llegado al sistema universitario, con las de un estudiante que comienza una licenciatura de segundo ciclo. Así, las necesidades de apoyo académico que tiene un estudiante de primer ciclo son sustituidas por requerimientos de formación encaminados a la orientación y desempeño profesional.

\section{13 El proyecto Tutor en Biblioteconomía y Documentación}

Pilar Gay Molins, Mª del Carmen Agustín Lacruz, Esperanza Velasco de la Peña, Luisa Orera Orera, José Antonio Salvador Oliván, Ana I. Sánchez Casabón, $M^{a}$ Isabel Ubieto Artur 
Los estudios de Biblioteconomía y Documentación participan dentro del Programa Tutor desde 2006. El objetivo general y los objetivos específicos son los propios de dicho programa en la Universidad de Zaragoza. Ente los principales resultados destaca el interés de los participantes y la alta valoración que reflejan las encuestas. No obstante, la primera promoción de egresados todavía está finalizando su proceso formativo. Se concluye que Programa Tutor en el Área de Biblioteconomía y Documentación es una herramienta de intervención didáctica idónea para el desarrollo de los procesos de enseñanza-aprendizaje, tanto para los estudiantes como para los profesores. Para los estudiantes, porque se muestran motivados y se implican en las tutorías; tienen un papel activo en las reuniones; conocen la utilidad de las asignaturas; mejoran el conocimiento inicial que tienen de su propia titulación, de las salidas profesionales y especialidades; incrementan su participación en actividades académicas y culturales; se muestran más autónomos y mejoran en sus resultados académicos. Para los tutores, el Proyecto permite: a) Mantener contacto directo con los alumnos; b) Conocer las dificultades a las que se enfrentan los alumnos y contribuir a la búsqueda de las soluciones y; c) Establecer relaciones de colaboración con otros profesores para armonizar los contenidos curriculares y los materiales docentes.

\section{14 Estrategias para despertar el interés del alumno por la investigación}

\section{Ma Concepción Junquera Escribano, Carmen Martínez Ciriano, Irene Cantarereo Carmona}

En el área biomédica los profesores universitarios tienen una doble vertiente como docentes e investigadores. Generalmente sólo se integra la labor investigadora en la docencia del tercer ciclo. Es un buen objetivo docente que los alumnos de grado o licenciatura conozcan qué es la investigación. Para ello se proponen seminarios en grupos reducidos de alumnos a los que se plantea un problema de investigación concreto, motivándoles para que contribuyan con su aporte personal y tras discusión en grupo, al desarrollo de la investigación.

VI. 15 Experiencia de utilización de metodologías activas en la docencia de Genética para la adaptación al EEES

Pilar Zaragoza Fernández, Clementina Rodellar Penella, Rosario Osta Pinzolas, Inmaculada Martín Burriel 


\section{Investigación Educativa e Innovación Docente en el proceso de Convergencia Europea}

Se exponen las experiencias realizadas en las asignaturas del Área de Genética basadas en el aprendizaje en problemas y resolución de casos y proyectos, como método de enseñanza-aprendizaje basado en el planteamiento de un problema y la búsqueda de la información necesaria para la resolución del mismo.

VI. 16 Experiencia en la aplicación del método del caso en la asignatura de Dermatología (Licenciatura de Veterinaria): Resultados y conclusiones

Laura Navarro, María Teresa Verde, Juan José Ramos, Luis Miguel Ferrer, Araceli Loste, Aurora Ortín, Antonio Fernández Casasnovas, Joaquín Pastor

Aprovechando la implantación del nuevo Plan de Estudios en la Licenciatura de Veterinaria y con la aparición de asignaturas optativas en los últimos cursos, como es el caso de la Dermatología de animales de compañía en $5^{a}$ curso, se inició la experiencia del aprendizaje basado en la aplicación de metodologías activas. El objetivo del proyecto se basó en la aplicación del método del caso para fomentar competencias y habilidades en los alumnos de gran utilidad en el ámbito profesional. A lo largo del cuatrimestre en el que se imparte la asignatura, el alumno individualmente tuvo que resolver varios casos clínicos en los que se representaban las enfermedades dermatológicas más frecuentes que se manifiestan en los animales de compañía. Mediante este método se expone al alumno a situaciones reales con las que tendrá que enfrentarse en su vida profesional. Además de potenciar el autoaprendizaje, la capacidad para resolver problemas, la toma de decisiones, la aproximación al diagnóstico clínico; también se potenciaron competencias transversales tan importantes como el desarrollo de habilidades sociales, de comunicación oral, etc. El resultado fue que los alumnos al final de la asignatura habían aprendido a aplicar, de forma automática, la sistemática básica que se debe seguir ante cualquier problema clínico que afecte a la piel de los animales domésticos. Con ello, aunque no tengan un elevado conocimiento de todas las enfermedades posibles, serán capaces en el futuro de llegar a aproximarse al diagnóstico definitivo.

VI. 17 Experiencias basadas en la realización de proyectos para la implantación de metodologías docentes activas en Ingeniería Industrial

Javier Domínguez Hernández, Enrique Cano Suñén, Beatriz Rodríguez Soria, José María Pérez Bella

Se presenta una experiencia docente de aplicación de metodologías activas de enseñanza-aprendizaje, desarrollada entre los años 1995-2003 en una asignatura troncal de $4^{\circ}$ curso, de la titulación de Ingeniería Industrial de la Universidad de 
Zaragoza. La impartición de la asignatura se fundamenta en la realización de proyectos por parte del alumno y se relaciona con el actual marco definido por el EEES, potenciando el desarrollo de competencias con una enseñanza práctica mediante un mayor grado de trabajo autónomo y un seguimiento personalizado por parte del profesorado. Se describen entre otros, innovadores parámetros docentes, tutoriales, de evaluación y de desarrollo temporal sobre los cuales se llevó a cabo la experiencia, con la singularidad que incluye su aplicación sobre una asignatura troncal de carácter generalista y gran número de alumnos, a través de una enseñanza, seguimiento y evaluación colegiadas por parte de todos los profesores del Área de Conocimiento. El documento concluye con una exposición crítica de resultados académicos y valoraciones sobre la experiencia proyectual realizada, así como un análisis de potencialidades y dificultades observadas, que culminan en la finalización de la experiencia docente y el regreso a metodologías tradicionales, debido principalmente a la falta de adaptación de la actual organización de centros y estudios a las nuevas exigencias para llevar a cabo dichas metodologías activas.

\section{18 Guía docente de la asignatura Modelos Estocásticos en Ingeniería y su adaptación al Espacio Europeo} de Educación Superior

\section{Carmen Galé}

De acuerdo con el nuevo marco del Espacio Europeo de Educación Superior se ha elaborado la guía docente de la asignatura Modelos Estocásticos en Ingeniería. Esta asignatura es optativa de segundo ciclo en la titulación de Ingeniería Informática. El tamaño del grupo de estudiantes que cursa esta asignatura ha permitido, en los últimos tres cursos académicos, implementar un sistema de enseñanza-aprendizaje que implica la introducción de nuevas metodologías docentes y sistemas de evaluación continua. En particular, se ha trabajado especialmente con ideas del aprendizaje basado en proyectos ("Project Based Learning") adaptado a una asignatura que en la actualidad se imparte de modo presencial. Con esta nueva metodología se pretende promover un aprendizaje autónomo, responsable y colaborativo de los estudiantes. El desarrollo de la guía ha permitido centrar los objetivos y las competecias profesionales que deben adquirir los alumnos en la asignatura, valorar el tiempo de trabajo de los mismos y realizar una primera aproximación de los créditos ECTS de la asignatura.

\section{19 La gestión diaria del contrato de trabajo en los despachos profesionales de graduados sociales}

José Jesús de Val Arnal, Eva María Muñoz Martínez 


\title{
Investigación Educativa e Innovación Docente en el proceso de Convergencia Europea
}

Se trata de establecer una asignatura eminentemente práctica que, sobre la base teórica del conocimiento de la regulación contractual del trabajo por cuenta ajena, prepare a los futuros profesionales para la gestión diaria de las diversas modalidades contractuales, la utilización de las herramientas que la Administración del Estado ha dispuesto, el sistema RED y contrat@, así como los programas informáticos que existen en el mercado para ayudar en la labor diaria.

\section{20 La metodología del caso en Organización de Empresas}

\author{
Pedro Sánchez Sellero
}

El método del caso se estudia en el marco del resto de metodologías activas para ser aplicado a la docencia universitaria del área de Organización de Empresas. El estudio de casos puede complementarse con el aprendizaje cooperativo, con el trabajo en equipo y con las nuevas tecnologías. Además, la evaluación debe recoger el aprendizaje del alumnado en los casos tratados. Por otra parte, se analizan las experiencias docentes en las que se utilizan estas estrategias de enseñanza aprendizaje, en base a la valoración del alumnado y al logro de los objetivos de la asignatura. Los resultados de este trabajo muestran que siguiendo las citadas estrategias se consigue mejorar la motivación, acercar al alumnado a la realidad empresarial, ser consciente de cómo funciona el equipo de trabajo para estar preparado para participar en él, así como familiarizarse con el uso de las nuevas tecnologías. Las prácticas docentes objeto de reflexión se encuadran dentro de un proyecto de innovación docente PIIDUZ 2007.

\section{21 Metodologías activas para el estudio del Derecho Internacional: Ejercicio e-Moot Court}

\author{
Yolanda Gamarra Chopo, Alejandra Vicente Carracedo
}

Exposición de un caso práctico (caso Vukovar) siguiendo la simulación de un juicio penal internacional (Tribunal Penal Internacional para la antigua Yugoslavia) recurriendo a distintas técnicas metodológicas: conferencia especializada, proyección de película sobre el caso, reparto de roles (Defensa, Fiscalía y Testigos) y vista. Se trata de adquirir destrezas y habilidades en el ámbito del Derecho Internacional humanitario. 


\section{Conclusiones}




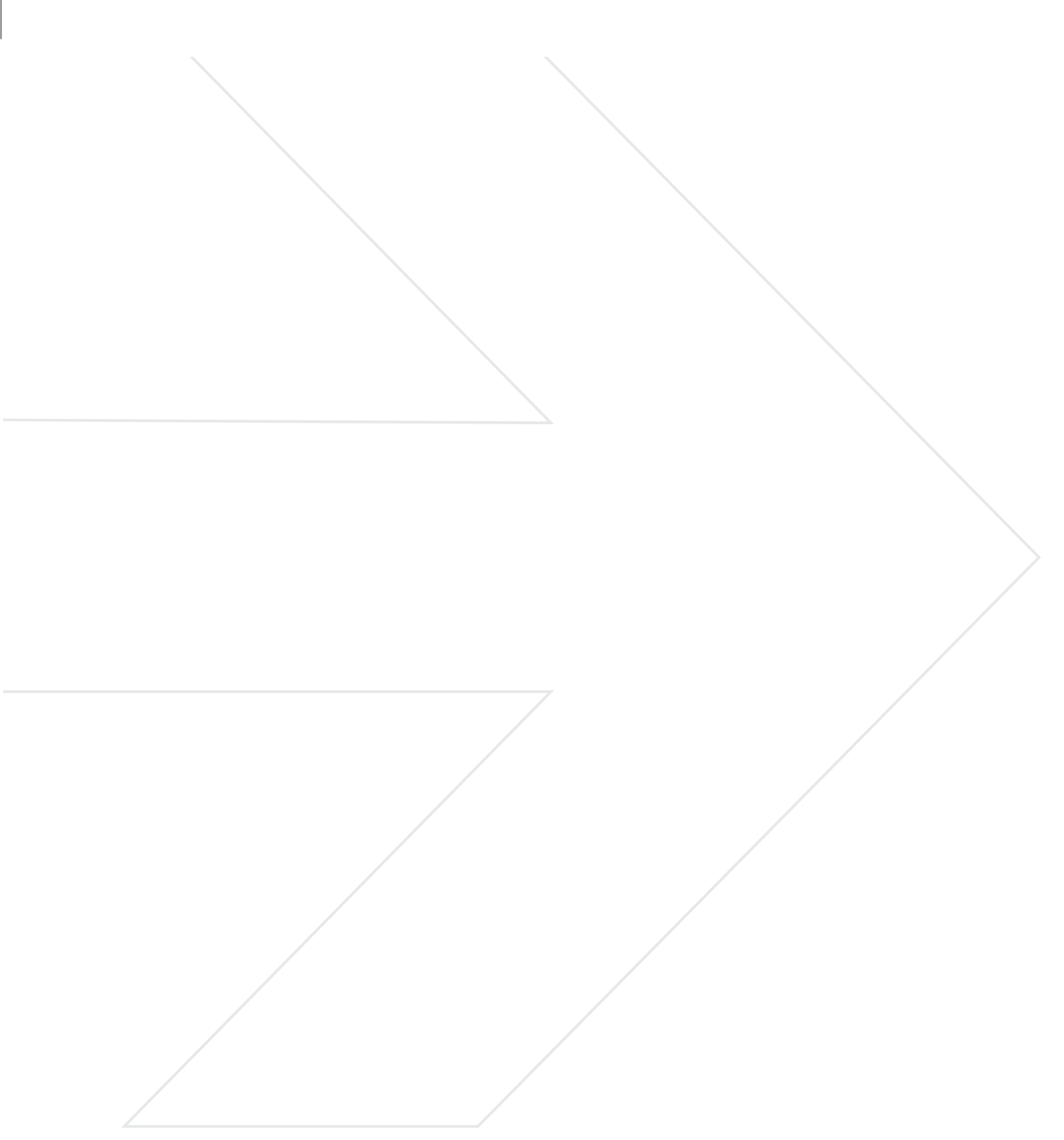


Más de la cuarta parte de los profesores de la Universidad de Zaragoza han participado activamente en las II Jornadas de Investigación Educativa e Innovación Docente en el proceso de Convergencia Europea en las que se ha confirmado el compromiso del cuerpo docente de esta Universidad con una docencia de calidad y al servicio del estudiante.

Durante dos días se compartieron intensamente modelos, experiencias y herramientas, aprendiendo nuevas técnicas y constatando la riqueza de criterios y la unidad de esfuerzos en un amplísimo abanico interdisciplinar.

Las conclusiones alcanzadas se pueden agrupar en siete apartados: Diseño curricular y desarrollo de competencias, autoaprendizaje y metodologías activas, tecnologías aplicadas al aprendizaje activo, aprendizaje cooperativo, evaluación, reconocimientos y retos y recomendaciones.

\section{Diseño curricular y desarrollo de competencias}

Los trabajos presentados confirman el apoyo generalizado al nuevo modelo de formación preconizado en el proceso de Bolonia. En particular, el aprendizaje centrado en el alumno, la preparación para aprender a lo largo de la vida y el desarrollo curricular basado en competencias son técnicas valoradas de forma muy positiva por alumnos, empleadores y profesores. Se constata que la Universidad de Zaragoza se encuentra efectivamente inmersa en un vasto proceso de diseño curricular con vistas a alcanzar en un tiempo record las especificaciones del nuevo modelo.

En el campo del desarrollo curricular, se resaltó la importancia de atender a las competencias genéricas y no sólo a las específicas. En particular, las competencias genéricas más resaltadas fueron la responsabilidad social, la comunicación y el conocimiento de idiomas y, en un segundo grupo, la colaboración, la interdisciplinariedad y la atención al autoconcepto y la imagen profesional del estudiante. Se constata que, aunque las competencias genéricas están bien atendidas en los postgrados, es necesario reforzar su aprendizaje en las titulaciones de grado.

\section{Autoaprendizaje y metodologías activas}

Se aprecia un avance generalizado en la comprensión del autoaprendizaje como paradigma básico de la formación universitaria, en el que se utiliza un amplio elenco de nuevos métodos, prácticas y modelos, en particular los "métodos activos", mapas conceptuales, portafolios, casos, problemas y proyectos.

Las metodologías activas son uno de los grandes centros de interés de los profesores implicados en la innovación docente. Se puede afirmar que "aprender haciendo" se ha convertido en una de las claves del aprendizaje en la Universidad de Zaragoza en particular, y del Espacio Europeo de Educación Superior en general. 


\section{Investigación Educativa e Innovación Docente en el proceso de Convergencia Europea}

Se pudo constatar como el trabajo con casos y el desarrollo de proyectos se aplica a una amplísima variedad de disciplinas, en las que esta metodología resulta fundamental para reforzar las competencias profesionales, ayudando a acercar la realidad al aula y promoviendo con notable éxito la motivación de los estudiantes.

\section{Tecnologías aplicadas al aprendizaje activo}

En la Universidad de Zaragoza se está realizando una intensa actividad en la aplicación de las tecnologías para facilitar el aprendizaje activo, actividad que va más allá de las experiencias más tradicionales que se limitan a compartir documentos y comunicaciones. Entre las tecnologías innovadoras, destacan el desarrollo de laboratorios virtuales, simuladores, webquest y herramientas de aprendizaje dirigido.

Junto a las aplicaciones orientadas a promover la pedagogía activa, destacan también los cursos en línea, que se caracterizan por su fuerte orientación internacional y la utilización cada vez mayor tanto de recursos audiovisuales y multimedia, como de las nuevas herramientas de creación de comunidad (web 2.0) en asignaturas y áreas, entre ellas, por ejemplo, el uso de wikis. Los cursos en línea han demostrado ser una herramienta fundamental para promover la cooperación entre estudiantes y profesores, creando espacios en los que es posible compartir documentos y comunicarse de forma estructurada, a la vez que acceder a recursos de aprendizaje activo y colaborativo.

En definitiva, se constató una vez más que las tecnologías permiten superar las limitaciones de otros recursos para facilitar tanto un trabajo más activo y comprehensivo por parte del estudiante, como una mayor eficacia y eficiencia en el trabajo de los profesores.

\section{Aprendizaje cooperativo}

Tanto los alumnos como los profesores realizan una valoración muy positiva de las iniciativas relacionadas con aprendizajes cooperativos, porque facilitan un aprendizaje más significativo en el que se potencia la transferencia de competencias tanto genéricas como específicas. El aprendizaje cooperativo es fundamental en muchas de las metodologías activas (casos, proyectos, etc.) y también es central en el uso de algunas de las tecnologías de la información y la comunicación más novedosas, a las que se denomina genéricamente Web 2.0. Se señaló de forma muy especial que la colaboración internacional entre alumnos y profesores de diversos países constituye una experiencia especialmente enriquecedora.

Sin embargo, el aprendizaje colaborativo no puede desarrollarse bien dentro de esquemas tradicionales, sino que requiere la integración programada de las actividades y las metodologías cooperativas dentro del diseño curricular completo y debe abordarse 


\section{Investigación Educativa e Innovación Docente en el proceso de Convergencia Europea}

dentro de la programación de espacios y tiempos. Por otra parte, es fundamental que los profesores den ejemplo de colaboración a través de una estrecha cooperación y coordinación en los asuntos de interés de los estudiantes.

\section{Evaluación}

En el ámbito de la evaluación, se constata la introducción generalizada y sostenida de nuevas prácticas y modelos, notablemente la evaluación continua y procedimientos innovadores como los mapas conceptuales y portafolios.

Los retos de la evaluación se presentan en ámbitos emergentes como la medida de la eficacia de los procesos de innovación docente -tanto en lo que se refiere a satisfacción como a resultados e impactos- así como de su eficiencia.

Se considera fundamental abordar también la evaluación de procesos poco considerados anteriormente, en particular la adquisición de competencias genéricas.

\section{Reconocimientos}

El profesorado otorgó su reconocimiento a la labor del Instituto de Ciencias de la Educación (ICE), así como a las iniciativas de promoción de la innovación docente universitaria desarrolladas por esta institución y por el equipo rectoral, que han resultado ser un apoyo y un estímulo fundamental. Entre las iniciativas realizadas se destacaron las actividades de formación, los diferentes programas para proyectos de innovación docente y el impacto muy positivo del Proyecto Tutor, muy valorado por estudiantes y profesores. Finalmente, se destacó también el éxito de la biblioteca universitaria como centro de recursos para el aprendizaje y la enseñanza.

\section{Retos y recomendaciones}

En el ámbito de los retos y las recomendaciones de alcance general, los docentes constataron el grave problema de administrar la carga de trabajo para los estudiantes y profesores implicados en procesos de innovación y la necesidad de disminuir la incertidumbre inherente a los grandes procesos de cambio, de los que la convergencia europea no es sino otro ejemplo.

Constatado su importante coste personal, resulta fundamental que los profesores y alumnos implicados en los procesos de innovación se vean acompañados, apoyados y reconocidos.

Un aspecto de este reconocimiento debería ser el incremento de los medios disponibles, que, en muchos centros, son todavía escasos. En particular, hay que acomodar los espacios docentes a disposiciones más flexibles que promuevan el trabajo cooperativo y activo y seguir dotando a estudiantes y enseñantes con mejores herramientas informáticas. 


\section{Investigación Educativa e Innovación Docente en el proceso de Convergencia Europea}

Pero el reconocimiento debe ir más allá de proporcionar medios: El diseño e implantación de un plan nacional o autonómico de innovación docente, con recursos suficientes y un reconocimiento del coste de un trabajo docente de calidad, supondría un mensaje inequívoco de apuesta integral institucional por la innovación docente. En definitiva, los profesores de la Universidad de Zaragoza solicitan que de los esfuerzos individuales e institucionales aislados se pase a una auténtica política general de la universidad, que sea visible como tal.

Por otra parte, esa nueva política debe considerar de una manera especial a los que más dificultades tienen en sus procesos de aprendizaje. Es necesario, especialmente, seguir luchando contra el fracaso estudiantil en los primeros cursos y contra el alargamiento del tiempo de terminación de los estudios. Además, se constató la necesidad de crear un programa específico para aquellos estudiantes en una situación difícil por arrastrar numerosos cursos y asignaturas.

Por fin, se sugirió reforzar la comunicación interna de los profesores mediante iniciativas como una página web con experiencias, ejemplos significativos, preguntas y dudas y una revista electrónica. Estas herramientas pueden ayudar a proporcionar continuidad durante el año a estas Jornadas, que han demostrado ser un importante catalizador de la renovación docente en nuestra Universidad. 
Material Docente 

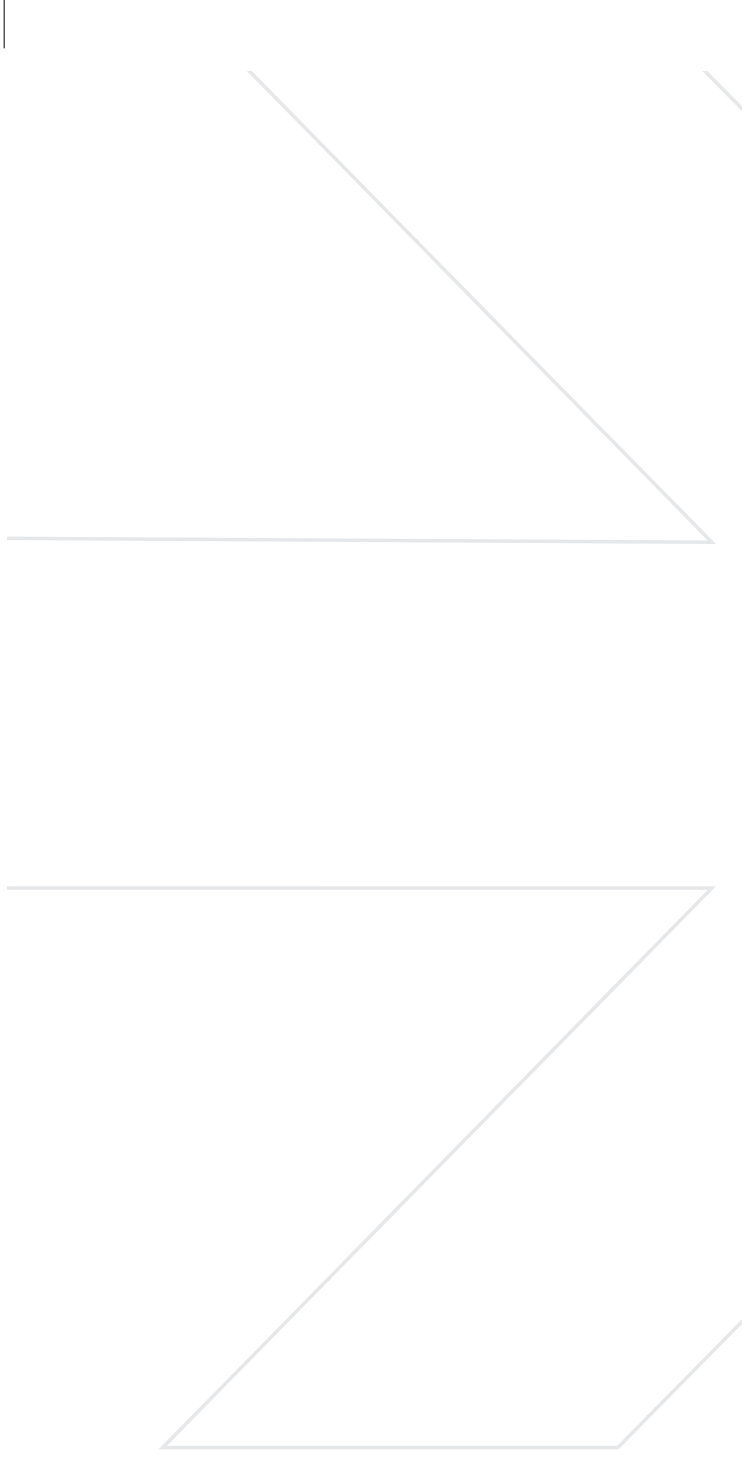


\section{Exposición de Material y Recursos Docentes}

\section{Esperanza Velasco de la Peña, Mª del Carmen Agustín Lacruz, Fernando Cruz Bello}

El objetivo de esta exposición es mostrar la riqueza y variedad de los recursos didácticos que emplean los profesores de la Universidad de Zaragoza en sus actividades docentes. En concreto, se pretende visibilizar y difundir tanto los materiales como las herramientas y los recursos que, dependiendo de las materias o titulaciones, se utilizan como soporte y apoyo de diferentes prácticas educativas.

Los materiales y recursos docentes están organizados en 7 apartados distintos:

- Asignaturas y material en el Anillo Digital Docente

- Webs docentes

- Monografías y artículos en soporte papel

- Material docente en soporte óptico

- Material docente en ficheros informáticos

- Posters

- Apuntes 


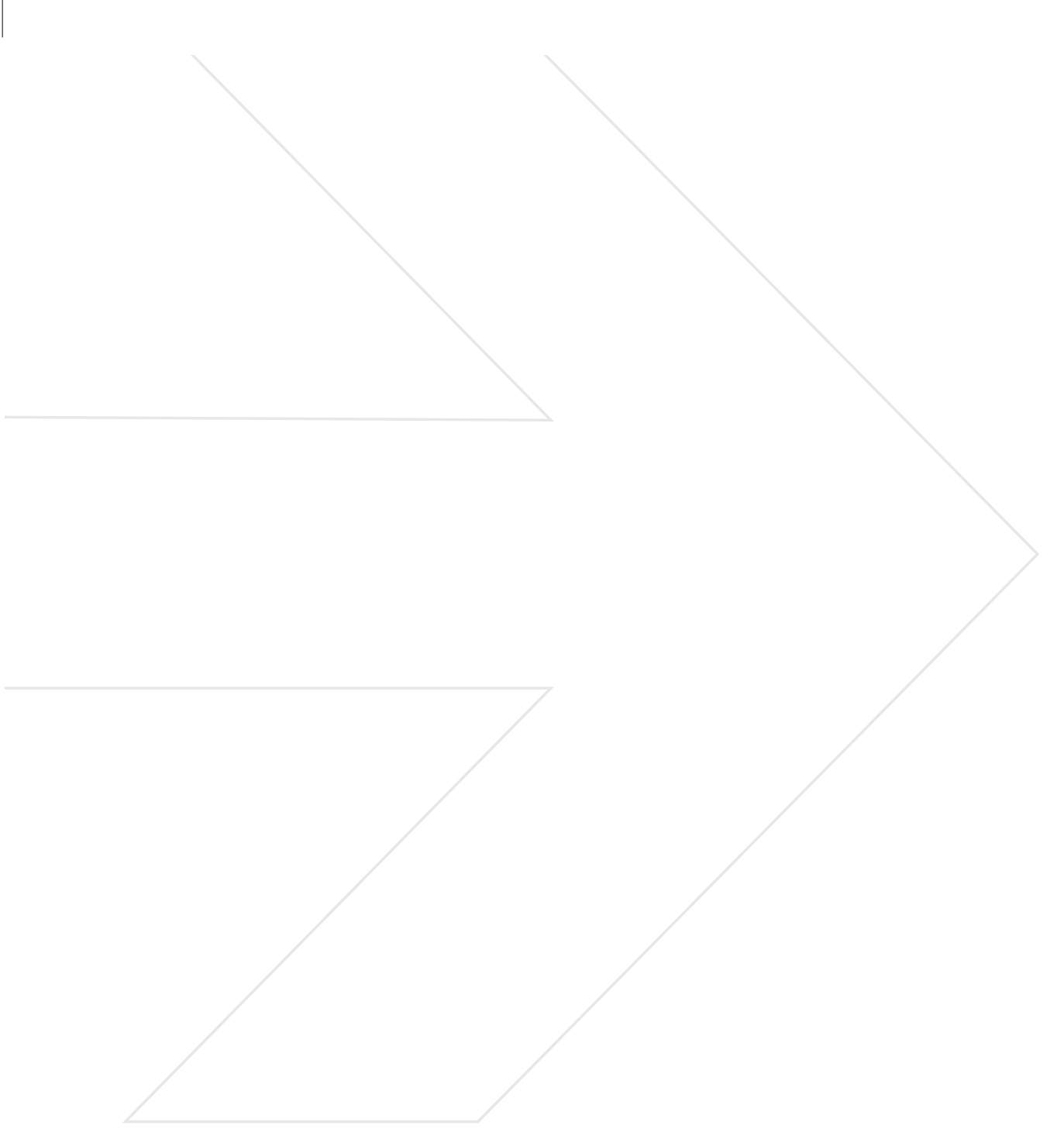


ÍNDiCe de Autores 


\section{A}

Abad Hiraldo, Ramón....58

Abadía Valle, Ana Rosa....52

Abella Garcés, Silvia....77

Aceña Fabián, $\mathrm{M}^{\mathrm{a}}$ del Carmen....77, 80

Aguado Benedí, Pedro Manuel....35, 49

Agudo Valiente, José María....32, 101

Agudo Valiente, Teodora....100, 101

Agustín Lacruz, Ma del Carmen....28, 30, 38, 93, 112, 125

Aísa, Rosa....25

Álava Martínez de Contrasta, María Ángeles....57

Albajez García, José Antonio....95

Alcalde Herrero, Ana Isabel....53, 90, 111

Aldabas Rubira, Emiliano....92

Aldea Chagoyen, Concepción.....38, 89, 96, 104

Alejandre Marco, José Luis....60, 66

Alesanco Iglesias, Alvaro....25

Allo Manero, M. ${ }^{a}$ Adelaida....28, 30, 93

Allueva Pinilla, Ana Isabel....60, 66

Alvarez Lanzarote, Ignacio.....70

Amaveda, Hippolyte....78

Anadón Mateo, Daniel....83

Andaluz, Joaquín....25

Andrés Bergareche, Ignacio....101

Andreu, Laura....36

Angulo Asensio, Eduardo....39

Angurel Lambán, Luis Alberto....78

Arcega Solsona, Francisco....92

Arenaz Villalba, Izaskun....79
Ariño Moneva, Agustín....70

Arraiz Pérez, Ana....46

Arranz Martínez, Pilar....75

Arribas Jiménez, Mercedes....75

Arribas Navarro, Luis Diego....27

Arruebo Loshuertos, Ma Pilar....90, 111, 112

Artal Bartolo, Enrique....89, 96

Artal Lerín, Manuela....89

Artal Sevil, Jesús Sergio....47, 107

Artigas Álava, Miguel....78

Ascaso Laliena, Miguel Ángel....100

Astigarraga Goenaga, Jesús....45

Aznar Rico, Virginia....66

Azúa Blanco, Ma Dolores Guadalupe....78, 81, 108

B

Babot Gaspa, Daniel....39

Baelo Allué, Sonia....72

Baeta Bafalluy, Miriam....108

Baeta, Miriam....71

Bailón Luesma, Raquel....25

Baldassarri, Sandra....69

Baldovín Oliver, José Antonio....84

Bañares Vazquez, Lidia Isabel....97

Bardina Tremps, Enrique....59, 107

Barquillas, José.....38

Barral Morán, M ${ }^{\mathrm{a}}$ José....83

Barrios Adán, $\mathrm{M}^{\mathrm{a}}$ Cristina.....111, 112

Basurco, Asier....77

Bauluz Lázaro, Blanca....89, 96 
Bayarri Fernández, Susana....70

Bayod López, Carmen....103

Bayod Rujula, Ángel Antonio....92

Bella, Jesús....34

Bellod Fernández de Palencia, Elena....103

Belloso Alcay, Ana....66

Beltrán Gracia, José Antonio....70

Benito Colón, Cristina....61

Benito Colón, Javier....52, 61

Benito Ruesca, Rafael...61

Berbegal Vázquez, Alfredo....46

Bermejo Latre, José Luis....39

Bernal Blay, Miguel Angel....39

Bernat Agudo, José Luis....81

Bernat Montesinos, Antonio....81

Berné Manero, Carmen....43

Bernués Aznar, Luis....31

Blanco Parmo, Domingo....70

Blasco de las Heras, Natividad....27

Blasco Oquendo, Julia....79

Blasco Solana, Mercedes....66

Boal Sánchez, Natalia....75, 80

Boldova Pasamar, Miguel Ángel....51

Bolea García, Miguel....108

Bolea, Miguel....71

Bolea, Pilar....28

Bregante Ucedo, Miguel Angel....52

Briz Villanueva, Ezequiel....31

Bueno García, Concepción....46
Bueno Gracia, Elena....57, 59

Bueno Lozano, Manuel....35, 37, 44

Bueso, Pablo....34

C

Caballero Navarro, Ana Luisa....35, 37, 44

Cáceres Sáenz, Alberto....77

Cadena Monllor, $\mathrm{M}^{\text {a }}$ Lourdes....63

Callejero Cornao, Bernardino....64

Calvo, Belén....38

Calvo Hernández, José Miguel....63, 69, 104

Calvo Medrano, Lucía....65

Calvo Pinilla, Manuel....62

Calvo Rebollar, Miguel....70

Campos y Sáez, Clemente A.....109

Canales Compés, María....25

Cano Fernández, Juan Luis....96

Cano Suñén, Enrique....33, 114

Cantarereo Carmona, Irene....113

Cañadas, María Consuelo....28

Carmona Martínez, José Manuel....76, 108

Carod Pérez, Eva Sara....44

Carramiñana Esteban, Juan José....70

Carrasquer Zamora, José....69

Carreras Gargallo, Alberto....33, 92

Carro Cevallos, Pedro Luis....25

Casalod Lozano, Yolanda....71, 108

Casal y Fabrega, Jordi....39

Castillo García, Francisco Javier....61

Castillo Suárez, Juan Ramón....86 
Castro Corella, Miguel....78

Castro López, Marta....90

Catalán, Carlos....34

Caudevilla Polo, Santos....57, 59

Cebollada Pras, Fernando....64

Cebrián Guajardo, Susana....76, 108

Celma Pueyo, Santiago....38, 104

Cerezo, Eva....69

Chueca Sancho, Ángel Gregorio....92

Cid, Eva....28

Cid Jiménez, Irene....83

Ciria Cosculluela, José Carlos....30, 84

Cisneros Gimeno, Ana Isabel....76

Climent López, Eugenio....72

Collado Giménez, Francisco Javier....32

Colomer Simón, Armando....66

Conchello Moreno, $\mathrm{M}^{\mathrm{a}}$ Pilar....70

Conde Ayuda, Tomás....110

Condón Usón, Santiago....70

Corbalán Fuertes, Montserrat....92

Correas Dobato, José Manuel....80

Cortés Gracia, Ángel Luis....63, 69, 104, 110

Cortés Pascual, Alejandra....46

Cruz Bello, Fernando....66, 125

Cruz Llanas, Santiago....25

Cuadra Pérez, Nieves....92

Cuartero Ruiz, Bienvenido....89

Cubero Marín, Juan José....100

Curty Alonso, Marcos....25
D

de Blas Giral, Ignacio....60, 71

de La Gándara Gómez, Milagros....69

Delgado Echeverría, Jesús....103

Diez Moñux, Juan Carlos....78

Domínguez Hernández, Javier....33, 114

Dominguez Longás, Alberto....44, 83

Domínguez Murillo, Eladio....30, 84

Domínguez Navarro, José Antonio....44

Domínguez Oliván, Ma Pilar....59, 78, 107

Domínguez Sanz, Pedro L.....44

Duarte, Rosa....25

Dueñas Lorente, José Domingo....36

$\mathbf{E}$

Echave Sanz, Ana de....44

Eito Mateo, Antonio....92

Ejea Arquillué, M $^{\text {a }}$ Victoria....53, 79

Elboj Saso, Carmen....29

Elduque Palomo, Ana Isabel....89, 96

Escalona Orcao, Ana Isabel....37

Escanero Marcén, Jesús Fernando....47, 48, 59, 76, 79, 82

Escario Jover, Inés....30, 53

Escartín Escudé, Víctor....39

Escolano, Rafael....28

Escolar Castellón, Asunción....79

Escolar Castellón, Juan de Dios....79

Escudero Escorza, Tomás....46

Espinosa Velázquez, Emilio....39

Estébanez de Miguel, Elena....57, 59 
Esteban, $\mathrm{M}^{\mathrm{a}}$ Dolores....25

Esteban Navarro, Miguel Ángel....28, 30, 65

Esteban Salvador, Luisa....43, 50

Estrada Marcén, Nerea Cristina....51

$\mathbf{F}$

Falceto Recio, Victoria....39

Fanlo Villacampa, Ana....79

Feijoo, $\mathrm{M}^{\mathrm{a}}$ Luisa....25

Fernández Casasnovas, Antonio....110, 114

Fernández Domínguez, $\mathrm{M}^{\mathrm{a}}$ Rosario....85

Fernández Fernández, Cristina....36

Fernández López, Javier....89, 96

Fernández Sora, Alberto....64

Fernández Turrado, Teresa....31, 85

Ferrando Roqueta, José Antonio....34

Ferreira González, Chelo....60

Ferrer Mairal, Ana....70

Ferrer Mayayo, Luis Miguel....110, 111, 114

Ferruz Agudo, Luis....33, 62, 65

Figueras Ara, Luis....111

Florén Serrano, Celia....58

Forcada Miranda, Fernando....39

Francés Román, Ángel....30, 84, 89

Franco Sierra, M ${ }^{\mathrm{a}}$ Angeles....59, 107

Frontera Sancho, María....85

G

Gairín, José María....28

Galán López, Mª Carmen....37
Galé, Carmen....115

Galindo Ayuda, Fernando....29, 64

Gállego Cortijo, Laura....77

Gállego Martínez, José Ramón....25

Gamarra Chopo, Yolanda....116

Gándara Gómez, Milagros de la....104, 110

García-Belenguer Laita, Silvia....77, 80

García García, Miguel Ángel....49

García Gonzalo, Diego....70

García Hernández, César....64

García, Inmaculada....25

García Marco, Francisco Javier....29, 30, 64

García Moros, José....25

García Pascual, Enrique....72, 75, 94

García Rivas, Blas....57, 59

García Sánchez, Jesús....112

Gargallo Castel, Ana F.....43, 50, 99, 103

Garrido Laparte, $\mathrm{M}^{\mathrm{a}}$ Ángeles....85

Garrido Picazo, Piedad....65

Gasa Gaso, Joseph....39

Gascón Catalán, Ana....66

Gascón Pérez, F. Manuel....77, 80, 89

Gascón Santos, Santiago....71, 108

Gay Molins, Pilar....30, 38, 93, 112

Gelpi Fleta, Paula....34, 51

Germán Bes, Concha....31, 67, 83

Gil, Agustín....25

Gil Ciria, María Carmen....85

Gil Herrando, Eduardo....25

Gil Quílez, Mª José....63, 69, 104 
Gil Ruíz, Milagros....62, 80

Gil Tomás, Joaquina....61

Gimeno Marco, Fernando....96

Giné Abad, Helena....77

Giner Soria, Armando....59

Gómez-Arrue Aspiazu, Javier....60

Gómez Bahillo, Carlos....37

Gómez Bernal, Francisco....101

Gómez Cotín, Maria Teresa....86

Gómez de Mena, Elisa....35

Gómez Martín, Tomás....84

Gómez Ochoa, Pablo....77, 89

González-Haro, Carlos....82

González Labrada, Manuel....92

González Pueyo, Mª Isabel....72

González Santos, José Miguel....66

González Sinde, M $^{\mathrm{a}}$ Carmen....47, 48

González Viejo, Natividad....101

Granada López, José Manuel....66

Grande Ventura, Tomás....89

Grasa López, Laura....90

Guerrero Manso, Carmen de....39

Guillén Galve, Ignacio....58

Gutiérrez Nieto, Begoña....27, 52

\section{H}

Heras Vila, Carlos David....25

Hernández, Jose $\mathrm{M}^{\mathrm{a}}$....25

Hernanz, Carlos....34

Herrando Rodrigo, Maria Isabel....111
Herranz Bercedo, Félix....57, 59

Herrero Nivela, M $^{\mathrm{a}}$ Luisa....85

Herrero Traver, Miriam....83

Hidalgo García, César....57, 59

Hijazo Gascón, Alberto....67

Horno Chéliz, María del Carmen....98

Hué García, Carlos....26

I

Ibáñez Carabantes, Pedro....64

Ibáñez Muñoz, David....101

Ibáñez, Raquel....28

Ibarretxe Antuñano, Iraide....98

Ibor, Carolina....25

Iguacel Linares, Manuel....34

Infante Díaz, Jorge....102

Iturralde Navarro, María....57

J

Jiménez García-Alcalá, María Sierra....86

Jiménez Villar, Josefina....89, 96

Jodrá Esteban, Pedro....80

Juan Perote, Marcos Sanso....25

Julve Moreno, Carmen....81

Junquera Escribano, $\mathrm{M}^{\mathrm{a}}$ Concepción....113

$\mathbf{L}$

Lacarta García, Pedro....83

Lacasta Lozano, Delia....110, 111

Lacaustra Bueno, Mª José....66 
Lacruz Mantecón, Miguel Luis....103

Lacuesta Gilaberte, Raquel....34

Lahoz Gimeno, Manuel....83

Lahoz Mustienes, Maria José....101

Lamarca Langa, Genaro....28, 30, 38

Lample Lacasa, Ana María....111

Lampreave Palacios, Fermín....57

Lanaspa, Luis Fernando....25

Lanuza Jiménez, Javier....53

Lapeña Marcos, María Jesús....30, 53

Larramona, Gemma....25

Larroche Garcés, Mª Carmen....66

Larrodé Pellicer, Emilio....97

Lasala Calleja, María Pilar....29, 64

Latorre Peña, Julio....34

Lázaro Gistau, Regina....70

León Puy, Juan Francisco....66

Lerís López, Ma Dolores....62, 75, 80

Letosa Fleta, Jesús....47, 107

Lidón López, Iván....96

Liesa Orús, Marta....100

Lizalde Gil, Enrique....34

Lizalde Gil, Manuel....34

Llera Sastresa, Eva....68

Llorente Mayor, Milagros.....36

Lloret Gazo, Jorge....30, 84

Logroño Ejea, Marga....53

Lope Domingo, Miguel Ángel....95

López Azcona, Aurora....103

López Buesa, Pascual....70
López Lacambra, Carmelo.....37

López Lucia, Alicia....25

López Tello, Celia....107

López Torres, Ana $\mathrm{M}^{\mathrm{a}}$....92

Lorán Ayala, Susana....70

Lorés Sanz, Rosa....58

Loscertales Palomar, Blanca....37

Loste Montoya, Araceli....77, 80, 110, 114

Lozano Chavarria, Pablo....43

Lucha López, M ${ }^{\text {a }}$ Orosia....57, 59

Luengo Gascón, Elvira....36

Luesma Bartolomé, María José....79

Luzón Marco, Gloria....76, 92, 108

Luzón Marco, María José....72

\section{$\mathbf{M}$}

Macia, Loreto....83

Magdalena Belío, José Felix....101

Mainar, Alfredo....25

Mañas Pérez, Pilar....70

Marca Andrés, M del Carmen....77, 80, 111

Marco Sanjuán, Isabel....33, 62, 65

Marcuello Pablo, Juán José....92

Marcuello Servós, Carmen....92, 102

Marcuello Servós, Chaime....92, 102

Marín, Amador....34

Mariscal, Isabel....83

Marques Lopes, Iva....70

Márquez, Josefa....83

Martin Burriel, Inmaculada....113 
Martínez Ciriano, Carmen....79, 113

Martínez de Aguirre Aldaz, Carlos....98

Martínez Domínguez, Francisco José....65

Martínez Gracia, Amaya....68, 84, 92

Martínez Jarreta, Begoña....71, 108

Martínez Jiménez, Raquel....34

Martínez Martínez, María....103

Martínez, Pedro A.....38

Martínez Peña, Mª Begoña....63, 69, 104

Martínez, Yolanda....25

Martín Gardel, Germán....99

Marzo Navarro, Mercedes....26, 43

Mateos Royo, José Antonio....91

Mayor del Hoyo, M ${ }^{\text {a }}$ Victoria....98

Medrano Marqués, Nicolás....38, 104

Medrano Sánchez, Carlos T.....92

Melguizo Béjar, Amor....101

Melguizo Garde, Marta....102

Mesonero Gutiérrez, José Emilio....53, 90, 111, 112

Miguel Artal, Ángel de....30, 84

Miguel Artiaga, Antonio....25

Molina Agudo, Pilar....95

Molina, José Alberto....25

Moliner Urdiales, Diego....27, 34

Moneva Abadía, José Mariano....92

Montaner Lavedán, Jesús Mª...62

Montijano Torcal, Juan Ignacio....62

Montolío Tena, Mari Carmen....68

Mora Alfonso, Mario....78

Morales Lamuela, M $^{\mathrm{a}}$ Jesús....93
Morales Villasevil, Julio....76, 108

Morandeira García de la cruz, José Ramón....99

Moreno Rodríguez, Mª Pilar...97

Moreu Carbonell, Elisa....39

Moseñe Fierro, José Antonio....37, 77

Muñoz Gonzalvo, Mª Jesús....52

Muñoz, José María....28

Muñoz Langa, Emilia....35

Muñoz Martínez, Eva Maria....115

Muñoz Sánchez, Fernando....33, 62

Mur Amada, Joaquín....47, 107

Murillo López de Silanes, Mª Divina....90, 111

Murillo Ornat, Silvia....58

Murillo Ros, Natividad....100

Mur Isaiz, Javier Enrique....94

Muro Baquero, Carmen....66, 78, 81, 108

Mur Sangrá, Melania....102

\section{$\mathbf{N}$}

Naranjo Palomino, Fernando....65

Nasarre López, José Ma

Navarro, Laura....77, 114

Navarro Soto, Ana Leonor....92

Nerín Rotger, $\mathbf{M}^{\mathrm{a}}$ Antonia....99

Nieto Amada, José Luis....76

Noriega Miguélez, Eva....89

Nuin, Carmen....83

Núñez Domingo, Carolina....71, 108

Nuño Pérez, Javier....85 
$\mathbf{O}$

Obón Nogué, Jesús....76

Orejudo Hernández, Santos....31, 85

Orera Orera, Luisa....30, 38, 93, 112

Oria Almudí, Rosa....70

Orta Costa, Maria José.....101

Ortega Jiménez, Alfonso....62

Ortega Rodríguez, Carmelo....58

Ortín Pérez, Aurora....80, 89, 111, 114

Ortiz, Cristina.....36

Osta Pinzolas, Rosario....113

Otal Piedrafita, Pilar....100

Otín, Aránzazu....38

$\mathbf{P}$

Pagán Tomás, Rafael....70, 112

Palacio Liesa, Jorge....89

Palacios Navarro, Guillermo....34

Palomero Pescador, José Emilio....85

Paniagua Royo, Jesús....81

Paricio Miravete, Asunción....35

Paricio Royo, Javier....48, 66, 92

París Roche, Fernando....96

Pastor Agustín, Gema....51

Pastor Meseguer, Joaquín....80, 114

Pastrana Blanco, Leyre....33

Pedraja Iglesias, Marta....26

Pedraza Gracia, Manuel J.....28, 30
Pedraz, Azucena....83

Pedro Herrera, Dolores de....78

Peiró Esteban, José María....70

Peláez Coca, María Dolores....25

Pelegrín Martínez de Pisón, Begoña....27, 52

Peña Tirado, Luis Fernando....90

Peña Torre, José Ignacio....78

Pérez Arquillué, Consuelo....70

Pérez Bella, José María....33, 114

Pérez Cabreras, $\mathbf{M}^{\mathrm{a}}$ Dolores....70

Pérez Castejón, Carmen....76

Pérez, Domingo....25

Pérez Legarda, Miriam....77

Perez-Llantada Auría, M ${ }^{\text {a }}$ Carmen....46

Pérez Monge, Marina....98

Pérez Sanz, Francisco Javier....43, 50, 99, 103

Pérez Valle, Beatriz....84

Pié Juste, Ángeles....53

Pié Juste, Juan....53

Plaza Carrión, Miguel Angel....90

Plaza García, Inmaculada....92

Plugaru, Neculai....78

Plumed Lasarte, Marta....77

Pollán Santamaría, Tomás....92

Posa Gómez, Ana Blanca....92

Pueyo Colomina, M. ${ }^{\text {a }}$ Pilar....28

Pueyo Paules, Esther....25

Puisac Uriol, Beatriz....53

Puyuelo Sanclemente, Miguel....85 


\section{$\mathbf{R}$}

Ramos Antón, Juan José....110, 111, 114

Ramos Cascón, Teresa....85

Ramos Fuentes, Feliciano J.....53

Rández García, Luis....62

Raso Pueyo, Javier....70

Ratia Serrano, Octavio....49

Rebollar Rubio, Rubén....96

Remón Oliver, Sara....70

Reverter Masia, Joaquín....27, 34

Ricomá, Roser....83

Ríos Jordana, Ricardo....78

Rivera Torres, Pilar....26

Roche Asensio, M ${ }^{\mathrm{a}}$ José....78

Rodellar Penella, Clementina....113

Rodrigo Luna, Carlota....111

Rodríguez Soria, Beatriz....33, 114

Rodríguez Villanueva, Áurea....53, 84

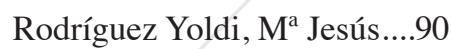

Rojo Martínez, José Antonio....78, 91

Romero Laceras, Antonio....60

Romero Martín, M ${ }^{\mathrm{a}}$ Rosario....51

Roncalés Rabinal, Pedro....70

Rota García, M Carmen....70

Royo Ochoa, Arantxa....101

Ruberte Sánchez, Mª Laura....62

Rubín Llera, Javier....78

Rubio Calvo, M Carmen....61

Rubio Cavero, Rut Agueda....101
Rueda Martín, Ma Ángeles....51

Ruiz Pardos, Manuela....63

\section{S}

Sabirón Sierra, Fernando....46

Sáenz Galilea, $\mathrm{M}^{\mathrm{a}}$ Angeles....53

Sáenz Gil de Gómez, María Jesús....96

Salas Murillo, Sofía de....98

Salvador Oliván, José Antonio....28, 30, 38, 93, 112

Sanagustín Fons, $\mathbf{M}^{\mathrm{a}}$ Victoria....37

Sánchez Casabón, Ana I.....28, 30, 38, 93

Sánchez Gimeno, Ana Cristina....70

Sánchez González, Mª Dolores....93

Sánchez Ibáñez, José-Ángel....36

Sánchez Ojanguren, Désirée....89

Sánchez Paniagua, Lourdes....70

Sánchez-Rubio García, Alfredo....103

Sánchez Sellero, Pedro....116

Sancho, Julio....28

Sanjuán Álvarez, Marta....36

Santamarina González, Clara....39

Santolaria Mazo, Jorge....95

Sanz, Fernando....25

Sanz, María Teresa....38

Sarsa Garrido, Javier....44, 72, 75

Sarsa Sarsa, María Luisa....89, 96

Satústegui Dordá, Pedro José....111

Scarpellini, Sabina....68

Sebastián Yagüe, Álvaro....57

Segales i Coma, Joaquim....39 
Sein-Echaluce Lacleta, $\mathrm{M}^{\mathrm{a}}$ Luisa....75, 80

Serna Porro, Cándida....66

Serón Arbeloa, Francisco J.....44, 69

Serrano García, Emilio....99

Serrano García, José Antonio....103

Serrano Roldán, Irene....35

Sevillano Rubio, Aurora....94

Simón Valencia, $\mathrm{M}^{\mathrm{a}}$ Carmen....58

Sinués Porta, Blanca....79

Solera Ureña, José Rufino....25

Solsona Martínez, Carmen....45

Soria Aznar, M ${ }^{\text {a }}$ Soledad....47, 48, 76, 79, 82

Soriano Bozalongo, Juana....81, 82

Soriano García, Roberto....89

Soriano Paola, M ${ }^{\mathrm{a}}$ Angeles....43, 50

Sosa Misuraca, Cecilia....71, 108

$\mathbf{T}$

Tabernero Sala, Rosa....36

Tena Piazuelo, Vitelio....29

Tena Porta, Inmaculada....34, 51

Teruel Melero, Pilar....85

Tobajas Asensio, José Antonio....111

Torrente Cera, Tamara....77

Torrente Gari, Susana....92

Torres Portero, Manuel....70

Torres Portero, Miguel Ángel....70

Torres Sánchez, Reyes....59, 107

Tramullas Saz, Jesús....28, 30, 65, 93

Tricas García, Fernando....80
Tricas Moreno, José Miguel....57, 59

Tricas Oliván, Jesús....37

Turégano Romero, José Antonio....84

\section{$\mathbf{U}$}

Úbeda Echarte, Juan Luis....39

Ubieto Artur, Antonio P.....30, 38

Ubieto Artur, $\mathrm{M}^{\mathrm{a}}$ Isabel....30, 38, 93

Ubieto Artur, Pedro....64

Uche Marcuello, Javier....84

Urruela Mora, Asier....51

Usón Sardaña, Antonio....47, 107

Usoz Otal, Javier....45

\section{V}

Val Arnal, José Jesús de....115

Valero Salas, Antonio....85

Vallejo Dacosta, Ruth....37

Vargas Magallón, María....51, 65

Vas Esteban, Pedro....99

Vázquez Bringas, Francisco José....60

Vázquez Martínez, Manuel....99

Vecino Soler, Ana....66

Vela Condón, Pablo....99

Vela Rodrigo, Jesús....80

Velasco Callau, $\mathbf{M}^{\mathrm{a}}$ Carmen....84

Velasco de la Peña, Esperanza....28, 30, 38, 93, 112, 125

Velilla Marco, Ma Jesús....44

Venturini Crespo, $\mathrm{M}^{\mathrm{a}}$ Eugenia....70

Vercet Tormo, Antonio....70 
Verde Arribas, $\mathrm{M}^{\mathrm{a}}$ Teresa....77, 80, 111, 114

Vicén Ferrando, María Jesus....97

Vicente Carracedo, Alejandra....116

Vicente, Luis....36

Vicente Romero, Jorge....79

Vigo Arrazola, Begoña....81, 82

Villacampa Naverac, Belén....89

Villalba Mata, Daniel....39

Villar Rivacoba, José Angel....76, 108

Villarroya Aparicio, Eva....89

Villellas Malo, Anselmo....78

Viloria González, Américo Josué....60

Vived Conte, Elias....100

W

White, Jaime....76

$\mathbf{Y}$

Yagüe Fabra, José Antonio....95

Yagüe Ruiz, Cristina....70

Yagüe Serrano, Ma Ángeles....49

Yangüela Martínez, Javier....70

Yusta Loyo, José María....49

$\mathbf{Z}$

Zabalegui, Adela....83

Zapata Abad, María Antonia....30, 53, 84, 89, 96

Zaragoza Fernández, Pilar....113

Zubiaurre, Julieta....25 


\section{Investigación Educativa e Innovación Docente en el proceso de Convergencia Europea}

\section{COMITÉ CIENTÍFICO:}

Antonio Herrera Marteache

Julián Muela Ezquerra

Francisco Serón Arbeloa

$M^{a}$ Victoria Sanagustín Fons

Javier Paricio Royo

Manuel Aguado Benedí

Javier García Marco

José Luis Bernal Agudo

Ramón Garcés Campos

Carmen Agustín Lacruz

Esperanza Velasco de la Peña Juan Luis Cano Fernández José Antonio Rojo Martínez Rubén Rebollar Rubio

José Antonio Moseñe Fierro

\section{COMITÉ TÉCNICO:}

Fernando Cruz Bello

Laura Encuentra Pardillos

$\mathrm{M}^{\mathrm{a}}$ Carmen Galán López

María Teresa Pérez Yago

\section{COORDINADORES DE MESA:}

Diseño curricular:

José Luis Bernal Agudo

Begoña Vigo Arrazola 
Evaluación, innovación y factores de calidad:

Ana Arraiz Pérez

Tomás Escudero Escorza

Fernando Sabirón Sierra

Tecnologías aplicadas al mundo de la enseñanza superior:

Javier Paricio Royo

Francisco Serón Arbeloa

Experiencias de trabajo cooperativo y trabajo en grupos:

Concha Bueno García

Javier García Marco

Metodologías activas

José María Rodanés Vicente

José Antonio Rojo Martínez

Herramientas de resolución de casos y Proyecto Tutor

Juan Luis Cano Fernández

Rubén Rebollar Rubio

\section{EXPOSICIÓN DE MATERIAL Y RECURSOS DOCENTES:}

Carmen Agustín Lacruz

Fernando Cruz Bello

Esperanza Velasco de la Peña 
ISBN 978-84-92774-13-5

|| || || ||| |||||||||||||||

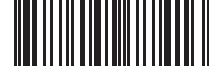

\|\|$_{788492}|||||||||||||||||||| \mid$
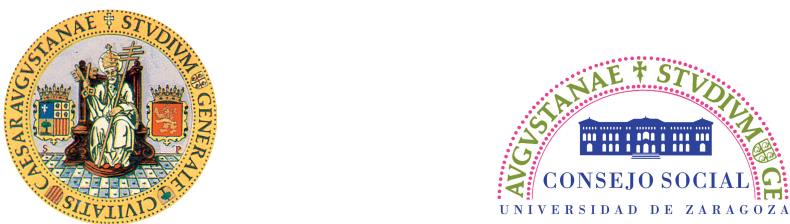